\title{
ORIGIN AND INTEGRATION: A STUDY OF MIGRANTS IN THE 2016 IRISH CENSUS
}

Frances McGinnity, Ivan Privalko, Éamonn Fahey,

Shannen Enright, Doireann O'Brien

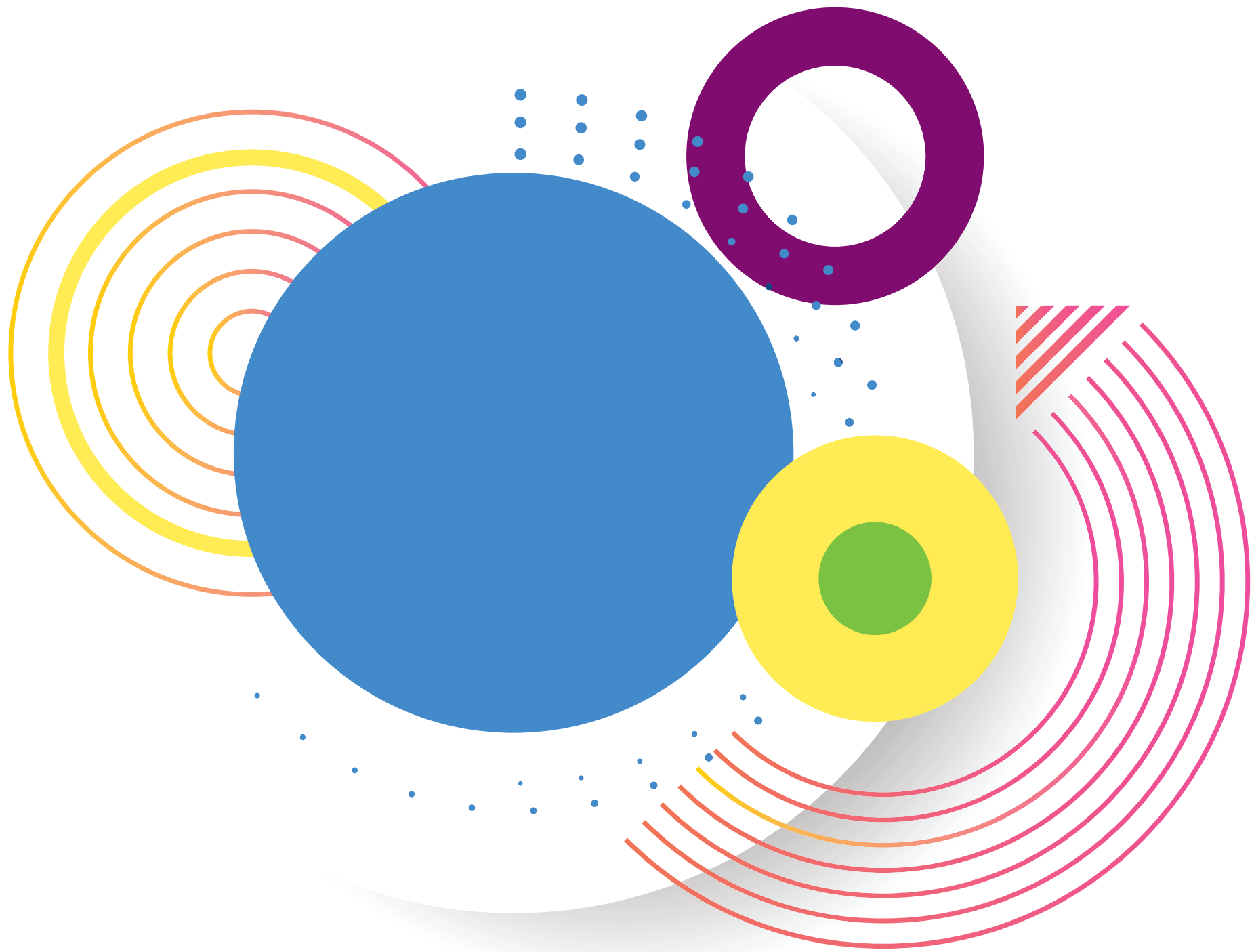


Funded by the Department of Justice and Equality in line with the Migrant Integration Strategy 2017-2020 


\title{
ORIGIN AND INTEGRATION: A STUDY OF MIGRANTS IN THE 2016 IRISH CENSUS
}

\author{
Frances McGinnity \\ Ivan Privalko \\ Éamonn Fahey \\ Shannen Enright \\ Doireann 0’Brien
}

June 2020

Economic and Social Research Institute;

Department of Justice and Equality

Available to download from www.esri.ie

The Economic and Social Research Institute

Whitaker Square, Sir John Rogerson's Quay, Dublin 2

ISBN 978-0-7070-0496-9

https://doi.org/10.26504/bkmnext392.pdf

This Open Access work is licensed under a Creative Commons Attribution 4.0 International License (https://creativecommons.org/licenses/by/4.0/), which permits unrestricted use, distribution, and reproduction in any medium, provided the original work is properly credited. 


\section{THE AUTHORS}

Frances McGinnity is an Associate Research Professor at the ESRI and Adjunct Professor at TCD. Ivan Privalko is a Post-Doctoral Researcher at the ESRI. Éamonn Fahey was a Research Assistant at the Economic and Social Research Institute (ESRI) and Doireann O'Brien was on a research internship at the ESRI at the time of writing. Shannen Enright is a research assistant at the ESRI.

\section{ACKNOWLEDGEMENTS}

This report was completed as part of a programme of research on Equality and Integration funded by the Department of Justice and Equality (DJE). We are very grateful to the Central Statistics Office for providing the Census Microdata for this report and supporting its use. We would also like to thank the members of the steering group for the research programme - Úna Ní Dhubhghaill (OPMI), Alice Wainwright (DJE), Bryan Fanning (University College Dublin) and Ann Marie McGauran (National Economic and Social Council). We thank our ESRI colleagues who reviewed the draft report, an external reviewer and Emer Smyth, who acted as editor. Helen Russell also provided valuable comments on a late draft. We would also like to acknowledge Liza Costello, who copyedited the report and Sarah Burns, who managed its publication.

This report has been peer reviewed prior to publication. The authors are solely responsible for the content and views expressed. 


\section{FOREWORD}

I am very pleased to introduce this study on migrant integration using data from Census 2016. The study has been funded by the Department of Justice and Equality under its Equality and Integration Research Programme with the Economic and Social Research Institute. Integration research such as this is essential to the development of evidence-informed policy on integration. This study - the fourth to be produced under the Research Programme, which commenced in 2017 makes an important contribution to what we know about outcomes for migrants to Ireland. More detailed analysis - made possible by access to the Census microdata - reveals variations in integration outcomes by country of birth, which have not been visible in previous studies. I would like to express my thanks to the Central Statistics Office for making this data available to the Research Programme.

By examining key indicators of integration by country of birth for the first time, this study gives us new insights into the ways that integration journeys differ depending on their point of origin. Data on English language skills, educational attainment, employment status and occupational attainment are analysed by country of birth and compared to data on the Irish-born population to build up a detailed picture of integration outcomes and how they vary across different groups. This gives us a better understanding of who is more likely to face barriers to integration, what these barriers are, and how to formulate effective policies to support people in overcoming them.

The evidence reaffirms the importance of certain key integration policies and supports, including sufficient provision of English language training for migrants; greater recognition of foreign qualifications; targeted labour market integration programmes for refugees; and measures to tackle ethnic discrimination in the labour market. These are being advanced through the implementation of the Migrant Integration Strategy 2017-2020, while this study will form part of the evidence base to inform our approach to integration beyond the lifetime of the current strategy.

David Stanton, T.D., Minister of State at the Department of Justice and Equality with special responsibility for Equality, Immigration and Integration. 



\section{TABLE OF CONTENTS}

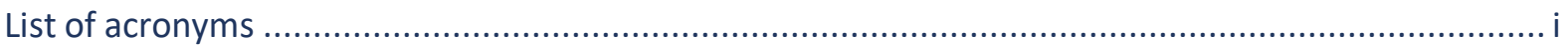

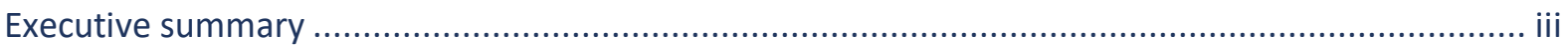

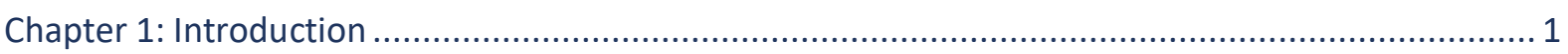

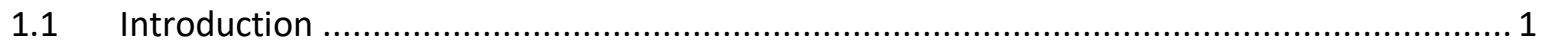

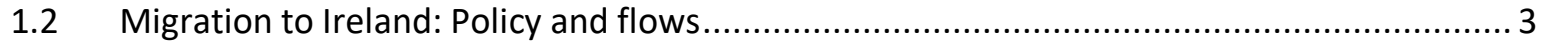

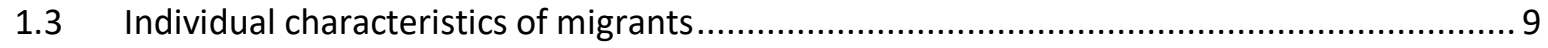

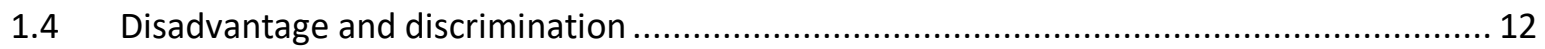

1.5 Research questions and expectations ......................................................... 13

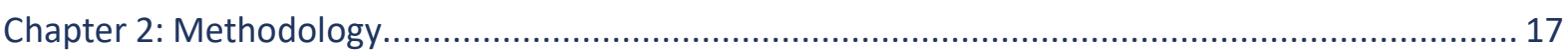

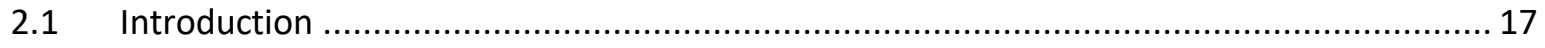

2.2 Evidence base: 2016 Census Microdata ............................................................. 17

2.2.1 Country of birth profiles................................................................. 17

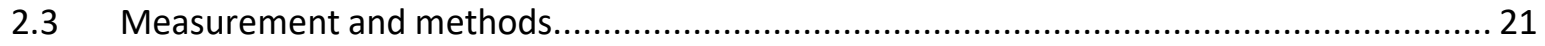

2.3.1 Resources and outcomes ............................................................... 21

2.3.2 Age, gender, ethnicity and time in Ireland............................................ 23

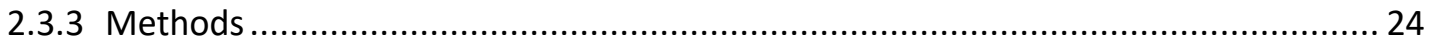

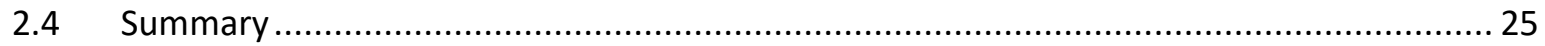

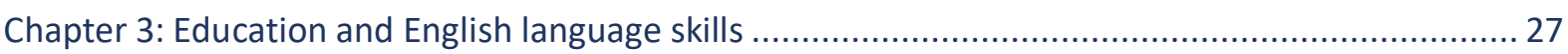

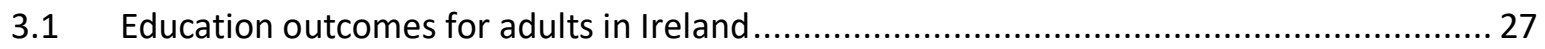

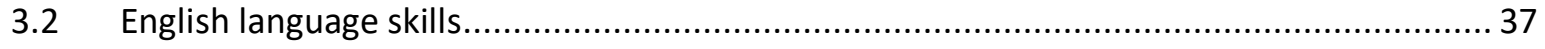

English language skills and education.............................................................. 44

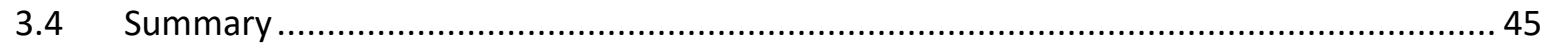

Chapter 4: Labour market outcomes: Unemployment and high-skilled jobs .............................. 47

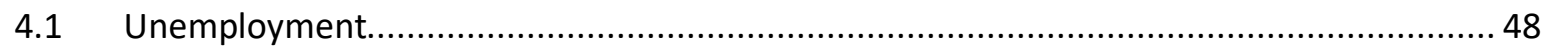

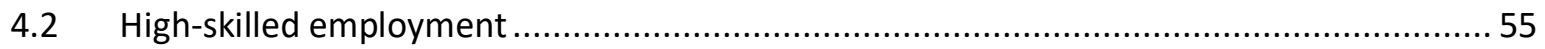

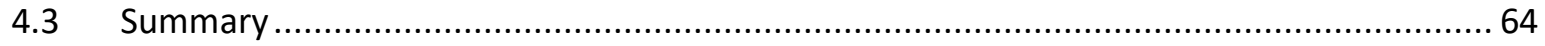


Chapter 5: Which migrants fare best in the Irish labour market?

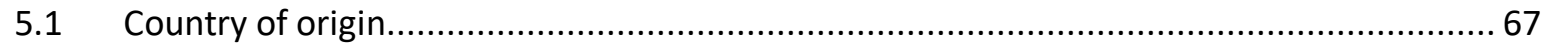

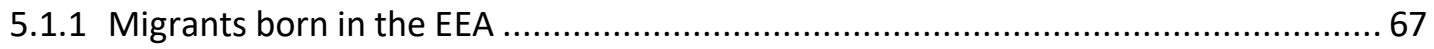

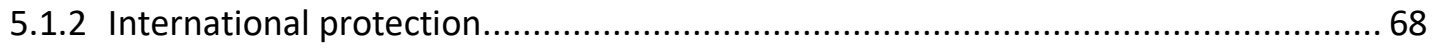

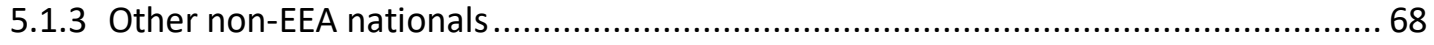

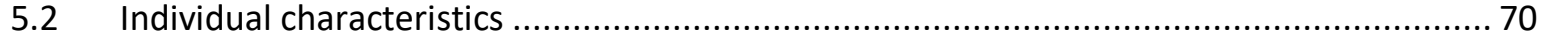

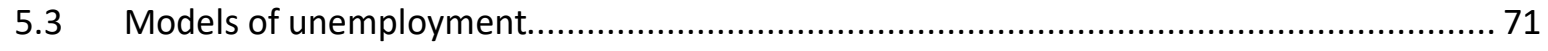

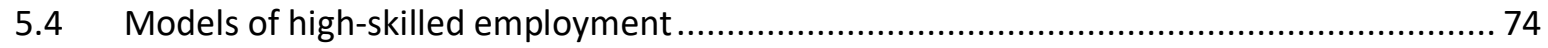

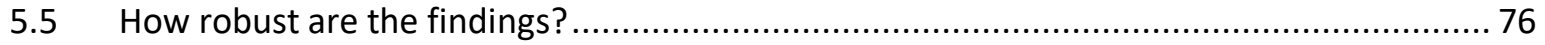

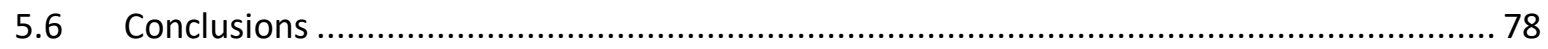

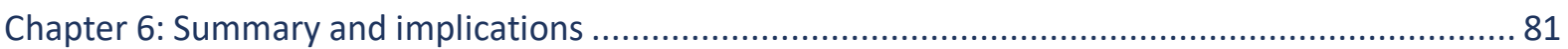

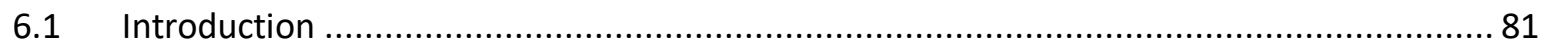

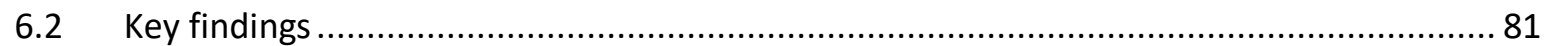

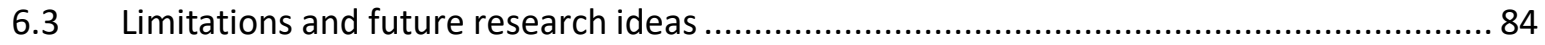

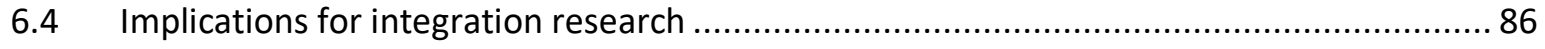

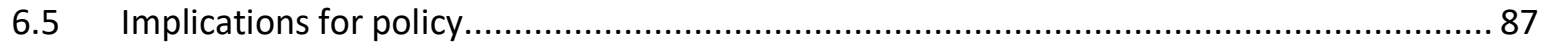

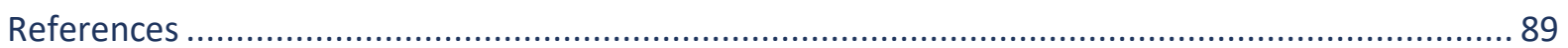

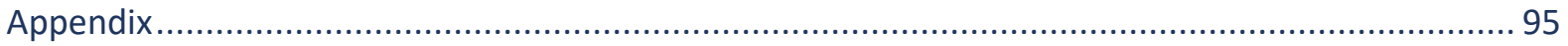




\section{LIST OF TABLES}

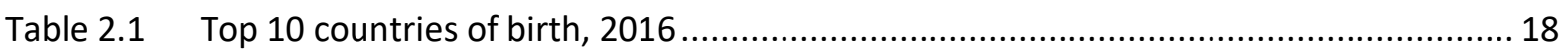

Table 5.1 Model estimates predicting odds of unemployment among migrants ........................ 73

Table 5.2 Model estimates predicting odds of high-skilled occupation ..................................... 75

Table A5.1 Model estimates predicting odds of unemployment by EEA and non-EEA country of

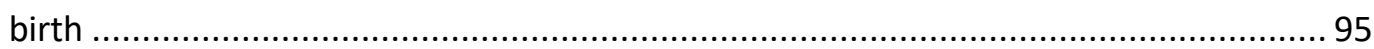

Table A5.2 Model estimates predicting odds of high-skilled occupation by EEA and non-EEA country

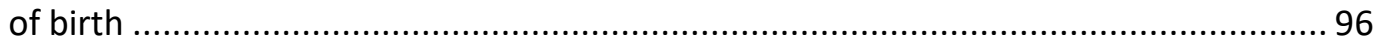




\section{LIST OF FIGURES}

Figure 1.1 Immigration, emigration and net migration, 1987-2017 ........................................ 5

Figure 1.2 Migration population by country of birth, 2002-2016........................................ 6

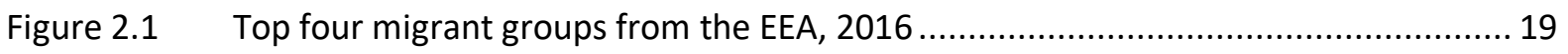

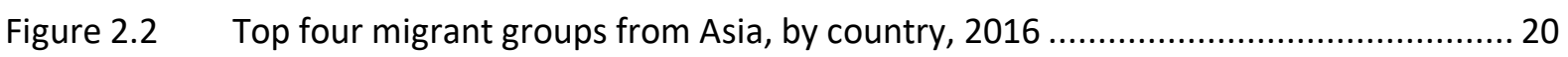

Figure 2.3 Top four migrant groups from Africa, by country, 2016........................................ 20

Figure 2.4 Top four migrant groups from the 'rest of the world' category, by country, 2016 ..... 21

Figure 3.1 Predicted probabilities of holding a third-level degree: Asian migrants and Irish

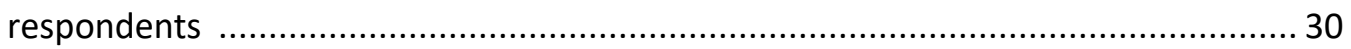

Figure 3.2 Predicted probabilities of holding a third-level degree: African migrants and Irish respondents

Figure 3.3 Predicted probabilities of holding a third-level degree: EEA migrants and Irish respondents 34

Figure 3.4 Predicted probabilities of holding a third-level degree: 'Other' migrants and Irish

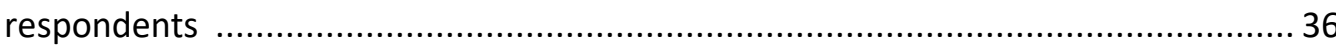

Figure 3.5 Predicted probabilities of having very good English: Asian migrants and Irish respondents 39

Figure 3.6 Predicted probabilities of having very good English: African migrants and Irish respondents 40

Figure 3.7 Predicted probabilities of having very good English: EEA migrants and Irish respondents 42

Figure 3.8 Predicted probabilities of having very good English: Migrants from other countries and Irish respondents 43

Figure 3.9 Relationship between third-level educational attainment and English language ability.

Figure 3.10 Relationship between third-level educational attainment and English language ability

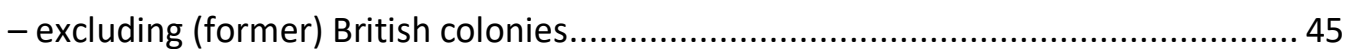

Figure 4.1 Predicted probabilities of being unemployed: Asian migrants and Irish respondents 49

Figure 4.2 Predicted probabilities of being unemployed, African migrants and Irish respondents 50

Figure 4.3 Predicted probabilities of being unemployed: EEA migrants and Irish respondents .. 52

Figure 4.4 Predicted probabilities of being unemployed: Migrants in the 'rest of the world'

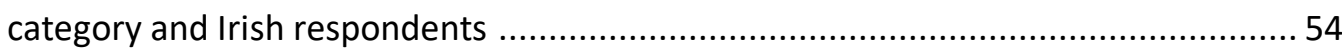

Figure 4.5 Predicted probabilities of being in high-skilled employment: Asian migrants and Irish

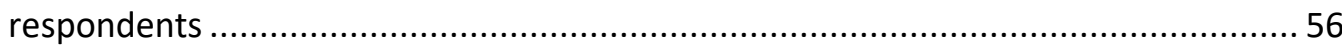

Figure 4.6 Predicted probabilities of Being In high-skilled employment: African migrants and Irish

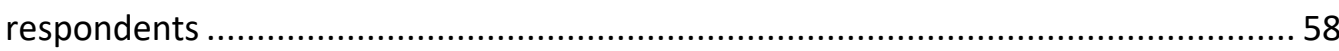

Figure 4.7 Predicted probabilities of being in high-skilled employment: EEA migrants and Irish respondents 60

Figure 4.8 Predicted probabilities of being In high-skilled employment: Migrants in the 'rest of the world' category and Irish respondents 


\section{LIST OF ACRONYMS}

CSO

DEASP

ECOSOC

EEA

ESOL

ETBI

FRA

GDP

ICT

ILO

INIS

JLD

LFS

NFQ

NGOs

OECD

ORAC

QQI

RCSI

SILC

UAE

UK

UN

UNHCR

UNICEF

US

WGI
Central Statistics Office

Department of Employment Affairs and Social Protection

Economic and Social Council (of the United Nations)

European Economic Area

English for speakers of other languages

Educational and Training Boards Ireland

European Agency for Fundamental Rights

Gross domestic product

Information communication technology

International Labour Office

Irish Naturalisation and Immigration Service

Jobseekers Longitudinal Dataset

Labour Force Survey

Irish National Framework of Qualifications

Non-governmental organisations

Organisation for Economic Co-operation and Development

Office of the Refugee Applications Commissioner

Quality and Qualifications Ireland

Royal College of Surgeons in Ireland

Survey on Income and Living Conditions

United Arab Emirates

United Kingdom

United Nations

United Nations High Commissioner for Refugees

United Nations Children's Fund

United States (of America)

World Bank's World Governance Indicators 



\section{EXECUTIVE SUMMARY}

Following decades of emigration, rapid inward migration during the economic boom of the late 1990s and early 2000s means that Ireland now has one of the highest proportion of foreign-born residents in the EU. Migration into Ireland rose rapidly during the economic boom of the late 1990s and early 2000s, peaking in 2007 before it declined sharply as a result of the recession. By 2015, net migration was positive once again, and applications for protection rose rapidly, though the flow of displaced persons into Ireland has been much lower than in many EU Member States and represents a very small proportion of overall immigration.

This report uses the complete 2016 Irish Census to measure four indicators of skills and labour market outcomes, comparing migrants with respondents born in Ireland: English language ability, educational attainment, unemployment and occupational attainment. Surveys in this area typically use respondents' continental region of birth but this approach can mask large differences within broad regional categories. Here, we use Census data that allows us to compare indicators by respondents' country of birth. We then investigate some potential explanations for why some migrants perform better than others in the Irish labour market, taking into account both characteristics of their country of birth and those of the migrants themselves.

In this study, migrants are defined as respondents born outside the Republic of Ireland, including respondents born in Northern Ireland and the United Kingdom (UK). Most migrants to Ireland were born in the European Economic Area (EEA). EEA nationals are free to live and work in Ireland without restriction, while nonEEA nationals are subject to managed migration policy and come to Ireland for a number of different reasons. We focus only on first-generation migrants, and we understand integration as 'the process of becoming an accepted part of society' (Penninx and Garcés-Mascarenas, 2016, p. 14). Because the concept of integration is multidimensional and cannot be measured directly, we consider indicators that clearly relate to it. While we acknowledge that integration is a two-way process of mutual accommodation by migrants and Irish-born, this study focuses on migrants' integration.

\section{KEY FINDINGS}

\section{Education and English language skills}

Education and English language skills are key resources for integration to the labour market and society more broadly. We consider two sources of variation: the 
difference between migrants and Irish-born respondents, and the large differences between migrants by country of birth.

Most migrant country-of-birth groups report higher educational attainment than the Irish-born population. The placement of the Irish-born group regarding the predicted probability of holding a third-level education (0.4) is below that of most migrant groups. This is true even after accounting for differences between the Irish-born and foreign-born groups in terms of age and gender.

Second, within broad regional groups of origin (EEA, Asia, Africa, 'rest of the world'), we find extensive variation. In educational attainment, for example, there is a group of highly educated migrants with high predicted probabilities of holding a third-level educational qualification (listed in brackets). Among Asian migrants, these are respondents born in Taiwan (0.9), South Korea (0.87), and India (0.83). Among EEA migrants, these are people born in Switzerland (0.81) and France (0.8). Among African migrants, these are respondents born in Zambia (0.74) and Tanzania (0.71). Among migrants from the rest of the world, these are respondents from Mexico (0.81), Venezuela (0.79) and the US (0.78). Differences between country-of-birth groups are likely to be linked to migration channels into Ireland; for example, high-skilled work permits for non-EEA migrants, protection applications for non-EEA migrants fleeing persecution and freedom of movement for EEA migrants.

Regarding self-rated spoken English, an unsurprising but important finding is that those who come from countries where English is widely spoken, for example former British colonies, have much higher chances of reporting their English to be very good. Both English language skills and third-level educational attainment are important indicators of integration; however, origin countries whose migrants score highly on one of these measures do not necessarily perform well on the other measure, though the two are related.

\section{Unemployment and high-skilled work}

Regarding labour market outcomes, we find significant differences between migrants and those born in Ireland, and between different migrant groups. These differences remain even when we control for factors associated with unemployment and access to high-skilled work.

Regarding unemployment, most first-generation migrants have higher chances of being unemployed when compared to respondents born in Ireland. Migrants born in African countries fare especially poorly on this measure, with migrants from only one country having a lower rate of unemployment than the Irish-born population. This difference between groups is partly explained by the fact that respondents of 
Black ethnicity have disproportionately high unemployment rates compared to those of White ethnicity. However, accounting for ethnicity and other controls does not fully eliminate the gap between migrant groups from African countries and the Irish population.

Generally, migrants from more economically developed countries fare better in the labour market than migrants from less developed economies. Among African migrants, those from more economically developed and politically stable countries do not fare as well as the Irish-born, though they do fare comparatively better than African migrants from other countries. Among migrants from Asian countries, we were not able to discern a pattern between economic development and unemployment. In the EEA, migrants from western European countries have lower predicted probabilities of unemployment than respondents born in Ireland, while migrants from eastern European and southern European countries typically have higher predicted probabilities of unemployment. In short, there is wide diversity within continental groupings of migrants.

Regarding the chances of working in a professional or managerial job, only those who have a job are included in the analysis, and there are differences between the skills of migrants in employment and migrant groups as a whole (employed, unemployed, and inactive). Those in employment are a positively selected group and tend to have more skills than those who are not employed. Migrants tend to fare better on this measure when compared to the Irish population, with just under half of the migrant country-of-birth groups having a greater chance of being in a high-skilled job when compared to respondents born in Ireland. Migrants from many Asian countries, as well as North America and South America (with the notable exception of those from Brazil), have higher rates of high-skilled work than those who are Irish born. By contrast, migrants from most African countries are less likely to work in professional/managerial jobs compared to respondents born in Ireland. Among EEA migrants, stark differences are found between those born in eastern Europe and those born in western Europe. Western European migrants perform better than respondents born in Ireland regarding occupational attainment. Eastern European migrants have lower occupational attainment when compared to respondents born in Ireland. Part of this difference is likely to be due to differences in the entry routes from different countries of birth: non-EEA migrants come to work in high-skilled jobs via the work permit system; EEA migrants have unrestricted access and do not need to be highly skilled; vulnerable groups of non-EEA migrants come to Ireland seeking international protection

\section{Modelling labour market outcomes among migrants}

We might expect migrants from within the EEA to differ from migrants outside of the EEA in terms of labour market outcomes. We might also expect that migrants 
who have come to Ireland seeking international protection to report worse outcomes than other migrants, for a number of reasons. We investigate these expectations by substituting migrant's country of birth for two country-level indicators. Firstly, we distinguish between EEA and non-EEA migrants. Secondly, as the data do not identify those who are current or former asylum seekers, we use a measure capturing the likelihood that a respondent will have come through the international protection system.

We find that migrants from countries with a high rate of protection applications tend to have worse labour market outcomes (unemployment and occupational attainment), even when controlling for their educational attainment, English language skills, age, gender, ethnicity, nationality and duration of residence. This could be because of factors related to the trauma and disruption experienced by protection applicants prior to and during migration. It is also likely that the length time an international protection applicant spends inside the State but outside the labour market plays a role, particularly if this period is prolonged.

We also find that migrants born in EEA countries have lower rates of unemployment than migrants born outside the EEA. However, EEA migrants are also less likely to be in high-skilled jobs than other non-EEA migrants. This is consistent with the earlier results, which show that migrants from several eastern European countries were less likely to occupy professional/managerial positions.

In these models, we also find that duration of residence plays a role: in general, recent arrivals are more likely to be unemployed when compared to more established groups. But if they do have a job, those who have arrived recently are more likely to be in a high-skilled occupation, which may be partly related to the work permit system. As expected, migrants with higher educational qualifications and better English language skills are less likely to be unemployed and more likely to be working in professional or managerial jobs.

Finally, controlling for other factors, having Irish citizenship is associated with lower unemployment rates among non-EEA migrants. The opposite is true for EEA migrants. This may be linked to differing incentives and reasons for having Irish citizenship across the two groups. Reporting Irish nationality has a strong, positive impact on the propensity of being in a high-skilled occupation for both EEA and non-EEA migrants.

\section{AVENUES FOR FUTURE RESEARCH}

This report focuses on the labour market and skills. One clear avenue for future research would be to explore outcomes in the housing and family domains. Indicators in the housing domain could include housing tenure, overcrowding and 
homelessness. In the domain of family life, family composition and the proportion of migrants married to or cohabiting with Irish-born residents are possible outcomes.

An alternative possible line of enquiry would investigate how country-of-birth outcomes vary by gender. This might be particularly pertinent to labour market outcomes, in terms of the proportion active in the labour market (including employment and unemployment), and how this varies by country of birth for men and women.

There has been increasing interest in the impact of naturalisation on integration outcomes, from both a policy and research perspective (OECD, 2011; Hoxhaj et al., 2019). A more in-depth project could investigate, firstly, which foreign-born nationals are Irish citizens and, secondly, controlling for duration in Ireland, whether migrants who are Irish citizens experience better integration outcomes.

\section{POLICY IMPLICATIONS}

What are the implications of these findings for policy? One relates to English language ability. Migrants with strong English language skills are less likely to be unemployed and more likely to work in a high-skilled occupation. Language provision is mentioned in a number of actions in the migrant integration strategy, though Kett (2018) argues that demand for English language training far exceeds supply. The findings in this report underscore the importance of helping migrants with poor English language ability to improve their skills, in order to enhance their labour market outcomes.

Recognition of migrants' qualifications is another important aspect of labour market integration. While many migrants may apply to have their qualifications recognised through the Quality and Qualifications Ireland (QQI) system, Arnold et al. (2019) note that awareness of the service is limited and that soft barriers have been reported, such as lack of familiarity with foreign university qualifications. Where migrants' skills and qualifications are not recognised, even if they are highly educated, they may be working in jobs for which they are overqualified.

The finding that those who are likely to have come through the international protection system experience particular difficulties accessing the Irish labour market suggests that these migrants may need additional supports and training to access the labour market in Ireland (UNHCR, 2014). It remains to be seen whether the changes introduced in June 2018, allowing protection applicants to work under certain conditions while their application is being processed, will make any difference to the labour market outcomes of this cohort of applicants. 
There are significant differences in the labour market outcomes between migrants from different ethnic groups. These remain even when we control for the migrant's country of birth, their level of education, their language ability and their gender and age. We suggest this difference may stem from ethnic discrimination and that measures to combat this discrimination would have important implications for migrant integration. This could include government and employer-led policies to monitor, prevent and respond to discrimination, awareness-raising measures among employers and the general public and the provision of information to migrant and ethnic minority groups regarding their entitlements.

Given jobs are the main source of income for migrants and a potential site of social integration, those groups with higher unemployment rates are at higher risk of poverty and social exclusion. 


\section{CHAPTER 1}

\section{Introduction}

\section{$1.1 \quad$ INTRODUCTION}

This report analyses four outcomes and resources of first-generation migrants (third-level educational attainment, English language proficiency, unemployment and occupational attainment), using Irish Census microdata from 2016. This approach allows us to explore detailed country-of-birth differences between migrants and Irish-born for the first time; all previous studies on this subject group migrants into broader regional groups, which they compared to respondents born in Ireland.

This report has two aims. First, it explores four measures of skills and labour market outcomes, comparing migrants from a range of countries to non-migrants (respondents born in Ireland). Previous studies on migrant integration have typically compared outcomes like employment by grouping migrants into regional or continental categories, especially when using survey methods with small sample sizes. In contrast, our approach allows us to be more precise about how outcomes differ by country of birth and to examine the variation within geographic regions of birth, as we have data on every migrant in Ireland. This makes this report an important contribution to the integration topic; we show that previous analyses often mask significant country-level differences when using regional groupings instead of country groupings.

A second aim of the report is to understand why some migrants integrate more successfully than others. We answer this question by modelling labour market outcomes among the migrant population using both individual-level and countrylevel variables. This enables a deeper understanding of why country-of-birth differences emerge. In doing so, this report enhances integration monitoring in Ireland by digging under the surface of regional groupings, and by exploring the extent to which these integration outcomes are influenced by observable factors.

In this report, migrant integration is understood as a process of settlement, interaction and inclusion, which occurs after an individual moves to Ireland. It is most clearly defined by Penninx and Garcés-Mascarenas (2016, p. 14) who claim it is 'the process of becoming an accepted part of society'. This understanding emphasises integration as a process rather than an end point; in addition, it does not specify the requirements for acceptance. According to the EU's 2004 Common Basic Principles of Integration, integration is 'a dynamic, two-way process of 
mutual accommodation by all immigrants and residents of Member States' ${ }^{1}{ }^{1}$ It is not just that migrants need to 'fit in' to their host country: the host country needs to adapt to the presence of migrants. Integration is also a multidimensional concept, involving many elements. While we cannot measure integration directly, we can consider indicators that are clearly related to it. In this report, the focus is on socio-economic integration: skills, qualifications and the labour market. The analysis also focuses primarily on the integration of migrants, rather than the adaptation and response of Irish society to their presence.

Immigrants' skills and the way in which they integrate into a labour market are fundamental factors in their becoming part of a society's economic fabric (OECD, 2018a). Although skills and qualifications are decisive elements in immigrants' social and economic integration, they also indicate the individual's potential to integrate and how they might fare in the labour market, rather than how they actually do so. Employment is often considered to be the single most important indicator of integration (OECD, 2018a). Jobs are a crucial source of income and, in many cases, enable people to afford accommodation, interact with others and learn or improve the host-country language. Yet, while having any employment is important, so too is job quality; for example, whether a job pays adequate wages, is secure, safe, involves a good use of skills and is free from harassment. We consider English language ability and attainment of third-level education in Chapter 3. Chapters 4 and 5 consider unemployment and the attainment of a highskilled occupation.

While using the Irish Census microdata provides large benefits for analysing migrant outcomes in Ireland, due to its coverage of the entire population, it does restrict the type of integration indicators we are able to use in this report, as it only contains information about certain aspects of integration. This means we are unable to consider how integrated migrants feel, their intention to stay, their experience of discrimination, voting behaviour or how much they interact with Irish people and culture. That said, all the indicators measured are likely to be related to other aspects of integration. For example, migrants with very poor English language skills will be limited in their ability to participate in Irish society. Migrants without employment are more likely to face economic hardship or difficulty making ends meet than those who are employed. Having detailed microdata on these indicators is therefore incredibly useful for examining migrant integration in Ireland.

The focus in this report is on first-generation migrants: individuals living in Ireland who were born abroad. This is different from a definition based on nationality or 
citizenship, as citizenship can change over time (see Sections 1.2 and 2.2 for further discussion). We cannot identify those whose parents were born abroad in the Census data. Because of the fairly recent nature of inward migration to Ireland (see Section 1.2), the estimated second-generation population is relatively small. For example, the Organisation for Economic Co-operation and Development (OECD) estimate that compared to around 17 per cent of the population born abroad, one per cent of the population were born in Ireland with both parents born abroad, and a further four per cent have one parent born abroad (mixed background) (OECD, 2018a). ${ }^{2}$ That said, the outcomes of the second generation are arguably the 'litmus test' of integration, and so represent a group certainly worth further investigation. This is a point we return to in the conclusion.

Migrant outcomes are influenced by a number of factors. On the one hand, outcomes depend on a person's characteristics, such as educational qualifications, English language ability, or general productivity or motivation (the latter two may not differ by country of birth). On the other hand, they may depend on contextual factors, such as their county of birth's level of development, labour market opportunities there (or lack thereof) and level of political stability. Such factors will affect their skills and work experience, for example. The mechanism that migrants use to arrive in Ireland is also an important consideration. The processes that influence integration may vary depending on whether migrants are from within the European Economic Area (EEA) or outside the EEA, whether they have come to Ireland on a work permission or student visa or seeking international protection. Migration policy and migration flows are the subject of the next section (1.2).

Section 1.3 discusses the impact of characteristics such as age, educational qualifications, work experience, language skills and length of time living in Ireland on labour market outcomes. Section 1.4 considers the role of the reception context, in particular the behaviour of the host population towards migrants and ethnic minorities, and how these can play a role.

\subsection{MIGRATION TO IRELAND: POLICY AND FLOWS}

Migration flows are complex and influenced by a number of factors: push factors from the country of origin, such as poverty, lack of job opportunities and political turmoil; and pull factors towards the 'receiving' country, such as job opportunities and economic growth, opportunities for personal development, including education and language skills, ${ }^{3}$ and even transnational social networks (so-called 'chain migration') (Massey, 1990). State-level policies and laws, in both origin and

2 Note that due to the lack of survey data on parents' place of birth in Ireland, these data are estimates from
multiple sources.

3 Luthra et al. (2016) highlight diverse motivations of migrants. 
destination countries, shape access channels and purposes of migration (whether and under what conditions migrants can work or study when they arrive in Ireland).

For most of the twentieth century, Ireland was a country of net emigration with a very small immigrant population, until the economic boom known as the 'Celtic Tiger', along with the eastward expansion of the European Union in 2004, helped to bring about much greater diversity in the population. Figure 1.1 shows that in the recession of the late 1980s, net migration was negative - more people were leaving Ireland than migrating to Ireland - but that during the 1990s, levels of immigration increased slowly, and emigration stopped increasing, so that by 1996 net migration (the grey dotted line) became positive, continuing to increase during the economic boom (from the mid-1990s to 2007). A major peak of immigration occurred after 2004, when ten new Member States joined the EU and were granted rights to free movement within the EU and the right to work in Ireland. EU membership was further expanded when Bulgaria and Romania joined in 2007 and Croatia in 2013. Between 2004 and 2007, over 300,000 people entered the country.

Immigration fell sharply during the Great Recession (2008-2011), and Ireland returned briefly to net outward migration, but by 2015 net migration had become positive once again. Because substantial inward migration has been largely confined to the twenty-first century, the population of second-generation immigrants remains relatively small and Ireland lacks significant long-established ethnic minority/immigrant populations. An important exception to this is the longer tradition of movement across the border from Northern Ireland and from elsewhere in the United Kingdom (UK); another exception is the Irish Traveller population, a small Irish-born ethnic minority community. 


\section{0,000}

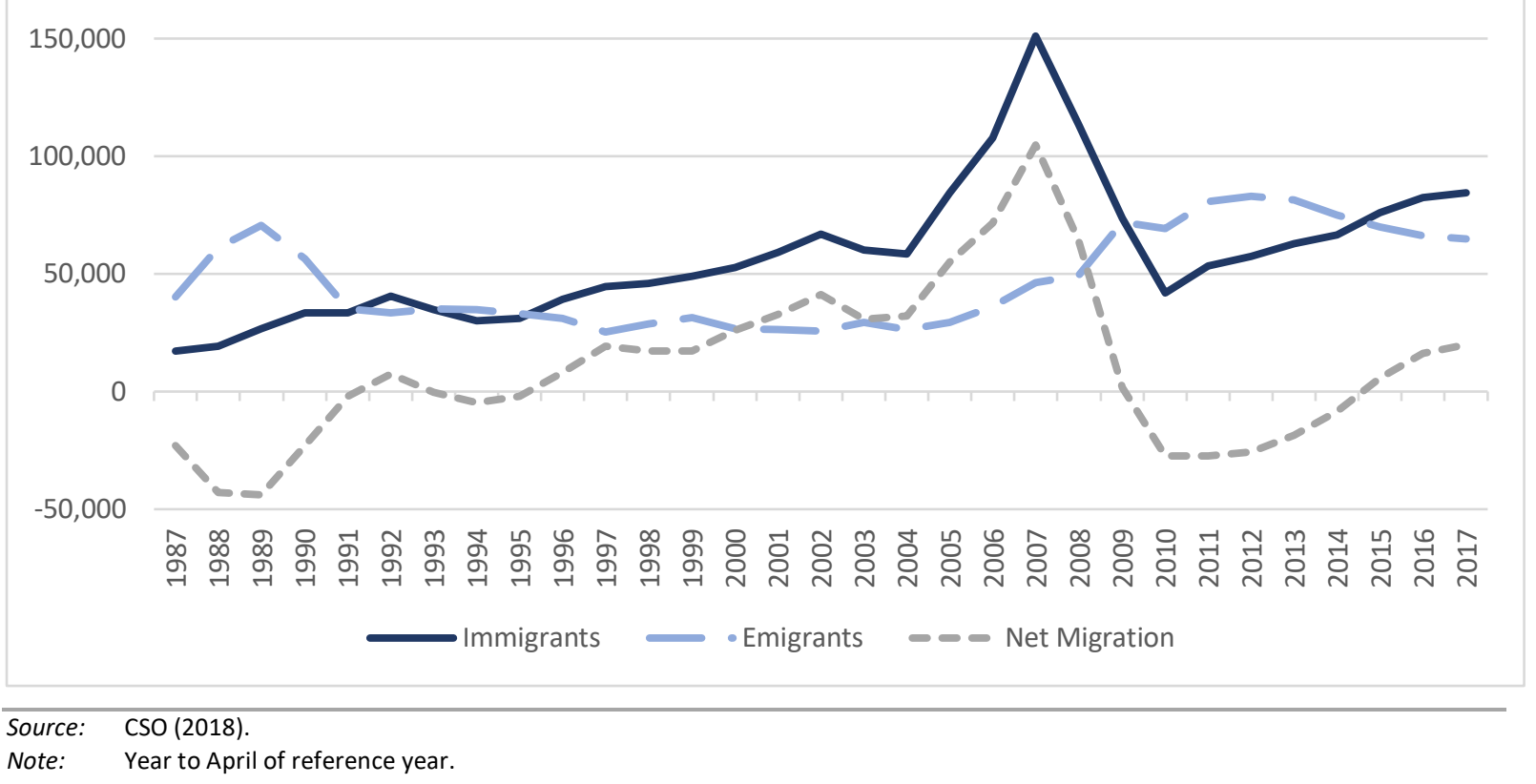

EEA nationals may move to Ireland and take up employment without restriction. ${ }^{4}$ Most migration to Ireland is from within the EU. Figure 1.2 shows that in 2016, 70 per cent of migrants living in Ireland and born abroad were born in the EU. This is one of the highest rates in the EU (McGinnity et al., 2018b). In Figure 1.2, UK-born migrants are presented separately given their importance in terms of size, their longer history of migration to Ireland and the common travel area. One-third of migrants born abroad in 2016 were born in the UK (including Northern Ireland). ${ }^{5}$ 


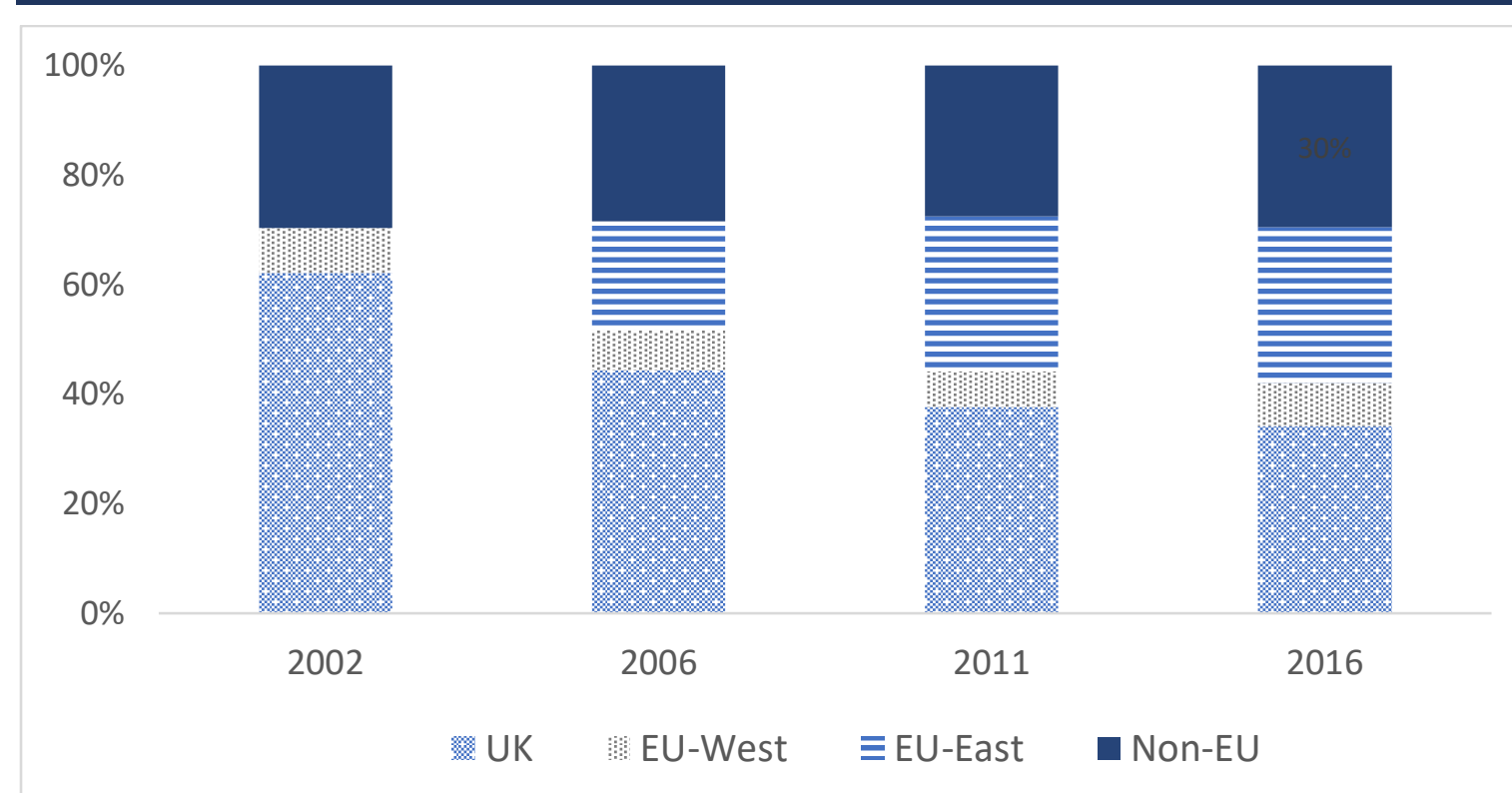

Source: $\quad$ Census of Population. CSO Statbank tables E7050 and C0428.

Note: $\quad$ EU-West is the original EU-15 countries less Ireland and the UK. UK includes those born in Northern Ireland, for ease of presentation. EU-East refers to the new Member States that acceded in 2004, 2007 and 2013.

Non-EEA nationals are subject to managed migration policy, which since 2004 is designed to meet most labour market needs from within the EEA and which relies on the employment permit system to meet skill shortages, mostly in high-skilled occupations. The employment permit system has been revised a number of times, and permits differ, but broadly the system requires many non-EEA nationals to have an employment permit for a specific job in order to work in Ireland. It also restricts mobility between employers and family reunification (see below). There are several different types of employment permits. The most flexible is the critical skills permit, available to migrants with a job paying at least $€ 30,000$ per year in a critical skills area (where the Irish government has determined there to be a skills shortage; for example, ICT professionals, professional engineers and technologists), and to migrants earning $€ 60,000$ or more, regardless of their area of work. ${ }^{6}$ General employment permits are less flexible; holders work in a wider range of occupations, but typically also need to earn more than $€ 30,000$ per year. ${ }^{7}$ In 2017, 45 per cent of the permits issued were critical skills employment permits (Arnold et al., 2018). After two years, critical skills permit holders can work without a permit, but this does not apply to other employment permit holders. This also influences who comes to work in Ireland from outside the EEA; these migrants are typically highly educated because of these employment permit restrictions.

6 As long as the occupation is not on the ineligible list of occupations for employment permits. See https://dbei.gov.ie/en/What-We-Do/Workplace-and-Skills/Employment-Permits/Permit-Types/Critical-SkillsEmployment-Permit/ for more details.

7 See https://dbei.gov.ie/en/What-We-Do/Workplace-and-Skills/Employment-Permits/Permit-Types/GeneralEmployment-Permit/ for details. 
Another important migration channel relates to those seeking international protection: refugee or subsidiary protection status. Non-EEA nationals fleeing persecution or serious harm in their country of origin may be granted international protection in Ireland, in line with Ireland's obligations under the 1951 Convention on the Status of Refugees and EU law. Consistent with overall immigration flows to Ireland, the number of persons seeking international protection in Ireland grew in the late 1990s. Applications increased from 39 in 1992 to 11,634 in 2002. From 2002, applications decreased year-on-year until 2014, rising again sharply by 53 per cent to 1,448 (ORAC, 2015). In 2015, applications rose again by 126 percent to 3,276 and declined by over 1,000 applications in 2016 to 2,244 (Arnold et al., 2018). From 2001 to 2013, Nigeria was recorded as the top country of origin of persons seeking international protection, while nationals of China, Democratic Republic of the Congo, Pakistan and Zimbabwe have also regularly featured in the top five countries of origin over this period. ${ }^{8}$

All protection applicants are offered accommodation within the Direct Provision system following the making of their application, but there is no legal requirement to accept it. Estimates from 2015 suggest that in that year around half of protection applicants lived in Direct Provision centres. ${ }^{9}$ These applicants receive a small weekly allowance, in addition to meals and accommodation. ${ }^{10}$ While the protection application process was intended to be a short one, in practice some applicants seeking international protection status wait years to receive a decision. In 2014, for example, around 38 per cent of residents of Direct Provision centres had lived there for five years or more, though this had fallen to 24 per cent in 2015, following changes in regulations and the introduction of a single application procedure (McGinnity et al., 2018b). ${ }^{11}$ In 2016, the year of the Census data, protection applicants, irrespective of living conditions, were not permitted to enter the labour market, set up their own business or access most social welfare benefits while they waited for a decision on their application (McMahon Report, 2015; Gusciute et al., 2016). ${ }^{12}$ Since June 2018, protection applicants can work under certain conditions, but the data on which this report are based predate this change. ${ }^{13}$ O'Connell (2019) suggests that this extended period out of the labour

$8 \quad$ EU migrants are typically not considered for international protection applications.

9 In 2015, for example, of an estimated 7,937 people in the protection system, over half of them $(4,330)$ resided outside Direct Provision accommodation centres or had left the State (McMahon report, 2015). In April 2016, this allowance was $€ 19.10$ per adult and $€ 15.60$ per child but has since been increased (McGinnity et al., 2018b).

11 The International Protection Act 2015, which commenced in December 2016, introduced a single application procedure for the first time.

12 The exclusion of protection applicants from the labour market is provided for in section 9(4)(b) of the Refugee Act 1996 and Regulation 4(7) of S.I. No. 426/2013 - European Union (Subsidiary Protection) Regulations 2013. The exclusion of protection applicants from most social welfare entitlements is provided for in the Social Welfare and Pensions (No. 2) Act 2009, which prevents protection applicants from fulfilling the habitual residence requirement that is a prerequisite to receiving certain social welfare payments. 
market led to a negative effect on the future employment prospects of those granted international protection, particularly for those born in Africa. Research using the Jobseekers Longitudinal Dataset (JLD) showed that African jobseekers have the lowest employment rate among all regional groups after 12 months, and in conclusion points to the potential (negative) impact of time spent out of the labour market as an asylum applicant and the need for further research in this area (DEASP, 2018). International research has also highlighted the potential detrimental effect of protracted asylum procedures on subsequent employment (Hainmueller et al., 2016).

While the flow of displaced persons into Ireland has been much lower than in many EU Member States, in response to the steep increase in applications the Irish government established the Irish Refugee Protection Programme in 2015, in which it committed to accepting persons in need of protection, mainly through EU relocation and resettlement, and established a cross-departmental task force (McGinnity et al., 2018b). In general, in Ireland resettled refugees are given programme refugee status on arrival.

Convention refugees, subsidiary protection holders and programme refugees have similar rights to Irish citizens, including access to the labour market and third-level education (Arnold et al., 2018). Between 2010 and 2016, 1,007 persons were granted Convention refugee status at first instance and 780 at appeal. A further 550 persons were awarded subsidiary protection in the same period, with another 145 gaining this status on appeal. In this period (2010 to 2016), 4287 people were granted leave to remain under section 3 of the 1999 Act, following submission of an unsuccessful application for international protection (see Groarke and Brazil, 2020). Finally, 828 persons were granted programme refugee status in the period 2010-2016 (Groarke and Brazil, 2020). ${ }^{14}$ Of course many people will have come to Ireland through the protection process and were granted a status before 2010 (see http:// www.orac.ie/website/orac/oracwebsite.nsf/page/orac-stats-en).

Student migration is also an important migration stream in Ireland. Indeed, students now form the largest category of non-EEA migrants arriving in Ireland each year, coming ahead of labour migrants and other groups (Groarke and Durst, 2019). ${ }^{15}$ Ireland allows nonEEA students with an honours degree or higher to remain in the State for 12 to 24 months after their studies to look for work under the Third Level Graduate Programme. This is uncommon among EU countries and is designed to retain high-skilled international graduates, which further affects the outcomes of migrants in Ireland.

Migration for family reasons is an increasingly important source of migration of non-EEA migrants to Ireland (McGinnity et al., 2018b). Critical skills permit holders

14 McGinnity et al. (2018b) note that in 2016 and 20171.5 per cent of residence permissions for non-EEA nationals over 16 years were for protection reasons.

15 Just over 9,300 first-residence permits were issued to higher education students in 2013 , increasing to around 13,500 in 2017. 
have immediate family reunification. ${ }^{16}$ General employment permit holders may apply for family reunification after 12 months (Arnold et al., 2018). These family members of non-EEA nationals with an employment permit are generally not allowed to access the labour market, although once resident in Ireland they may apply for an employment permit for an appropriate job in their own right (Arnold et al., 2018). Immediate family members of Irish and EU citizens may access the labour market without an employment permit (INIS, 2016).

Discussing different migration streams and reasons for migration is helpful, though it is also acknowledged that it is not always possible to strictly separate categories. For example, those who originally came as students may subsequently work in Ireland. Similarly, those who came to join family members may subsequently work. Migration is often seen as a permanent move, but it may be temporary. This has been particularly highlighted regarding migration within the EU, which Favell (2008) highlights is both more flexible and more complex given freedom of movement.

A final relevant state policy in the area concerns naturalisation. Adult non-Irish nationals can apply for Irish citizenship if they are of 'good character' and have lived in Ireland for five of the previous eight years. ${ }^{17}$ Previous research notes that Ireland experienced a rapid increase in naturalisation rates, which peaked in 2012 both due to an increase in eligible applicants and the introduction of reforms to reduce a backlog of applications at the time (McGinnity et al., 2018b). By the end of 2015, McGinnity et al. (2018b) estimate that a sizeable minority of adult nonEEA migrants had acquired Irish citizenship. While some migrants who have naturalised might have left Ireland, figures do suggest that many migrants of nonEEA origin may be Irish citizens by April 2016. As Irish citizens, these migrants are free to live and work in Ireland without restrictions, which may affect their integration outcomes. Recent comparative work suggests that citizenship is associated with better labour market outcomes in 13 West European countries (Hoxhaj et al., 2019), though Ireland is not included in the analysis.

\subsection{INDIVIDUAL CHARACTERISTICS OF MIGRANTS}

A second set of factors that influences outcomes concerns individual characteristics of migrants. Among the most important of these are education level and English language ability, as both have a large effect on whether and to what extent migrants can integrate into both host country labour markets and to society more generally.

16 As of March 2019, the spouses and partners of critical skills employment permit holders may access the Irish labour market without needing an employment permit (see below).

17 See Barrett et al. (2017), Box 5.1, for detailed regulations. 
Education is a key factor in the integration process as it can play a decisive role in improving economic and social outcomes (OECD, 2018b). Across Organisation for Economic Co-operation and Development (OECD) countries, those with higher educational attainment report better physical health and improved socioemotional well-being; they are also more likely to be active participants in their societies. On this factor, human capital theory has been hugely influential in terms of explaining labour market outcomes. According to this theory, educational qualifications and work experience are key to labour market success (Becker, 1975). Higher levels of education are associated with improved labour market outcomes - both much lower unemployment rates and higher occupational attainment (McGinnity et al., 2018b). From this, it may be inferred that poorer labour market outcomes among migrants may be due in part to lower educational attainment and that educational qualifications play a key role in understanding labour market outcomes such as unemployment.

From the Census data, we are unable to differentiate between migrants who have completed qualifications in Ireland from those who have completed them abroad. For those who completed education in Ireland, their experience and achievement in the second-level system is relevant, in addition to particular regulations about cost and access to third-level education for non-EEA migrants (see Chapter 3 for further discussion).

The educational qualifications of those who completed their education abroad are more related to processes in their country of origin and the route they used to enter Ireland than they are to the integration process. Their education outcomes may reflect the nature and quality of education systems in the sending countries; for example, they may imply that migrants from less developed countries in the global south have lower qualifications than those from OECD countries. ${ }^{18}$ The educational qualifications of migrants also reflect migration channels. As described in Section 1.2, whereas EEA nationals may come and work without restriction, most non-EEA nationals can only get a work permit for high-skilled occupations.

While much of the early literature on immigration, particularly in the United States (US), focuses on low-skilled labour migrants, McGinnity et al (2018b) shows that in fact non-Irish nationals in Ireland typically have higher qualifications than Irish nationals. This is partly due to their younger age profile. Those from western Europe and from non-EEA countries are particularly highly qualified. While the number of respondents in the Labour Force Survey are not high enough to permit 
detailed analysis by country of birth, such analysis is possible in this report as we use Census data.

One important issue for migrants is that Irish employers may not rate educational qualifications acquired in their home country as highly as they rate Irish qualifications. This may be particularly true of those from poorer or less developed countries. The same may occur in relation to work experience, which employers may value more highly if acquired in Ireland than abroad. This can harm the integration prospects of migrants, especially from these less developed countries, even if they are more educated than the average Irish-born person.

Host country language skills have been shown by several studies to be key to both labour market integration and social integration (Portes and Rumbaut, 2001). This implies that migrants from English-speaking countries like the UK may fare better in the Irish labour market than those from non-English-speaking countries, as found by Barrett and McCarthy (2007). Of course, this should also apply to nonEEA English-speaking countries, such as the US and Canada, as well as countries like India and Nigeria, where English is commonly spoken. Using 2011 Census data, O'Connell (2019) finds fluency in English increases the likelihood of employment among ethnic minority groups, suggesting that this is an important factor to consider. Of course, language skills may influence the decision to migrate in the first place. In general, while many European countries do not have English as a dominant language, learning in school or exposure to English-language media may lead to high English-speaking ability. Those with a higher level of education may also be more likely to have good language skills, and those with very good English language skills may be more likely to migrate to an English-speaking country like Ireland. Proficiency in the host country language is also very important for migrants to be able to leverage their educational qualifications and experience (Esser, 2004).

Much of the early research on migrant integration was based on the assumption that the longer migrants reside in a host country (and invest in local skills such as language, as well as acquire country-specific work experience that helps them acquire new and better jobs), the more they will 'assimilate' (Borjas, 1999). According to this theory, while a migrant's education and language skills may have an influence, these can be enhanced during their stay in the country, depending on the opportunities afforded them. Duration in the country not only increases opportunities to acquire skills and work experience; it also enhances access to social networks to improve social and labour market integration and knowledge of 'how things work' - the 'rules' of the game (Esser, 2004). However, as discussed below, the process is not always so straightforward.

While the Census data used here allow us to construct a measure of duration of stay, the requisite information is missing for many individuals, so we cannot use it 
in the analysis of outcomes by country of birth. Therefore, we use age as a proxy for experience in the labour market, although we cannot know whether this experience was gained in Ireland or not. ${ }^{19}$

\subsection{DISADVANTAGE AND DISCRIMINATION}

Often, differences in education, experience, language, duration and country of origin do not adequately explain the disadvantage observed in labour market outcomes for some migrants. Migrant integration may relate to the situation and context migrants find themselves in, influenced by the host country response to migrants and immigration.

Early work by Barrett and Duffy (2008) found migrants in Ireland were less likely to be working in high-level occupations than native Irish and that those from eastern Europe had the lowest occupational attainment, with little evidence of improved attainment over time among this group (see also Voitchovsky, 2014). More recent work has highlighted considerable diversity between migrant groups in their propensity to occupy disadvantaged segments of the labour market (McGinnity et al., 2018a).

Discrimination, whether it is because employers consider migrants or ethnic/racial minorities to be less productive ('statistical discrimination') or because they prefer to hire from their own national or ethnic group ('taste-based discrimination') (Becker, 1975; Arrow, 1973), is the unequal treatment of people on the basis of their membership of a specific group that represents 'who they are' (Eichhorst et al., 2018). Discrimination implies that despite having the same level of education, experience and labour market skills, some groups will always have poorer outcomes in the labour market (OECD, 2013). As McGinnity et al. (2018a) note, the presence of discrimination is a powerful counter to theories of assimilation; it seems that because of this, certain groups will not achieve their potential and integrate fully into the labour market or social life without further intervention. In particular, the literature on discrimination has centred on racial or ethnic discrimination, showing that while White migrants can experience discrimination (for example, see McGinnity and Gijsberts, 2017), non-White migrants in predominantly White societies experience higher levels of discrimination (Zschirnt and Ruedin, 2016).

There is plenty of evidence regarding the existence of discrimination against migrants and ethnic minorities in Ireland. McGinnity and Lunn (2011), in their field experiment exploring discrimination in recruitment in 2008 , found that candidates with clearly African, Asian or German names were half as likely as Irish candidates 
to be invited for an interview. Discrimination among Africans was somewhat higher than the other groups, but this difference was not significant for the number of applications tested.

Kingston et al. (2015) found that, between 2004 and 2010, the overall rates of discrimination experienced by minority groups in Ireland declined, but that in the same period high levels of work-related discrimination reported by Black Africans persisted. Later work by McGinnity et al. (2017) also found much higher levels of reported discrimination in the workplace by Black respondents and that the gap in the experience of discrimination between Black and White Irish respondents grew between 2004 and 2014. Conversely, in recruitment, McGinnity et al. (2017) found that the gap between White non-Irish and White Irish fell, so that by 2014 there was no difference between these groups. A comparative survey conducted by the European Agency for Fundamental Rights (FRA) in early 2016 found the highest rates of discrimination in the workplace experienced by sub-Saharan African respondents in Europe were documented in Luxembourg, Sweden and Ireland (in the 12 months prior to the survey) (FRA, 2017). All these findings suggest that people of different ethnicities are very likely to have different integration outcomes in Ireland, with Black Africans likely experiencing the worst outcomes. With regards to this report, these findings mean it is important to control for ethnicity as a possible explanatory factor of migrant outcomes, particularly as countries of origin vary in terms of their ethnic make-up. Do certain groups display poorer outcomes because of their ethnic composition?

It could also be that migrants from certain countries of origin are discriminated against because they are asylum seekers or perceived as such. A survey of racism and discrimination against migrants in 2005 in Ireland found much higher rates of racism and discrimination experienced by asylum seekers than work permit holders (McGinnity et al., 2006). Of course, it is difficult to disentangle this effect from ethnic discrimination in many situations, but it is not implausible that there is additional stigma attached to being a refugee.

\subsection{RESEARCH QUESTIONS AND EXPECTATIONS}

Based on previous literature and the discussion above, this section discusses expectations regarding how migrants from different countries of origin are likely to differ in terms of their skills and outcomes. This is to inform subsequent analyses of differences between migrants from different countries and those who are Irishborn across the four outcomes of educational qualification, English language skill, access to employment and job quality.

1. Following what we know about the rights of EEA and non-EEA migrants to live in Ireland, we expect outcomes to differ between these groups. All else being 
equal, we would expect those from EEA countries to have higher levels of education, partly because of the education systems in those countries, though this may be more the case for those from western European countries than for eastern European countries, given previous findings that education levels for western European nationals tend to be better than those from eastern European countries (OECD, 2019; ECOSOC, 2019). However, some non-EEA countries - some Asian countries, the US, Canada and Australia have education systems that are comparable to those in Europe. As non-EEA migrants can only come to work in Ireland in high-skilled jobs (see above), at least those who come to work may have higher educational qualifications. With superior rights to employment than non-EEA nationals and very limited student flows, we expect higher employment rates and lower unemployment rates for those born in the EEA than those born outside the EEA. On the face of it, one might expect EEA migrants to have better access to high quality jobs than non-EEA migrants, though given previous findings we might expect this to be more the case for western European than for eastern European migrants. However, given the work permit system described above, it could be that nonEEA migrants are more likely to have high-skilled jobs, as those who are eligible for work permits are allowed to come to Ireland.

2. Another key distinction is between migrants from English-speaking countries and those from non-English-speaking countries. In general, we would expect that migrants from English-speaking countries to have better outcomes than those from non-English-speaking countries. This applies to English language ability and, as a result of this, labour market access and job quality.

3. We expect that refugees or those with leave to remain in Ireland are likely to have poorer outcomes in the labour market than those found for other groups of migrants. As this group have entered the country for humanitarian reasons, they are not selected by the work permit system to work in high-skilled jobs, or even matched to particular jobs. Additionally, as mentioned above, there may be bias against refugees, distinct from ethnic bias, among potential employers. This group may also find it harder to access high quality jobs or the labour market due to their prolonged period of non-employment in the protection system (O'Connell, 2019). Ideally, we would be able to test for this by knowing whether or not an individual came through the protection process, but unfortunately that information is not available in the Census data. However, we do know which countries have high rates of protection applications in Ireland and might therefore expect migrants from those countries to have worse outcomes. 
4. Given the role of discrimination on the basis of ethnicity in Ireland, discussed above, we expect those of White ethnicity to have an advantage in the labour market, both in terms of access to employment and job quality.

5. To the extent that the acquisition of Irish citizenship increases employment rights and security of residence, this may improve both access to the labour market and the likelihood of being in a high-skilled job. This we investigate in Chapter 5.

In the following analyses, we test these hypotheses by examining whether there are differences between the Irish and country-of-birth groups in relation to education, English language skills and labour market outcomes. Are there differences within broader regional groupings used in previous research on integration? Are the country rankings maintained across outcomes? Do we see a pattern whereby some countries perform well across a range of outcomes?

It is also important to bear in mind that the report considers a range of outcomes - educational qualifications, English language skills, access to employment and job quality, in the form of occupational position. It could be that the groups fare differently depending on which outcome is considered, or at least that there is not an entirely consistent 'ranking' of country-of-origin groups for each outcome.

Age will play a role in many of these outcomes, given that younger cohorts tend to be more highly educated, yet have less labour market experience. Gender is also salient in understanding outcomes concerning education (Buchmann et al., 2008) and the labour market (Russell et al., 2017). To the extent that country-of-origin groups will differ in composition, we may want to 'rule these out'. This we do using statistical modelling techniques.

In order to explore these expectations and to go beyond broad regional groupings in the Irish labour market, we need to distinguish country-of-birth groups and explore whether and how the outcomes differ across groups. The next chapter sets out how we do this using Census 2016 microdata. 



\section{CHAPTER 2}

\section{Methodology}

\subsection{INTRODUCTION}

This chapter presents the methodology used in this study. We discuss the sample, measures and estimation techniques used. We also discuss the wider models presented in Chapter 5, which substitute country-level factors for respondent country of birth to explore mechanisms of integration in more depth.

\subsection{EVIDENCE BASE: 2016 CENSUS MICRODATA}

We use a dataset provided by the Central Statistics Office (CSO) based on the 2016 Census microdata. This dataset contains 4.7 million responses (the total population of the Republic of Ireland), of which 3.8 million are from respondents born in Ireland. The remaining 0.9 million responses belong to those born outside of Ireland (including Northern Ireland). To speed up computation, we randomly select a five per cent sample of respondents born in Ireland as a representative group of Irish-born. As a result, we rely on around one million responses throughout the report, 194,774 of which belong to respondents born in Ireland. These respondents are representative since they are selected at random.

As a robustness check, we expand the Irish sample in a separate analysis to contain 15 per cent of the population. Having run the models with this wider sample, we confirm that differences between estimates are minimal and that the pattern of country-level differences is also similar. We present the results from the five per cent Irish sample throughout the report.

\subsubsection{Country of Birth Profiles}

We use 'country of birth' categories as representative measures of the migrant population. Because nationality can change over time (through naturalisation) we instead focus on a time-invariant measure. Barrett et al. (2017) report that between 2005 and 2015, 121,100 non-Irish nationals became Irish citizens through naturalisation. Naturalised citizens could represent as much as 45 per cent of the population of non-European Economic Area (EEA) origin resident at the end of 2017 (McGinnity et al., 2018b). Individuals can also hold dual nationalities, and this group has grown in recent years. ${ }^{20}$ 
This definition contains two important limitations. First, children born abroad to Irish parents are considered migrants under our definition. In this way, certain migrant groups are likely to contain individuals born abroad to Irish parents who have subsequently moved back to Ireland. Many of these migrants were born in the United Kingdom (UK). These respondents may resemble the Irish population more closely than other migrants. However, we expect their impact to be minimal, in that most migrants under our definition were born outside of Ireland to parents also born outside of Ireland.

Second, using an individual's country of birth to define migrant status does not permit analysis of integration of the children of migrants, or the so-called 'second generation'. This omission understates the progress made by second-generation migrants, who are counted as non-migrants in our report. However, here too the second-generation population in Ireland is estimated to be very small (see Chapter 1) and so it is likely to have a minimal impact on our estimates.

Both of these limitations raise worthwhile topics that are not within the scope of our current project, though in Chapter 5 we do consider the effect of being an Irish citizen on the labour market outcomes for those born in Ireland.

TABLE 2.1 TOP 10 COUNTRIES OF BIRTH, 2016

\begin{tabular}{|l|r|r|}
\hline Country of birth & Freq. & $\begin{array}{c}\text { Percent of all migrant } \\
\text { respondents }\end{array}$ \\
\hline UK* & 203,480 & $27.5 \%$ \\
\hline Poland & 100,227 & $13.6 \%$ \\
\hline Northern Ireland* & 52,239 & $7.1 \%$ \\
\hline United States & 29,010 & $3.9 \%$ \\
\hline Lithuania & 28,329 & $3.8 \%$ \\
\hline Romania & 25,572 & $3.5 \%$ \\
\hline India & 18,048 & $2.4 \%$ \\
\hline Latvia & 16,036 & $2.2 \%$ \\
\hline Brazil & 15,625 & $2.1 \%$ \\
\hline Germany & 14,684 & $2.0 \%$ \\
\hline
\end{tabular}

Source: Census (2016). All migrants aged 15+ years.

Notes: *Northern Ireland is listed separately from the UK for the purpose of this report.

Most migrants are born in the UK (just under 28 per cent) and Northern Ireland (seven per cent). A significant share are also born in Poland (just under 14 per cent) and Lithuania (four per cent). Of the countries above, the vast majority are European nations, except for those from Brazil, India and the United States (US).

The analysis in Chapters 3 and 4 groups individuals by their country of birth, though we are also interested in whether similarities occur between countries within specific world regions. In total, we consider migrants from 118 countries grouped 
into four regions: Africa, Asia, the EEA and the 'rest of the world'. ${ }^{21}$ These regional groupings are similar to other migrant categories used in reports like the monitoring report on integration (McGinnity et al., 2018b).

Defining migrants using regions of birth alone would conceal much variation. Within regional groups, there are large differences in the population sizes of the countries that make up such groups. As a result, certain countries come to dominate regions; for this reason, conclusions about migrants from eastern Europe, for example, are drawn from mostly Polish respondents, and may differ substantially from the experiences of Estonian migrants. We illustrate the point below for each region.

FIGURE 2.1 TOP FOUR MIGRANT GROUPS FROM THE EEA, 2016

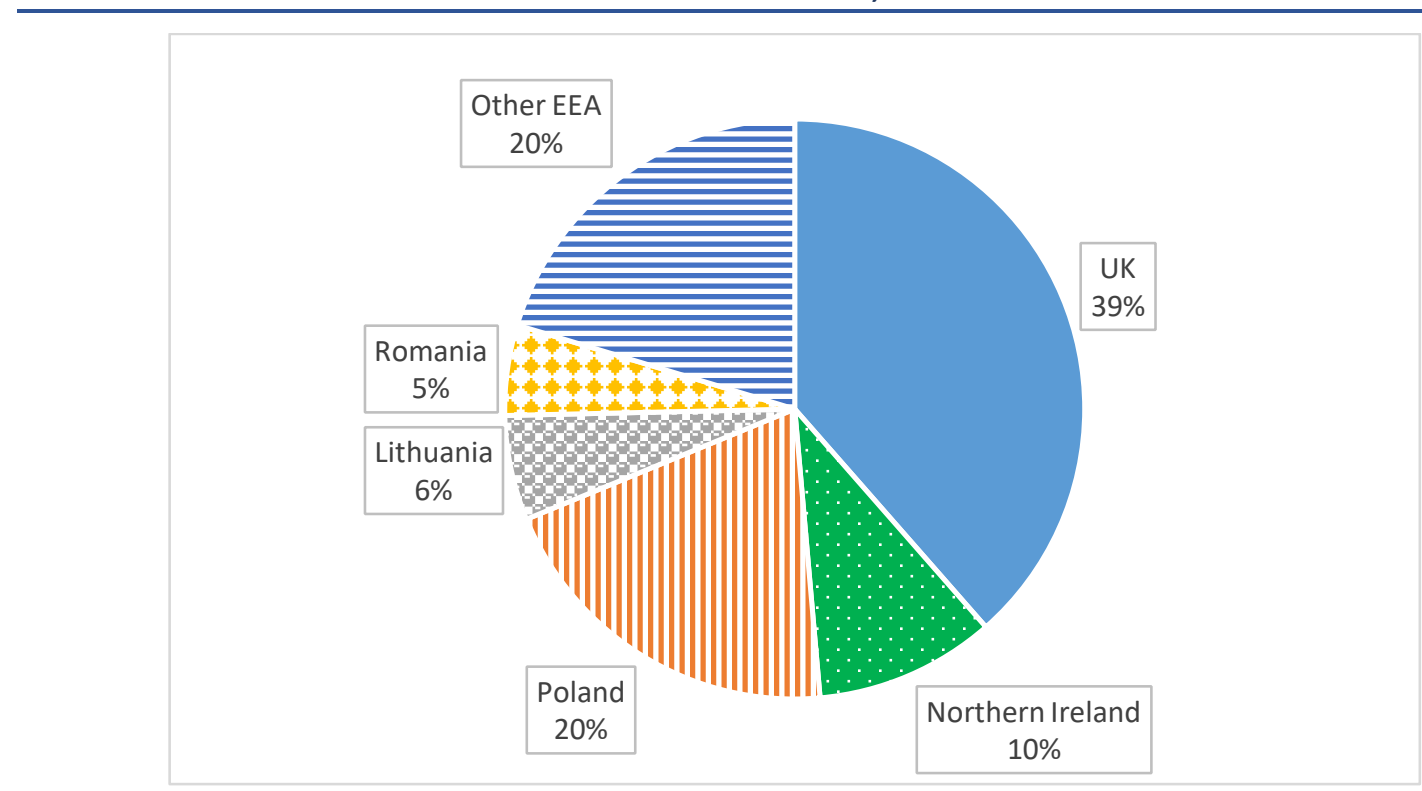

Source: Census (2016). Own calculations.

Notes: UK does not include Northern Ireland, which is listed separately from the UK for the purpose of this report.

Almost half of all EEA migrants were born in the UK (39 per cent in GB and 10 per cent in Northern Ireland). ${ }^{22}$ There is also a substantial share of Polish (20 per cent), Lithuanian (six per cent) and Romanian (five per cent) migrants within the migrant population. The remaining group of countries hold 20 per cent of the EEA migrant share. Previous research has typically identified three sub-groups: EU-East, EUWest and UK migrants. 


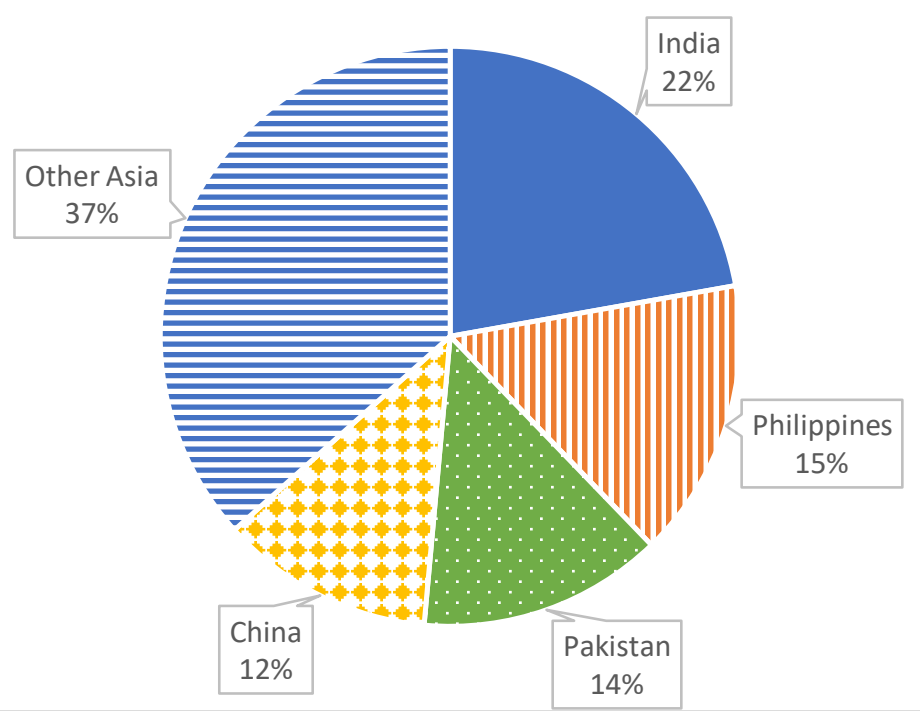

Source: Census (2016). Own calculations.

Migrants from China (12 per cent), India (22 per cent) and Pakistan (14 per cent) dominate the 'all Asian migrants' category. The remaining countries, including Malaysia, Bangladesh, Saudi Arabia and Thailand, make up the remaining 37 per cent of all Asian migrants.

FIGURE 2.3 TOP FOUR MIGRANT GROUPS FROM AFRICA, BY COUNTRY, 2016

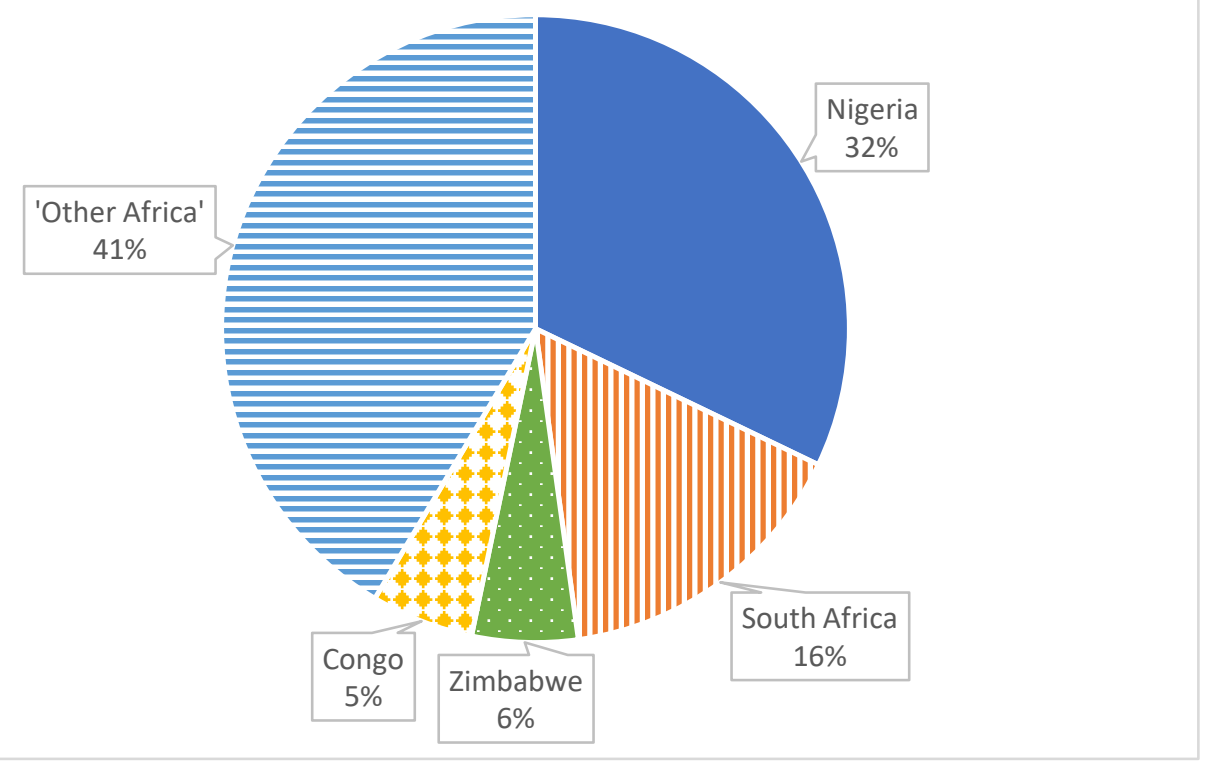

Source: Census 2016, own calculations.

A significant portion of migrants from Africa come from Nigeria (32 per cent) and South Africa (16 per cent). 'Other' African countries, including Algeria, Egypt, Somalia and Sudan, make up 41 per cent of the migrant share. 


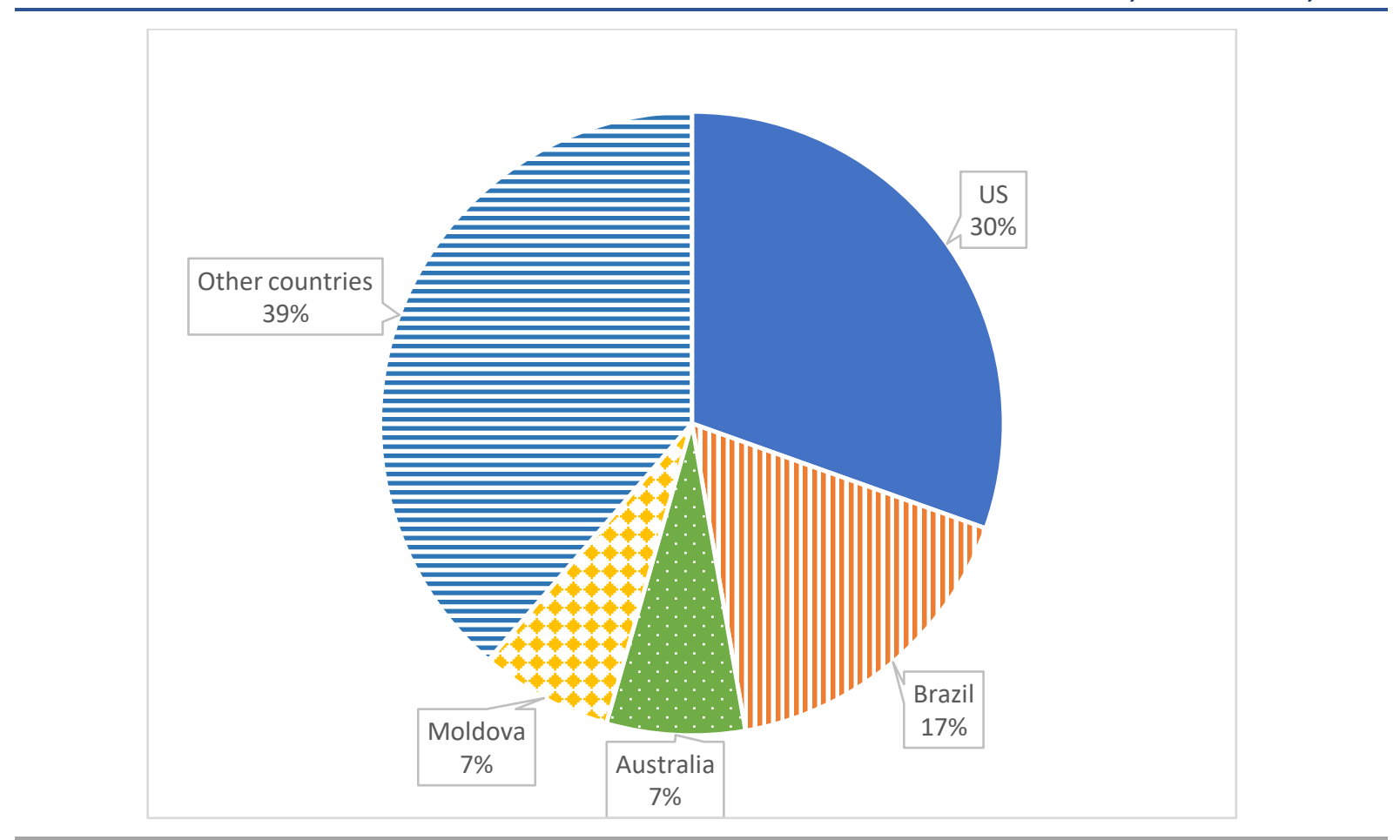

Source: Census 2016, own calculations

Lastly, migrants from the US (30 per cent), Brazil (17 per cent), Australia (seven per cent) and Moldova (seven per cent) make up the majority of migrants in the 'rest of the world' category.

The charts highlight the importance of focusing on countries within regions, showing how certain countries can influence overall results regarding migrants from Asia, Africa and Europe. They also highlight that using regional categories alone would mask the huge influence key countries have within each region group. By using Census data, this problem is avoided.

\subsection{MEASUREMENT AND METHODS}

\subsubsection{Resources and outcomes}

This report focuses on two dimensions of integration: skills and employment. On the topic of skills, we also focus on two measures - whether the respondent has a third-level education, and whether they describe their English language ability as 'very good'. The Census measures educational attainment using the Irish National Framework of Qualifications (NFQ) and distinguishes between 11 possible education types. The research dataset operationalises education into four categories: primary; lower secondary; upper secondary or vocational; and thirdlevel education. A residual category contains respondents who do not state their education. We recode educational qualifications into a binary measure, separating those with third-level education and those without. Respondents who indicate that 
their education has not yet ceased are not included in the analysis for educational attainment. Our measure cannot distinguish between respondents who acquired third-level education in Ireland and those who acquired third-level education abroad. Migrants from countries that appear particularly successful in integrating may simply come from countries with high levels of educational attainment, or they may come from countries whose migrants to Ireland are disproportionately highly educated. They may have originally come to Ireland to study from abroad and now may be working, or they may have progressed to third-level education from second-level schooling in Ireland, if they came to Ireland as children. This is a limitation in the data.

Regarding language ability, respondents are asked 'How well do you speak English?' This measure contains four options, ranging from 'very well' to 'not at all'. We operationalise strong English skills using the top category: those who speak English 'very well' are compared to all other answers. Respondents aged under 20 years are omitted from the analysis. The model for English language ability also controls for whether a respondent is currently a student. Since the measure is a subjective evaluation, it may not be an entirely accurate assessment of a respondent's language ability (Edele et al., 2015). Of particular concern for us is that there may be country-specific biases that influence a respondent's answer. First, there may be cultural sensitivities about self-evaluation that could either understate or overstate a person's ability. Second, there may be a country-level difference in what is evaluated as 'very good' English, most likely stemming from the commonality of English within the migrant's country of birth. We acknowledge these issues but note that no other measure captures English language ability in the Census. In fact, English-language ability is not typically measured in surveys in Ireland. Individuals who have poor English language ability may have completed the Census in another language, as in 2016 the Census was completed in 21 different languages, excluding Irish and English.

It is important to note that both measures above are not measures of integration themselves, though they are strongly correlated with integration. Having both a third-level education and strong English language ability could represent a milestone to integration for migrants born outside of Ireland.

On the topic of employment, we again focus on two measures: whether the respondent is unemployed and whether they hold a high-skill occupation - both are internationally recognised measures of integration (Heath and Cheung, 2007). On the first measure, we focus only on labour market participants and do not consider those who are economically inactive (students, pensioners and others who are not looking for work). The Census form contains eight measures of 'principal economic status' and distinguishes between those working for pay or profit, those looking for their first job, those who are unemployed, students, those 
looking after a home or a family, retirees, and those living with a disability. Although these measures are not mutually exclusive, the respondent must choose one 'principal' economic status. ${ }^{23}$ The research dataset contains just four measures of principal economic status: working, unemployed, student and other. Our analysis of unemployment distinguishes between those who are working and those who are unemployed, excluding those in the other two categories. Measures for both employment and unemployment only include respondents who are aged between 15 and 64 years.

Regarding the second measure, there are 26 occupational categories in the data using standard occupational classifications (SOC2010), ranging from 'corporate managers and directors' to 'elementary administration and service occupations. We focus on 11 occupational subgroups from the top three major occupational groups: managers, directors and senior officials; professional occupations; and associate professional and technical occupations. ${ }^{24}$ All the remaining categories are deemed 'not professional and managerial' and act as a reference category. When analysing occupational attainment, we restrict the sample to those who are in employment.

\subsubsection{Age, gender, ethnicity and time in Ireland}

This section presents the main controls of the study. Migrant groups typically differ from non-migrant groups in terms of age, economic status, ethnicity and gender composition. These differences should be considered to give a better comparison between country groups.

We control for age using a categorical measure using bands of five-year intervals. Due to privacy concerns, we cannot include precise age. We control for gender throughout the report. When modelling English language ability, we control for whether or not the respondent is a student. When estimating migrant differences in unemployment or occupational attainment, we include education and English language ability as controls. These are theoretically important measures of human capital (see Chapter 1). Excluding them from the analysis would overstate certain country-level effects in unemployment and occupational attainment between countries. In an effort to capture ethnic disadvantage in the labour market or the educational system, we control for the ethnicity of respondents. The Census in the LFS, the ILO definition. The ILO definition counts any hours of work as being in employment, so full-time students working 10 hours per week would count as employed, whereas their principal economic status would be student. The ILO measure is not available on the Census.

24 The subgroup categories include: corporate managers and directors, other managers and proprietors, science, research, engineering and technology professionals, health professionals, teaching and educational professionals, business, media and public service professionals, science, engineering and technology associate professionals, health and social care associate professionals, protective service occupations, culture media and sports occupations, and business and public service associate professionals. 
distinguishes between four main types of ethnicity: 'White', 'Black or Black-Irish', 'Asian or Asian-Irish' and 'Other'. These ethnicities contain subcategories for ethnicities who are Irish, non-Irish or members of the Travelling community. KingO'Riain (2007) highlights the limitations of the Census ethnicity measure, arguing that it is a compromise between simple categories to measure diversity and the complex lived reality of race and ethnicity. The result is ethnic 'meta-categories', which are limited in both number and explanatory power. While we acknowledge the limitations of the measure, exploring the role of ethnicity in migrant integration is an important feature of this report. We are especially interested in what impact the measure has on understanding differences between country-of-birth groups.

An important and often cited measure of integration is the duration of time spent in the host country. This measure exists within the Census but refers to a respondent's latest 'spell' in Ireland. The measure is not capable of capturing multiple spells in Ireland. Further, the measure has a high rate of missing values and migrants from outside the EEA are particularly likely to hold missing values for the duration question. We do not include this measure in the models distinguishing country of birth, but we incorporate the measure in additional models in Chapter 5. Due to these limitations we suggest its estimates should be read with caution.

\subsubsection{Methods}

Each chapter uses binary logistic regression to consider country-level differences in an outcome. In each chapter, we present the full model, in that we show country-level differences in an outcome controlling for a range of composition differences between countries.

Estimates in a logistic regression are typically interpreted as odds ratios. In this way, Ireland would be considered the reference category and country deviations would be explored relative to Ireland. This form of estimation is often referred to as relative risk. For clarity of presentation, we convert the estimates above into predicted probabilities of experiencing an outcome; this form of estimation is often referred to as absolute risk. ${ }^{25}$

In Chapter 5, we also estimate logistic regressions, but here the focus is less on individual country-of-birth differences. We substitute country of birth for two macro indicators of the migrants' country. We do this in an effort to isolate three main sources of migration; the first is the free movement of migrants from Europe, the second is the flow of economic migrants from outside the EU who gain access to live and work in Ireland through work permits, and the third group comprises migrants seeking asylum or safety in Ireland who have limited resources. We 
cannot identify former students or those who came to Ireland for family reasons. ${ }^{26}$ Isolating the first group is relatively simple: we simply separate country of birth based on whether it is within the EEA or not. Migrants from countries outside the EEA are split based on the likelihood that they arrived in Ireland through the international protection system. Here, we consider the number of asylum applications put forth by migrants from the country and express this number relative to the number of migrants living in the state in 2016. Chapter 5 contains a detailed discussion of this method, which resembles previous approaches (O'Connell 2019).

We cannot identify migrants from outside the EEA who are in the labour market but who came to Ireland as students, or those who are in the labour market and came to join family members (family reunification). Those whose principal economic status is student, home duties or 'other' (labour market inactive) are also not included in the labour market analysis.

Although the Census data contain Ireland's full population in 2016, we rely on hypotheses and statistical tests throughout. Several authors have taken a similar approach, especially those who use confidence intervals and statistical tests to consider group-level differences in national population studies. Subramanian (2001) suggests using confidence intervals to make comparisons between groups in Census data. He uses a multilevel estimation approach to compare literacy differences across small areas. Elsewhere, Leckie et al. (2012) use Census data to model school segregation. They use confidence intervals to test whether measures of diversity between schools are significant. Allebeck (1998) summarises this issue in a discussion of Scandinavian register-based surveys. On the topic of statistical estimates, he cites the problem of 'mass significance'. He concludes that 'relative risks' for multiple variables without prior hypothesis should be interpreted with caution. These estimates will lead to 'scattered findings of increased risk'. In short, meaningful hypotheses should be outlined before estimating relationships. We consider this advice throughout.

\subsection{SUMMARY}

This chapter outlined our general approach. Two measures related to integration explicitly and two related to resources and processes tied to integration. Throughout the report we are less interested in the measures that explain our outcomes (age and gender) and more interested in country-level differences of these outcomes, and how certain controls lower these differences. The gaps 
presented in subsequent chapters capture gaps in integration between migrant groups from similar regions.

In order to illustrate these gaps, we will turn to Ireland's Census microdata for 2016, which considers each respondent's country of birth, as well as measures of employment and education, and other important controls. We estimate these effects using binary logistic regression and consider country-level differences in absolute terms using predicted probabilities. Although we are using Census data for the entire population, we will rely on statistical tests and confidence intervals to compare migrant groups. Previous authors have taken a similar approach. 


\section{CHAPTER 3}

\section{Education and English language skills}

Education and language skills are strong predictors of integration and job security among migrants. Whether because of productivity through human capital (Becker 1975) or signalling (Weiss et al., 2014), people with third-level education are more likely to be employed, more likely to have high earnings, and more likely to secure life chances in the labour market, such as promotions or training opportunities, when compared to people without third-level education.

Regardless of migrant status, respondents in Ireland with less than a secondary education have the lowest levels of employment (50 per cent), compared to all other education groups (the figure is 72 percent for those with a secondary education and 85 per cent for those with a tertiary education) (OECD, 2018b). Further, workers in Ireland with less than a secondary education on average earn 20 per cent less than workers with an upper secondary education; while workers with a tertiary education typically earn 68 per cent more than those with an upper secondary education. In addition, across countries, Ireland's employment rate for respondents with less than a secondary education is one of the lowest in the Organisation for Economic Co-operation and Development (OECD) (2018b). Educational attainment is crucial, not only for migrant integration, but also for the labour market stability and bargaining power of all workers. In short, holding a third-level qualification is associated with improved labour market outcomes such as occupational attainment and higher pay (McGinnity et al., 2018a; OECD 2018b; Becker, 1975; Weiss et al., 2014).

This chapter explores variation in two skill measures: whether respondents hold a third-level degree and whether respondents rate their English language proficiency to be 'very good'. As outlined in Chapter 1 , integration outcomes are influenced by multiple factors: circumstances in the countries of origin; policies and the national context in Ireland; and individual characteristics of migrants. In this section, we present country-of-birth differences while controlling for a range of individual-level measures. While we cannot control for all individual-level factors, we suggest that country-level differences between migrants cannot be entirely explained by factors not considered here.

\subsection{EDUCATION OUTCOMES FOR ADULTS IN IRELAND}

In this section, we consider the Central Statistics Office's (CSO) Census data for 2016, comparing migrant groups to the Irish-born population in relation to their likelihood of holding a third-level qualification. In defining migrants, we use the respondent's country of birth. We analyse this outcome in two steps, but present 
only the final model, predicting respondents' likelihood of holding a third-level degree, accounting for both gender and age.

Before considering the results, it is worth noting findings from the most recent Integration Monitor, which drew conclusions about migrants using continental or regional categories (McGinnity et al., 2018b). The report found that western European, North American and Australian migrants had the greatest advantage in educational attainment, with almost 75 per cent of these respondents holding a third-level degree. Eastern European respondents were most likely to hold postsecondary, technical qualifications; this result stems from the prevalence of vocational qualifications in that region. African migrants reported higher levels of third-level education than Irish respondents but lower levels than other migrant groups. Finally, Asian respondents also fared better than the Irish population, while respondents from the 'rest of the world' fared worse than Irish respondents. In general, results suggest that, in most cases, migrants have higher educational qualifications than the Irish, with only migrants in the 'rest of the world' category reporting lower levels of educational attainment.

Importantly, we consider all respondents in our analysis - those who received their education in Ireland and those who received their education abroad. ${ }^{27}$ We do not have enough information to split these respondents into separate groups, but it is likely that different factors may influence educational attainment across the two groups. For example, those who achieved their highest qualifications abroad may be more influenced by factors in their country of origin - the education system, for example, and opportunities there - as well as selective migration; this is particularly relevant to non-European Economic Area (EEA) migrants, who may need a third-level qualification before they can apply for a high-skilled work permit to live and work in Ireland.

Migrant differences in educational attainment may stem from differences in access to education and educational achievement in Ireland. Primary and second-level education is available to all students, regardless of citizenship or place of birth (McGinnity et al., 2018b). However, even within schools, migrant children face obstacles in addition to those faced by non-migrant children, including language difficulties, discrimination and differences in parental resources (Darmody and Smyth, 2018). Second-level achievement, particularly Leaving Certificate grades, are closely related to access to third-level education in Ireland.

27 There may also be a group who came to Ireland to study and have now completed their education, so they had primary and secondary education in their country of origin but acquired their degree in Ireland. The focus is on education completed, so those still in education, for example current students, are excluded. 
At third level, in order to qualify for 'free fees', migrants must be either an EEA citizen, have official refugee status, or have humanitarian leave to remain in Ireland and have been resident in a European country in three of the last five years. For most non-EEA nationals, fees can be substantial, though they vary among thirdlevel colleges. Even with 'free fees', the cost of third-level education may also be prohibitive for low-income migrants.

We cannot formally distinguish between migrants who attain third-level education in Ireland and those who attain third-level education in their country of birth, although we do consider these differences using an imperfect measure for a robustness check. ${ }^{28}$

In the figures below, we present the predicted probability of having a third-level education, controlling for the age and gender of respondents, or the probability of having very good English, controlling for age and whether they are currently students. Language ability among migrant students may differ from that among those who have come to Ireland for other reasons. We estimate the effects for all countries together in one model but present their predicted probabilities separately, by region. Throughout this section, we show large country-level differences within regions in terms of educational attainment and English language ability. Our confidence intervals suggest that within regions there are wide and statistically significant differences between countries of birth. possible for us to accurately estimate the respondent's age when they arrived in Ireland. First, our dataset does not measure the respondent's age using a continuous measure but rather age bands. Second, the measure for 'year arrived in Ireland' is missing for around half of the migrant sample. As a robustness check, we use these measures to create a rough, binary measure of respondents educated abroad and respondents educated in Ireland. This measure is likely to contain errors or misclassifications and is only available for a limited number of respondents. Nonetheless, we find that the country-level differences in education remain broadly similar when we estimated models only for those educated in Ireland. Improvements to the year-of-arrival measure in the Census to ensure all respondents have valid responses would considerably enhance integration research using the Census. 
FIGURE 3.1 PREDICTED PROBABILITIES OF HOLDING A THIRD-LEVEL DEGREE: ASIAN MIGRANTS AND IRISH RESPONDENTS

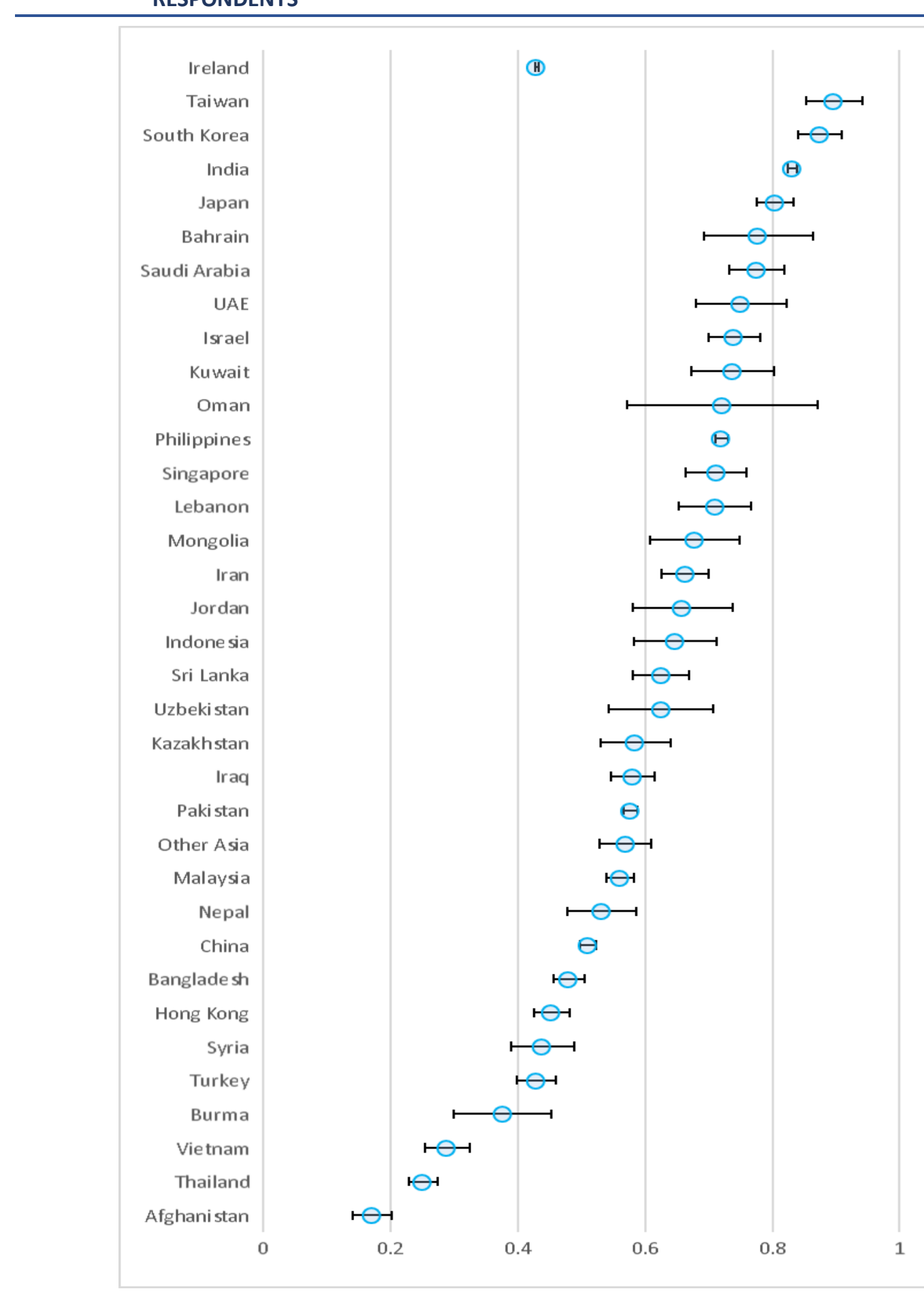

Source: Census 2016, own calculations. Migrants and Irish-born (5 per cent sample) who have finished education ( $n=666,145)$.

Note: $\quad$ Predicted probabilities are highlighted with a blue circle, controlling for the gender and age of respondents. Black bars represent $95 \%$ confidence interval. Countries are sorted in descending order according to the modelled country-level estimates.

Within the 'Asia' category, we find substantial variation in educational attainment. ${ }^{29}$ Respondents range from a probability of 0.17 (Afghan migrants) to 
one of 0.9 (Taiwanese migrants) of holding a third-level degree. In previous reports, both migrant groups would be conflated into a single 'Asian' category.

Near the top of the distribution are migrants from the highly developed nations of Taiwan (0.9), South Korea (0.87) and Japan (0.81). These are followed by a cluster of wealthy Middle Eastern countries such as Bahrain (0.78), Saudi Arabia (0.78) and the United Arab Emirates (UAE) (0.75). Migrants from poorer countries in the region, such as Afghanistan (0.17), Burma (0.38), Nepal (0.53) and Bangladesh (0.53), are in the bottom third of the chart. Indian migrants comprise one exception to this pattern; despite coming from a relatively poor country, this group scores highly (0.87) on this measure of educational attainment. This is a significant exception, because Indian migrants make up the largest Asian migrant group in Ireland, constituting 22 per cent of the total. Almost three-quarters of the next largest group - Philippine-born migrants (16 per cent of the Asian total) - have third-level qualifications.

Results for Ireland (0.4) are on par with the 2018 Monitoring report on integration. However, that same report gave migrants from Asia and the Middle East a probability of 0.68 . This score captures the general propensity of Asian migrant to hold degrees, but masks wider country-level differences found among individual countries.

The range in predicted probabilities among African migrants (Figure 3.2) suggests there is less country-level variance in educational attainment among African than Asian migrants. However, differences between country groups remain substantial. The probabilities range from 0.19 (Somalia) to 0.74 (Zambia). As with Asian migrants, Irish respondents have a lower predicted probability of holding a thirdlevel degree than many African groups; however, groups with lower probabilities than that found for the Irish population were found: Togo (0.25); Somalia (0.19); and Angola (0.36).

Despite there being a good deal of variance across countries, no clear pattern emerges in terms of the geographic, social or economic characteristics of the countries of origin. For instance, relatively wealthy African countries are found near the top (e.g. Libya), middle (e.g. South Africa) and bottom (e.g. Algeria) of the distribution. Except for a potential clustering of the southern African countries of Zimbabwe (0.64), Botswana (0.58) and South Africa (0.63) in the middle of the chart, there is no evidence of regional groupings. For instance, the bottom of the distribution contains the west African nations of Togo (0.25) and Liberia (0.37), the southern country of Angola (0.36) and the eastern country of Somalia (0.19). Finally, countries that have experienced civil conflict appear at all levels of the distribution. For example, war-torn Libya and Sudan appear near the top, while the Congo and Somalia show up at the bottom. 
FIGURE 3.2 PREDICTED PROBABILITIES OF HOLDING A THIRD-LEVEL DEGREE: AFRICAN MIGRANTS AND IRISH RESPONDENTS

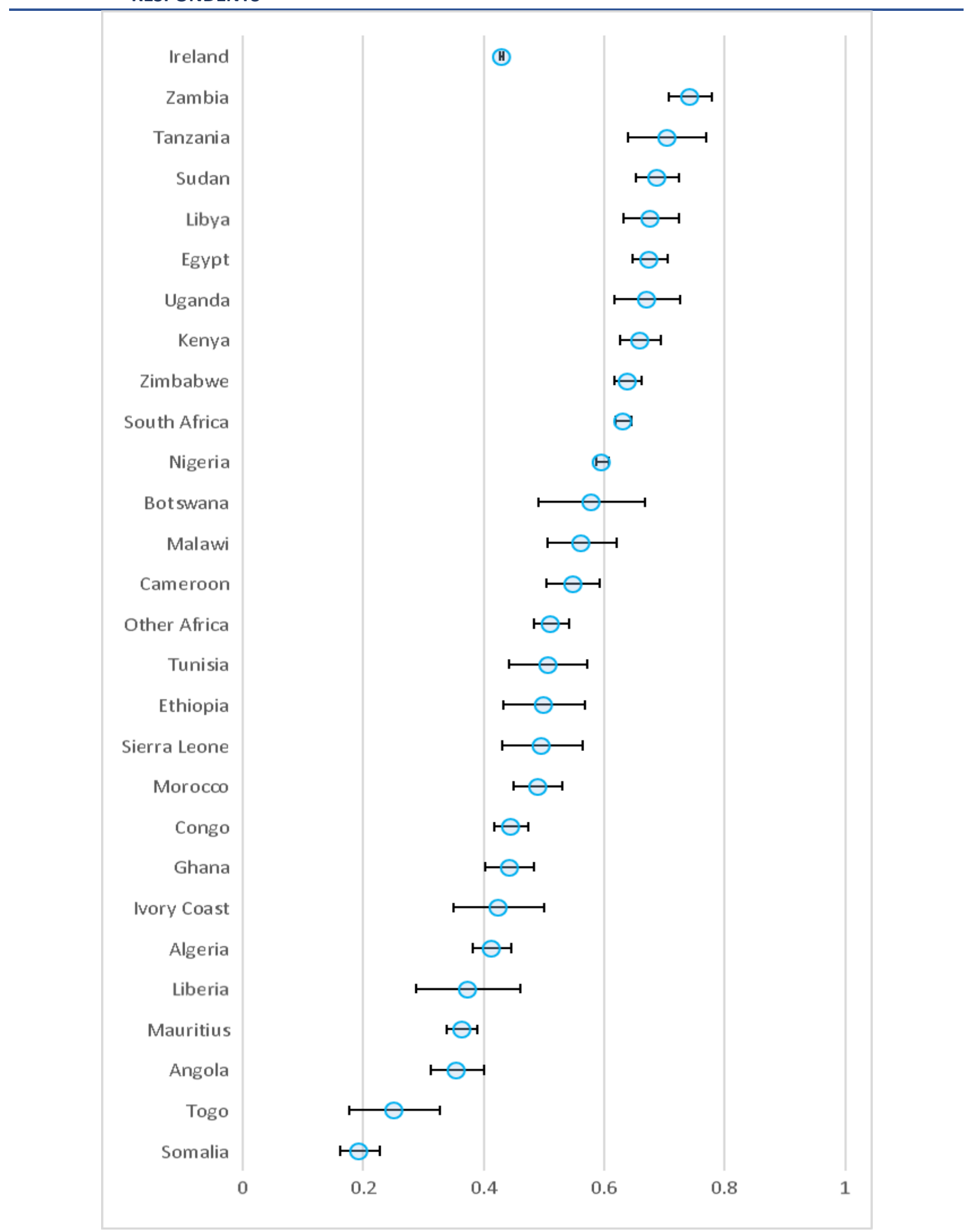

Source: Census 2016, own calculations. Migrants and Irish-born (5 per cent sample) who have finished education ( $n=666,145)$.

Note: $\quad$ Modelled results are highlighted with a blue circle, controlling for the gender and age of respondents. Black bars represent $95 \%$ confidence interval. Countries are sorted in descending order according to the modelled countrylevel estimates.

As a regional grouping, African migrants do not achieve the educational attainment levels of the top-level Asian migrants (predicted probability ranging from 0.8 to 
1.0). However, the more populated group (ranging 0.6 to 0.8 ) contains 13 countries, including Sudan (0.69), Libya (0.68) and Kenya (0.66). A third group (ranging from 0.4 to 0.6 ) contains ten countries, including Tunisia (0.51), Morocco (0.49) and Algeria (0.41) - these are on par with Ireland but below other migrant groups from Africa. A final group of African countries with education levels below those of the Irish-born population contains only three countries: Angola (0.36), Togo (0.25) and Somalia (0.19). 
FIGURE 3.3 PREDICTED PROBABILITIES OF HOLDING A THIRD-LEVEL DEGREE: EEA MIGRANTS AND IRISH RESPONDENTS

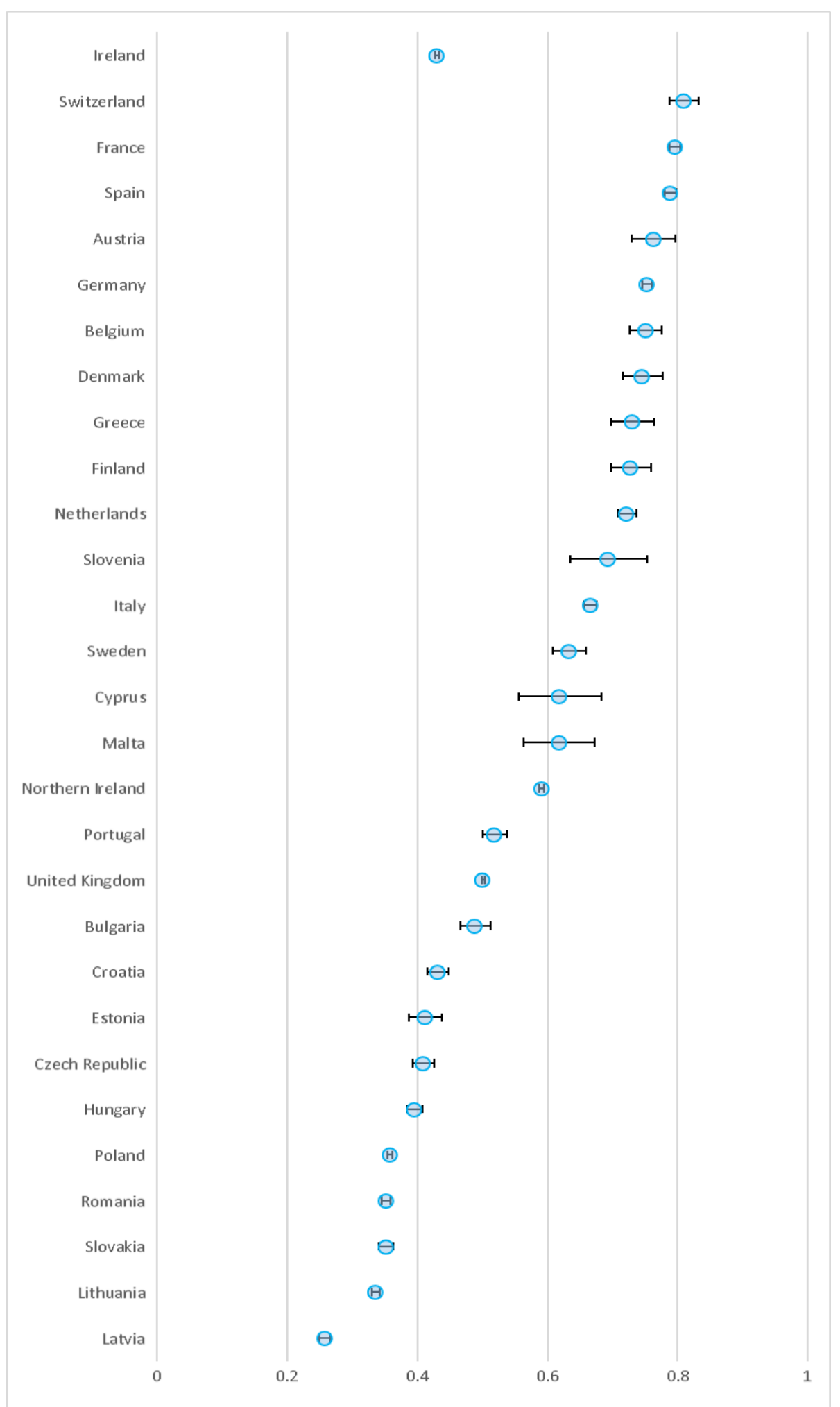

Source: Census 2016, own calculations. Migrants and Irish-born (5 per cent sample) who have finished education ( $n=666,145)$.

Note: $\quad$ Modelled results are highlighted with a blue circle, controlling for the gender and age of respondents. Black bars

represent $95 \%$ confidence interval. Countries are sorted in descending order according to the modelled country-

level estimates. 
A similar distribution emerges for EEA migrants (Figure 3.3). Here too, there is a substantial difference between countries in relation to educational attainment, which ranges from a predicted probability of 0.26 (Latvia) to 0.79 (Spain). This suggests there are substantial differences between migrant groups, with eastern European migrants having lower scores and those from central and western Europe reporting higher scores. Except for Slovenia (0.69), the average probability of migrants from new Member States having a third-level education is below 0.6 in all cases. Except for Portugal (0.52) and the United Kingdom (UK) (0.5), all migrants from the pre-2004 Member States have an average probability greater than 0.65 .

Within the original west European group, Spain (0.79), France (0.8) and Switzerland (0.81) have rates of attainment ranging around 0.8. A second group (0.6 to 0.8 ) contains ten countries, including Greece (0.73), Germany (0.75) and Sweden (0.63), all of which have lower probabilities than the upper group, but higher probabilities than respondents born in Ireland. A third group of countries ( 0.4 to 0.6 ), containing Cyprus (0.62), Croatia (0.43) and the UK (0.50), have rates of attainment similar to respondents born in Ireland. The final group contains countries with attainment levels similar to or below Ireland: Romania (0.35), Lithuania (0.34) and Latvia (0.26). 
FIGURE 3.4 PREDICTED PROBABILITIES OF HOLDING A THIRD-LEVEL DEGREE: ‘OTHER' MIGRANTS AND IRISH RESPONDENTS

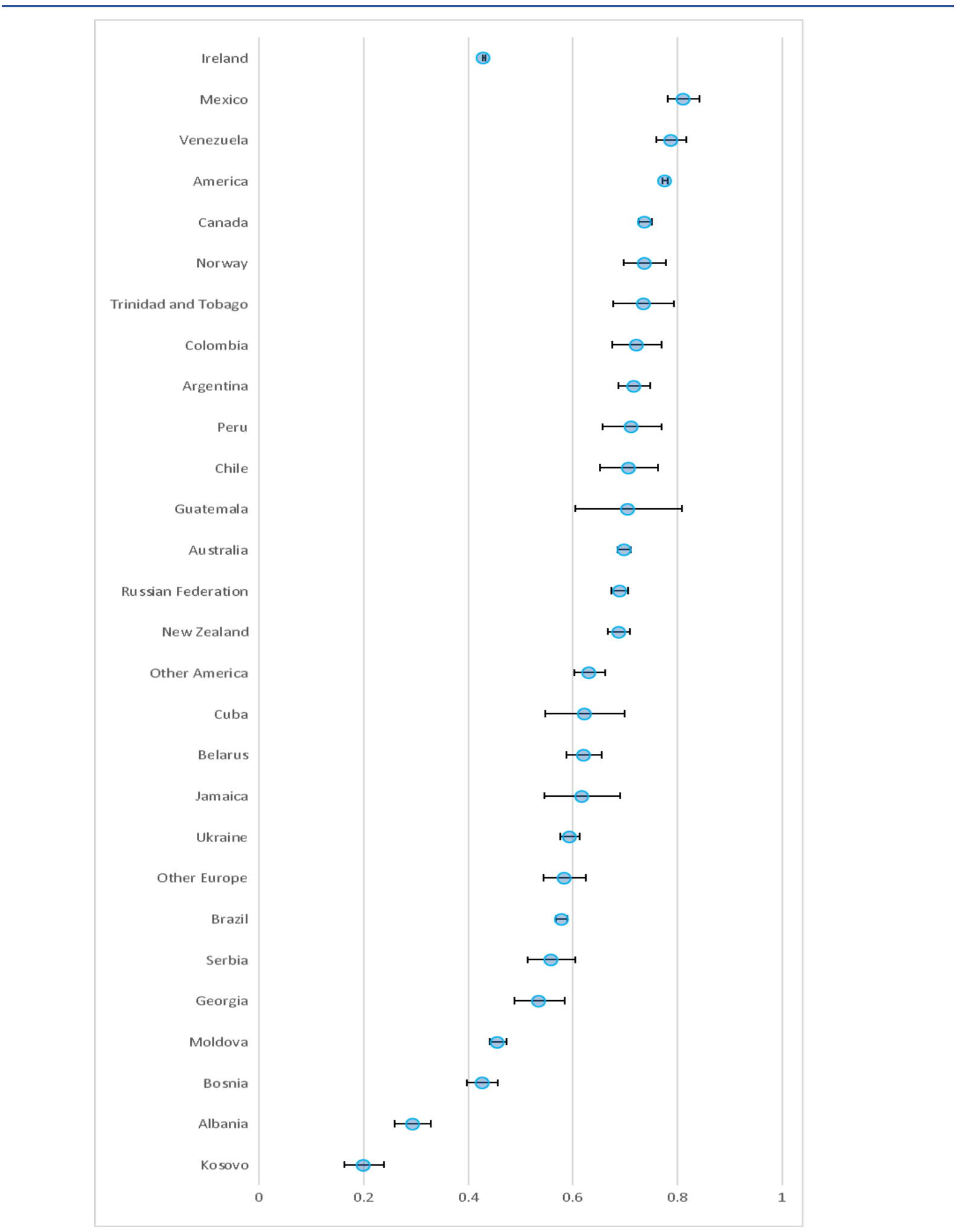

Source: Census 2016, own calculations. Migrants and Irish-born (5 per cent sample) who have finished education ( $n=666,145)$.

Note: $\quad$ Modelled results are highlighted with a blue circle, controlling for the gender and age of respondents. Black bars

represent $95 \%$ confidence interval. Countries are sorted in descending order according to the modelled countrylevel estimates.

The 'rest of the world' category is by far the most geographically diverse grouping in this report (Figure 3.4). It includes migrants from both North America and South 
America, Oceania and non-EEA European countries. The strongest geographic pattern to show up in the data is that migrants from non-EEA European countries perform worst in the realm of educational attainment, where they typically score below 0.6. Migrants from the Russian Federation (0.69) and Belarus (0.62) are an exception. There is also a weaker trend whereby migrants from Latin America report high levels of educational attainment. However, this is less so for the largest Latin American group, Brazilians migrants, of whom only 57 per cent have a thirdlevel education. This figure is still substantially higher than the value for the Irishborn population, even after controlling for age and sex differences.

The Monitoring report on integration 2018 (McGinnity, 2018b) estimates that 58 per cent of respondents in the 'rest of the world' category are educated to degree level or higher. Our results suggest that this estimate masks substantial differences between countries.

Overall, migrants arriving in Ireland are more likely to hold a third-level qualification (or to gain a third-level education in Ireland) than the Irish-born population. Controlling for age and gender does not eliminate this difference. It is important to note that strong selection effects are likely to be at play in that education level can be a pre-condition of coming to Ireland for some migrants. For example, approximately 82 per cent of Indian migrants in Ireland hold a third-level degree (Figure 3.1); the rate of educational attainment in India is considerably lower than this.

\subsection{ENGLISH LANGUAGE SKILLS}

In this section, we consider self-evaluated level of spoken English. We focus only on people aged 20 years and older. In the Census, this question is only asked of those who say that they speak a language other than Irish or English in the home. Here, we assume that people who do not speak another language have very good English language skills, which is the highest response category (see Section 2.3 for details of measurement). We first consider the raw country-level differences between respondents born outside of Ireland and respondents born in Ireland. We then control for possible individual characteristics that could explain migrant differences in language ability. Specifically, we consider the age of respondents and whether their principle economic status is 'student'. As before, we only present the final model by region.

An important but omitted measure is the duration of the time migrants spend in the country. This measure was available but contained a significant portion of missing values, as noted in in Chapter 2. Since we cannot establish if these 
omissions were random, we exclude the measure from the current models. ${ }^{30}$ This means we likely overstate many of the country-level effects in the graphs below because migrants from different countries may have different average durations in Ireland (McGinnity et al., 2018b).

The 2018 Integration Monitor report did not consider English language proficiency as an outcome. However, among 15 -year olds, it did note a difference in reading scores between those of migrant origin who speak English or Irish in the home, and those of migrant origin who speak a language other than English or Irish in the home (McGinnity et al., 2018b). Once again, there is likely to be wide variation within each of these groups in terms of country of origin.

Figure 3.5 shows wide country-level variance in English language ability among Asians; the probability of those rating their English language skills as very good ranged from 0.22 (Vietnam) to 0.90 (Bahrain). Not surprisingly, Irish-born respondents have a very high predicted probability of rating their English as very good (over 0.95). As discussed in Chapter 1, we would expect migrants from English-speaking countries, or from countries that have historical or colonial ties to English-speaking countries, to perform well on this measure. That is indeed what we find for Asian migrants (see Figure 3.5). Except for Lebanon (0.68), the top 10 countries of origin are all either former British colonies/protectorates or have close historical and cultural ties to the United States (US) (Israel, at 0.69, and the Philippines, at 0.65$)$. That said, there are some exceptions to this trend. Former British colonies Burma (0.26), Bangladesh (0.26), Hong Kong (0.45), Nepal (0.38) and Malaysia (0.40) appear near the bottom half of the chart. The Asian migrant populations with the lowest levels of self-rated proficiency in English are generally either economically underdeveloped (e.g. Vietnam (0.22), Burma (0.26) and Afghanistan (0.22)) or are situated in East Asia (e.g. China (0.22), South Korea (0.26) and Taiwan (0.34)). 
FIGURE 3.5 PREDICTED PROBABILITIES OF HAVING VERY GOOD ENGLISH: ASIAN MIGRANTS AND IRISH RESPONDENTS

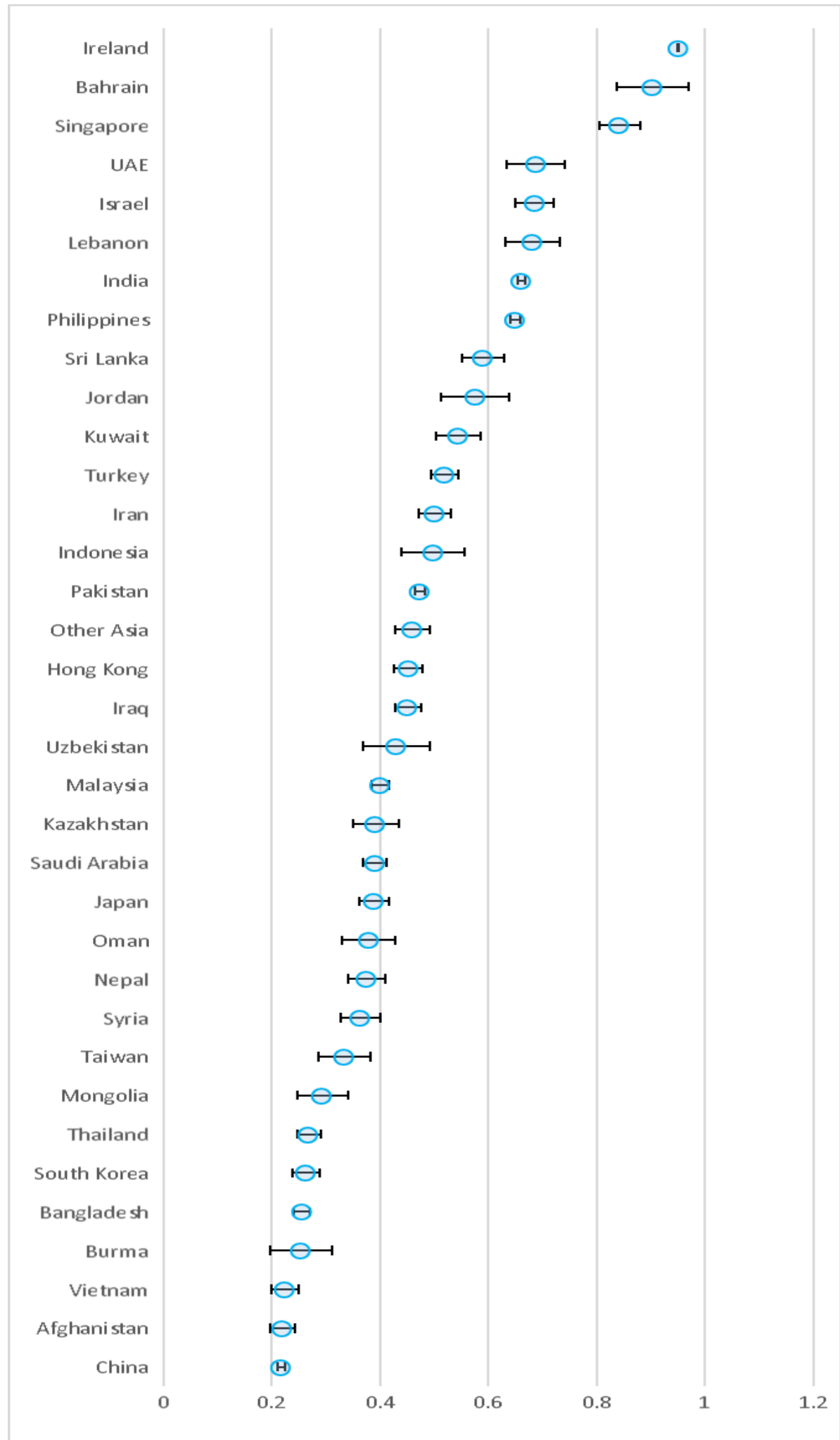

Source: $\quad$ Census 2016, own calculations. 20+ years old migrants and Irish-born (5 per cent sample) $(n=691,976)$.

Note: $\quad$ Modelled results are highlighted with a blue circle, controlling for age of respondents and whether they are students.

Black bars represent $95 \%$ confidence interval. Countries are sorted in descending order according to the modelled country-level estimates. 
FIGURE 3.6 PREDICTED PROBABILITIES OF HAVING VERY GOOD ENGLISH: AFRICAN MIGRANTS AND IRISH RESPONDENTS

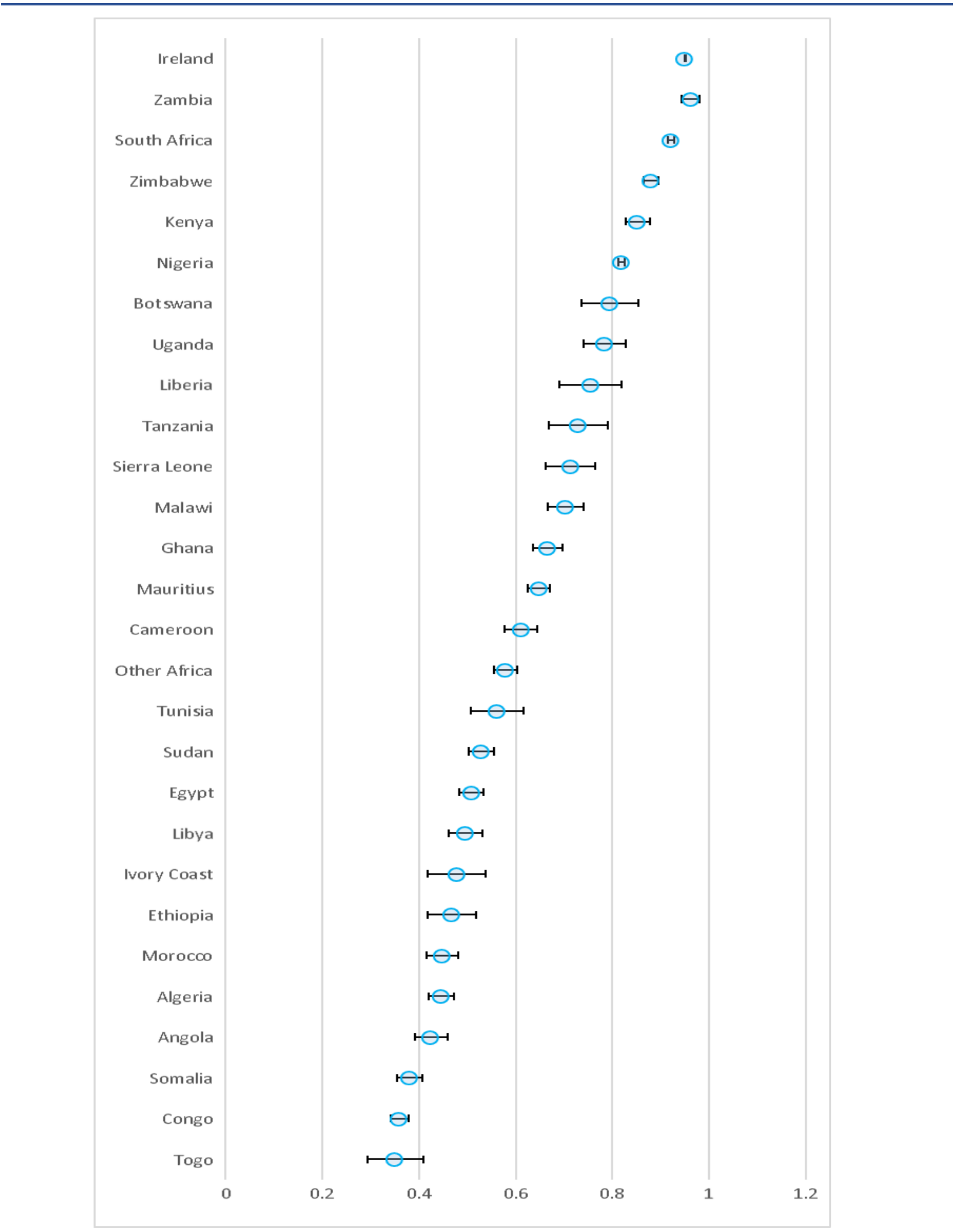

Source: Census 2016, own calculations. 20+ years old migrants and Irish-born (5 per cent sample) $(n=691,976)$.

Note: $\quad$ Modelled results are highlighted with a blue circle, controlling for age of respondents and whether they are students. Black bars represent $95 \%$ confidence interval. Countries are sorted in descending order according to the modelled country-level estimates.

The distribution of African migrants also differs widely by country of birth. Here, the results are less varied than among Asian migrants, with estimates ranging from 
0.35 (Togo) to 0.96 (Zambia). Overall, Zambians have a very similar predicted probability of rating their English as very good compared to Irish respondents. Clearly, countries where English is spoken regularly report higher levels of English language proficiency, such as Zimbabwe (0.88), South Africa (0.92) and Zambia (0.96). Countries where English is not the most common language, like Morocco (0.45), Algeria (0.45) and Somalia (0.38), have much lower predicted probabilities.

Figure 3.7 shows that European migrants vary substantially in their English language ability, ranging from a predicted probability of 0.31 (Lithuania) to 0.94 (UK). Eastern European countries occupy the lowest tiers, while some Scandinavian countries like Denmark (0.84) and Sweden (0.85) hold higher positions. Southern European states vary in their English language ability, ranging from Italy (0.49) to Cyprus (0.89). 
FIGURE 3.7 PREDICTED PROBABILITIES OF HAVING VERY GOOD ENGLISH: EEA MIGRANTS AND IRISH RESPONDENTS

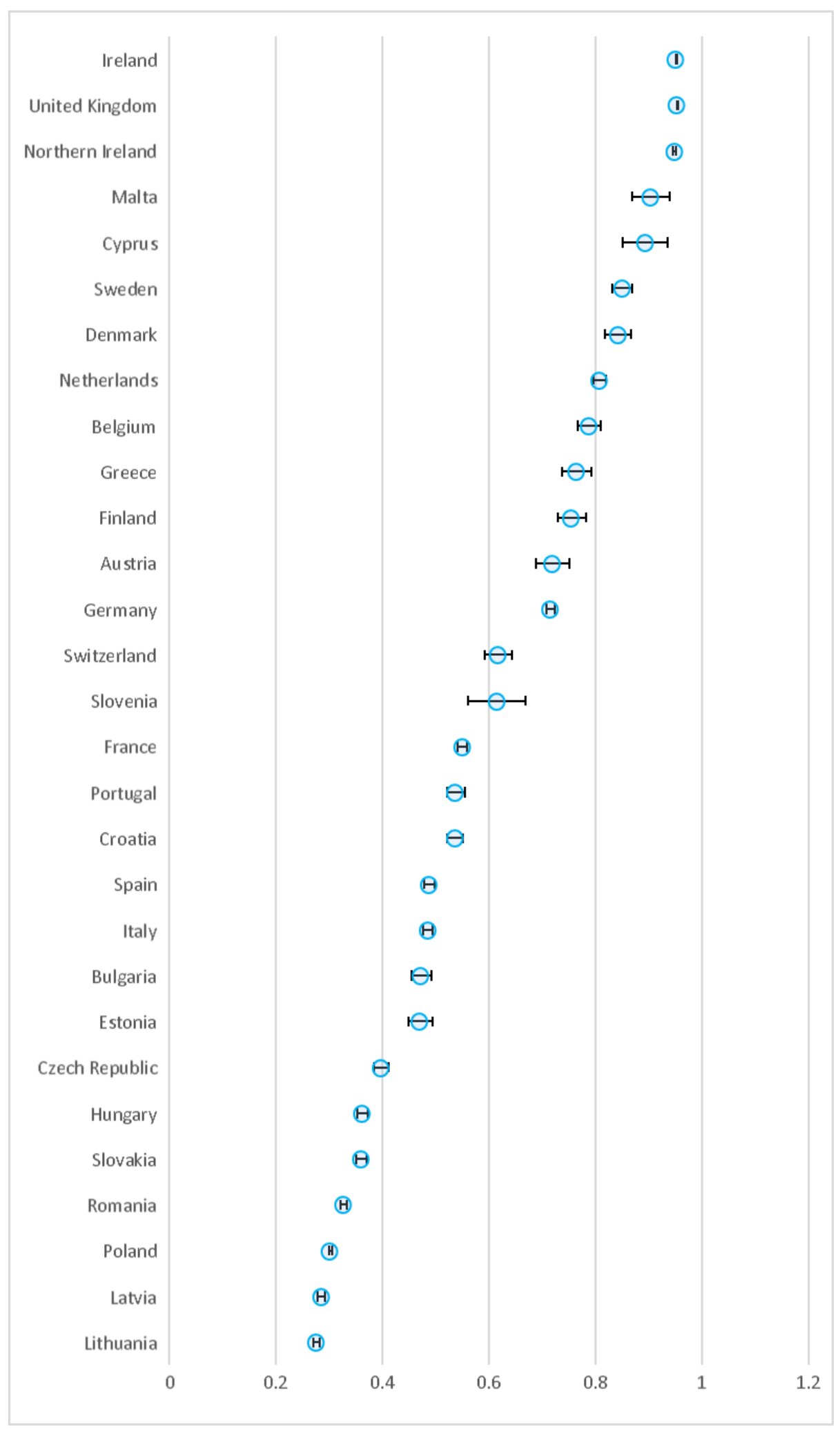

Source: Census 2016, own calculations. 20+ years old migrants and Irish-born (5 per cent sample) $(n=691,976)$.

Note: $\quad$ Modelled results are highlighted with a blue circle, controlling for age of respondents and whether they are students.

Black bars represent $95 \%$ confidence interval. Countries are sorted in descending order according to the modelled country-level estimates. 
FIGURE 3.8 PREDICTED PROBABILITIES OF HAVING VERY GOOD ENGLISH: MIGRANTS FROM OTHER COUNTRIES AND IRISH RESPONDENTS

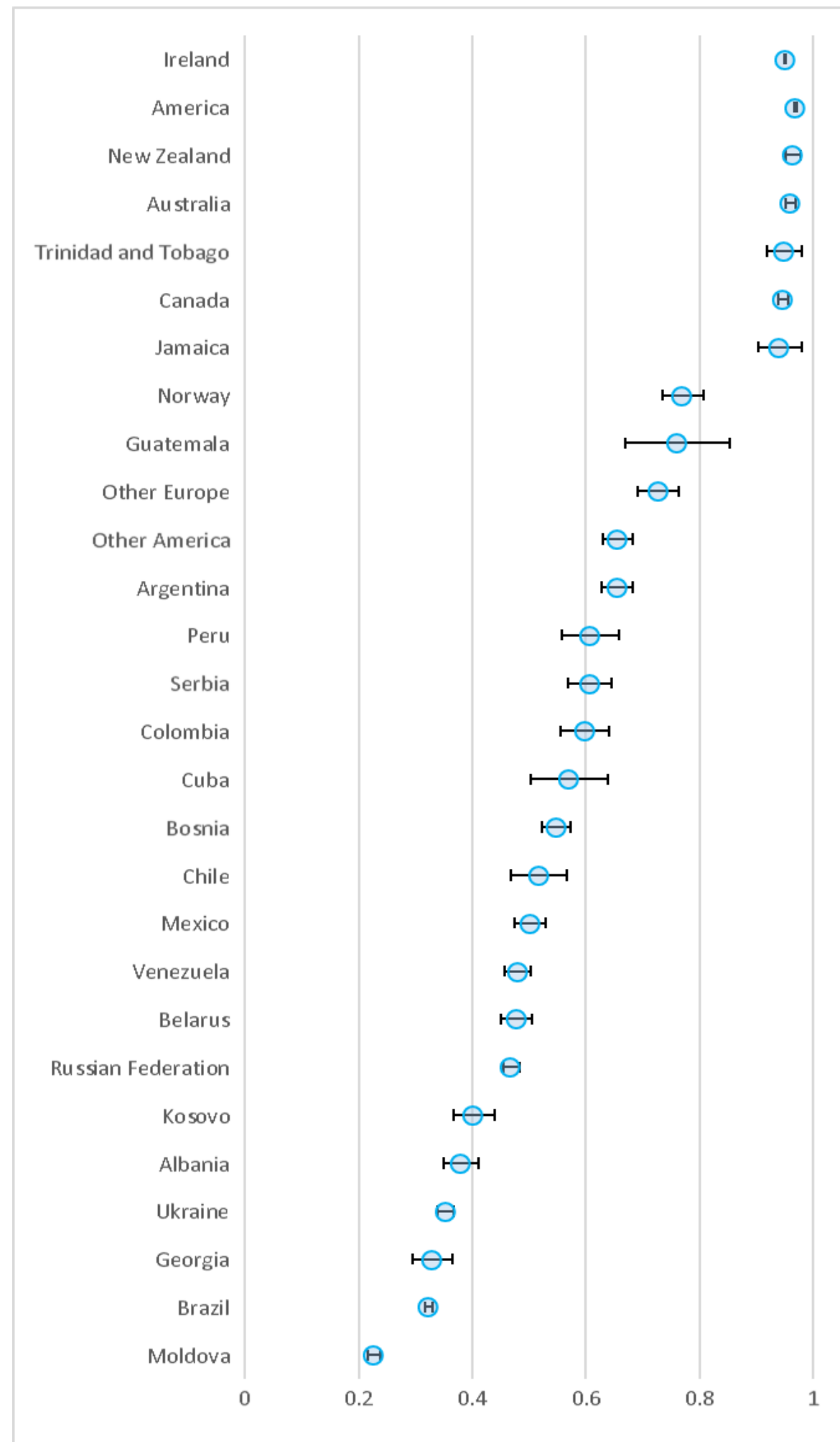

Source: Census 2016, own calculations. 20+ years old migrants and Irish-born (5 per cent sample) $(n=691,976)$.

Note: $\quad$ Modelled results are highlighted with a blue circle, controlling for age of respondents and whether they are students.

Black bars represent $95 \%$ confidence interval. Countries are sorted in descending order according to the modelled country-level estimates.

Once again, migrants from the remaining countries differ widely in their predicted probabilities, ranging from 0.25 (Moldova) to 0.95 (New Zealand). Again, English- 
speaking countries have a clear advantage, as can be seen in the top bloc of the figure. Latin American countries, like Peru (0.63) and Colombia (0.63), appear to hold a middle ground in the distribution, while eastern states (and Brazil) hold the lowest predicted probabilities.

Overall, migrants in Ireland report varying degrees of English language ability. Some, but not all, of this ability could be explained by whether the country's national language is English. Once again, it is likely that powerful selection effects regarding who travels to Ireland are at play in the data. One important finding in the analysis is, that within each regional distribution, there are tiers of countries ranging from the top to the bottom. This finding highlights the arbitrary nature of continental categories for migrants, and the risks of treating all migrants in a region as similar.

\subsection{ENGLISH LANGUAGE SKILLS AND EDUCATION}

Importantly, we find that migrants from countries with high levels of education do not necessarily score highly, as a group, in terms of English language ability. We present a group-specific scatter plot below, which has a correlation coefficient of 0.39 . Although we are generalising using country-specific groups, the correlation is relatively weak.

FIGURE 3.9 RELATIONSHIP BETWEEN THIRD-LEVEL EDUCATIONAL ATTAINMENT AND ENGLISH LANGUAGE ABILITY

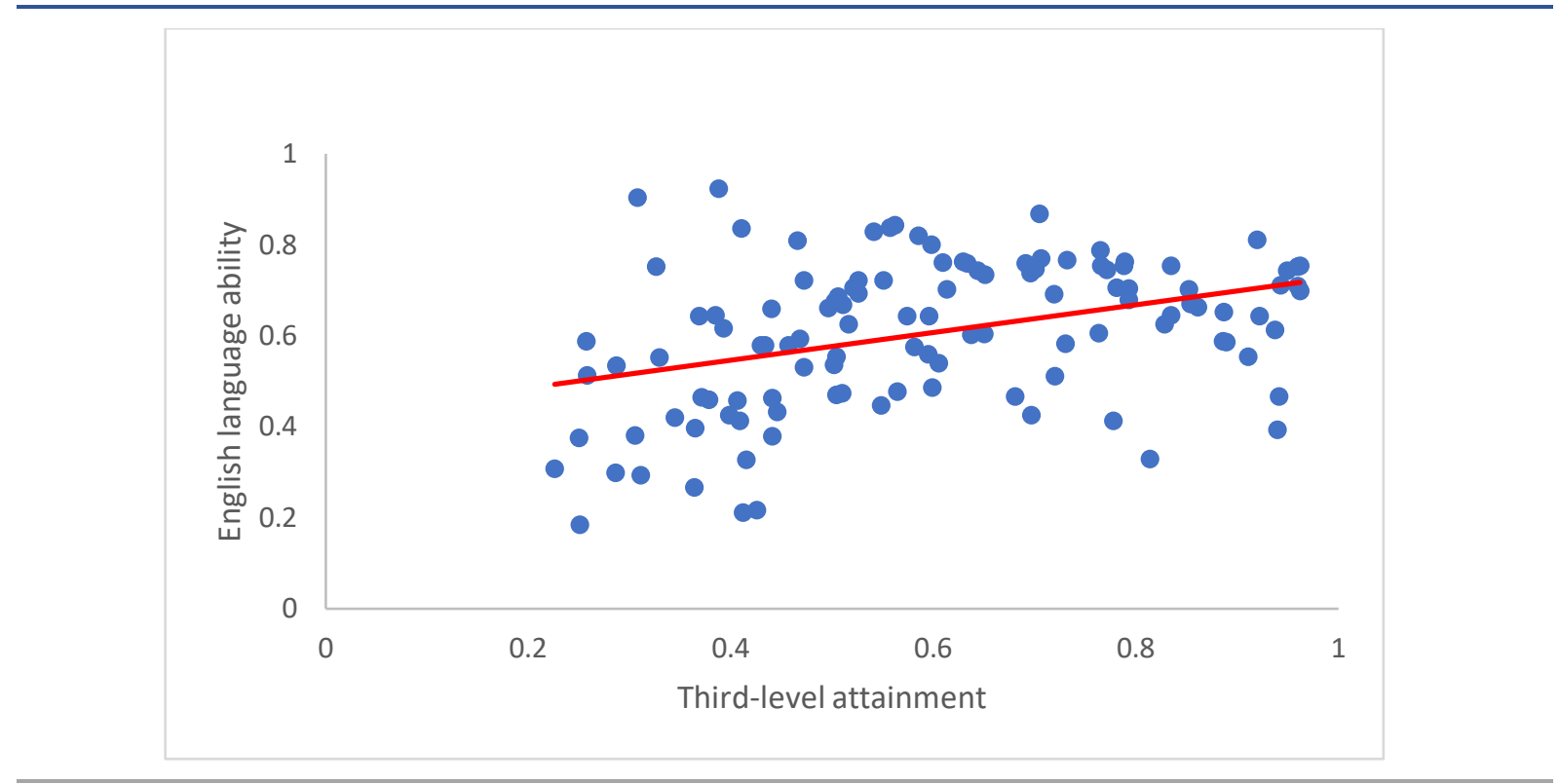

Source: Census 2016, own calculations.

However, when we remove migrants from former or current British colonies, we see that this relationship strengthens somewhat, with the correlation coefficient increasing to 0.55 , as shown in Figure 3.10 . 


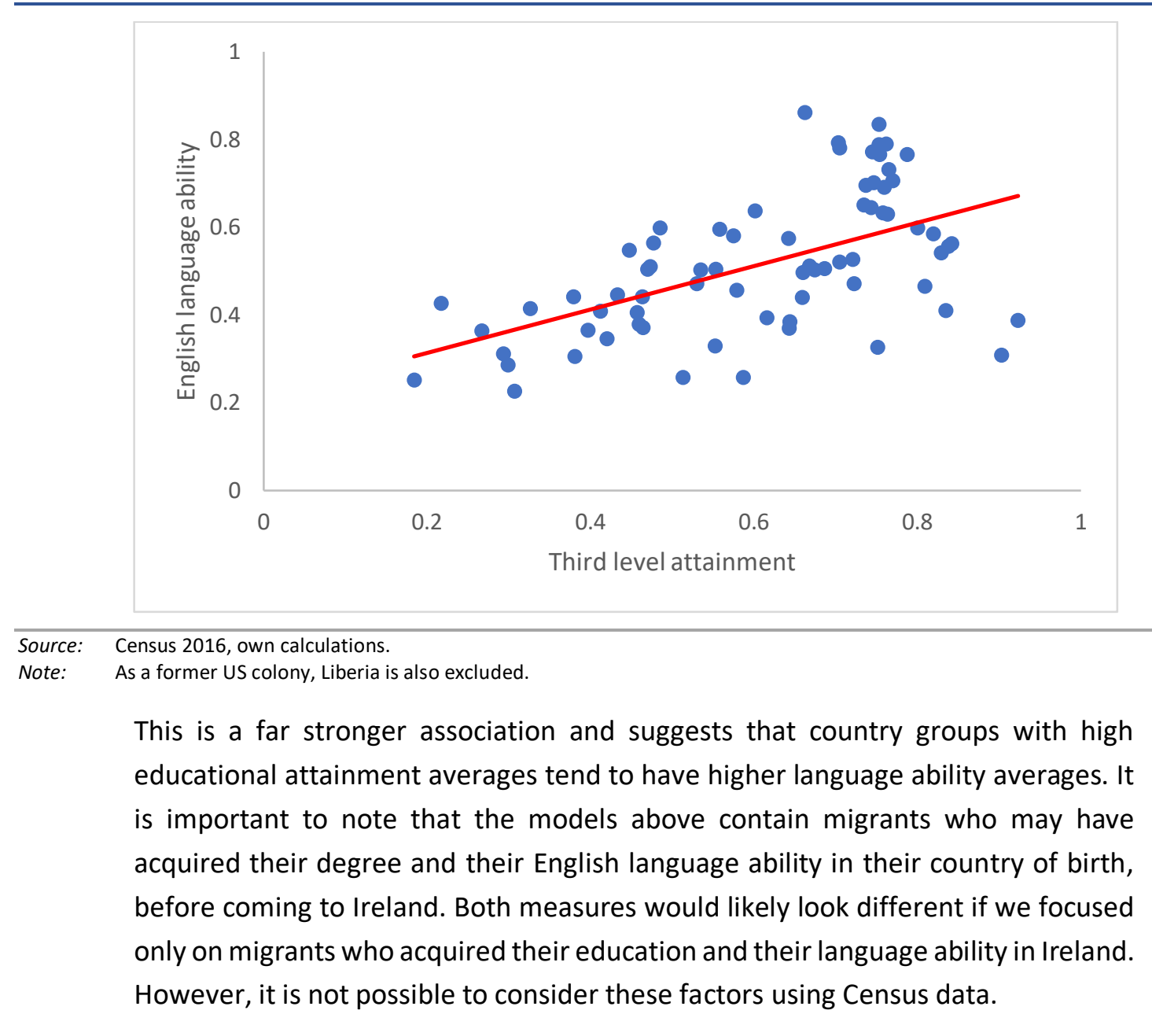

\subsection{SUMMARY}

This chapter has explored country-level differences in educational attainment and English language ability. It highlights the country-level differences embedded within regional categories. These differences are not affected by controls for age, gender (for education models) or student status (for English language models). Within regions, there are significant country-level differences regarding both education and language ability. Our results suggest that each region is tiered, with high performers at the top of the distribution, regardless of region, and low performers at the bottom, also regardless of region. Our results suggest that a general tiering system can be applied to all regions, with high performers at the top and low performers at the bottom. In other words, region alone is not a useful indicator of educational attainment or language ability.

First, we find that most migrant groups report higher educational attainment than that of the Irish population. The predicted probability of having a third-level degree 
for those born in Ireland (0.4) is below that of most migrants within each region. Although this difference may stem from a difference in host country and origin country respondents, even controlling for age and gender does not eliminate this difference.

Regarding the outcome of English language ability, respondents born in Ireland appear at the top of the distribution.

Second, within each region we find we find extensive variation between migrant groups. In educational attainment, for example, there is a core group of highly educated migrants - those born in India, South Korea and Taiwan among Asian migrants, those born in France and Spain among EEA migrants and those born in Sudan and Zambia among African migrants. Other such migrant groups include those from Colombia, Mexico and Venezuela. Regarding English language ability, we also find significant country-level differences, and it is not always origin countries with high levels of education that have high proficiency in English. This partly relates to the fact that some migrants come from former British colonies; when these are excluded the relationship between education and English language skills (at country level) becomes stronger.

In general, we would expect the country-of-origin groups that have better Englishlanguage proficiency and higher levels of educational attainment to have higher employment rates and higher occupational attainment. We explore these outcomes in the next chapter. 


\section{CHAPTER 4}

\section{Labour market outcomes: Unemployment and high-skilled jobs}

In this chapter, we compare the labour market outcomes of migrants and nonmigrants. We focus on unemployment and high-skilled employment throughout the chapter. Employment is a crucial factor for integration and the independence of migrant groups (OECD/EU, 2018a). Occupational attainment, in this case holding a professional or managerial occupation, is typically associated with higher wages and prestige, greater job security, superior working conditions and better career prospects (McGinnity et al., 2018a).

These outcomes capture the disadvantage (unemployment) and advantage (highskilled job) of migrant groups in Ireland. Beyond country of birth, we consider two sources of variation in unemployment and occupational attainment. First, we look at the importance of individual-level predictors such as age, gender, English language proficiency and educational qualifications. These factors are particularly important, since not all sending countries have the same age, gender or educational profiles; thus, many of the differences between migrant and nonmigrant groups could be explained by the age profile of migrant respondents. Second, given previous research in Ireland, we also control for differences in ethnic background between respondents, which, combined with education and country of birth, helps to capture potential instances of labour market discrimination.

Throughout the chapter, we will present predicted probabilities of unemployment and occupational attainment by migrants' country of birth, controlling for individual factors noted above. We argue that these differences between countries (in unemployment and occupational attainment) cannot be explained by the age, gender, education or ethnic composition of migrants. This in turn suggests that country of birth is playing a significant role in labour market outcomes.

As in Chapter 3, these models are estimated over the entire sample, but for ease of interpretation results are shown separately for four separate global regions Asia, Africa, the European Economic Area (EEA) and the 'rest of the world'. Rather than discussing outcomes relative to Ireland, we instead opt to use predicted probabilities, which help to understand migrant outcomes by country of birth overall. In the charts below, the predicted probabilities from our statistical models are highlighted with a large blue circle. Black bars represent the 95 per cent confidence intervals surrounding the predicted probability.

We begin by discussing unemployment rates, before turning to occupational attainment and high-skilled work. 


\subsection{UNEMPLOYMENT}

This section examines the probability of migrants from different countries being unemployed. A low probability suggests that migrants are able to secure employment if they look for work, which is a positive integration outcome. Crucially, we do not consider respondents who are inactive in the labour market, and so we omit students, full-time parents and older people, among others. (The sample selection is outlined in Chapter 2.)

Figure 4.1 shows the probability of unemployment among migrants from the Asian region. Predicted probabilities range from 0.37 (Iraq) to 0.09 (Philippines). Certain clusters are prominent; for example, people from countries of birth with high levels of civil conflict or persecution of minorities generally have higher predicted probabilities of being unemployed. Such countries include Syria (0.37), Iraq (0.37) and Iran (0.29), all of which have relatively high unemployment probabilities compared to Ireland's probability of 0.145 .

Other than the above finding, no strong pattern can be discerned from the chart displaying unemployment rates of Asian migrants. Migrant groups from highly developed countries have varied unemployment rates. For instance, 19 per cent of South-Korean-born migrants are unemployed, compared to just 10 per cent of Hong-Kong-born migrants. 16 per cent of Indian-born migrants are unemployed, despite India's relatively low gross domestic product (GDP) per capita. There is also no real geographic pattern, with migrants from the Middle East, South Asia and the East Asia scattered throughout the chart. The vast majority of countries have higher rates of unemployment than those for the Irish-born population. Controlling for the age, gender, ethnicity and educational composition of these migrants does not eliminate this effect. 
FIGURE 4.1 PREDICTED PROBABILITIES OF BEING UNEMPLOYED: ASIAN MIGRANTS AND IRISH RESPONDENTS

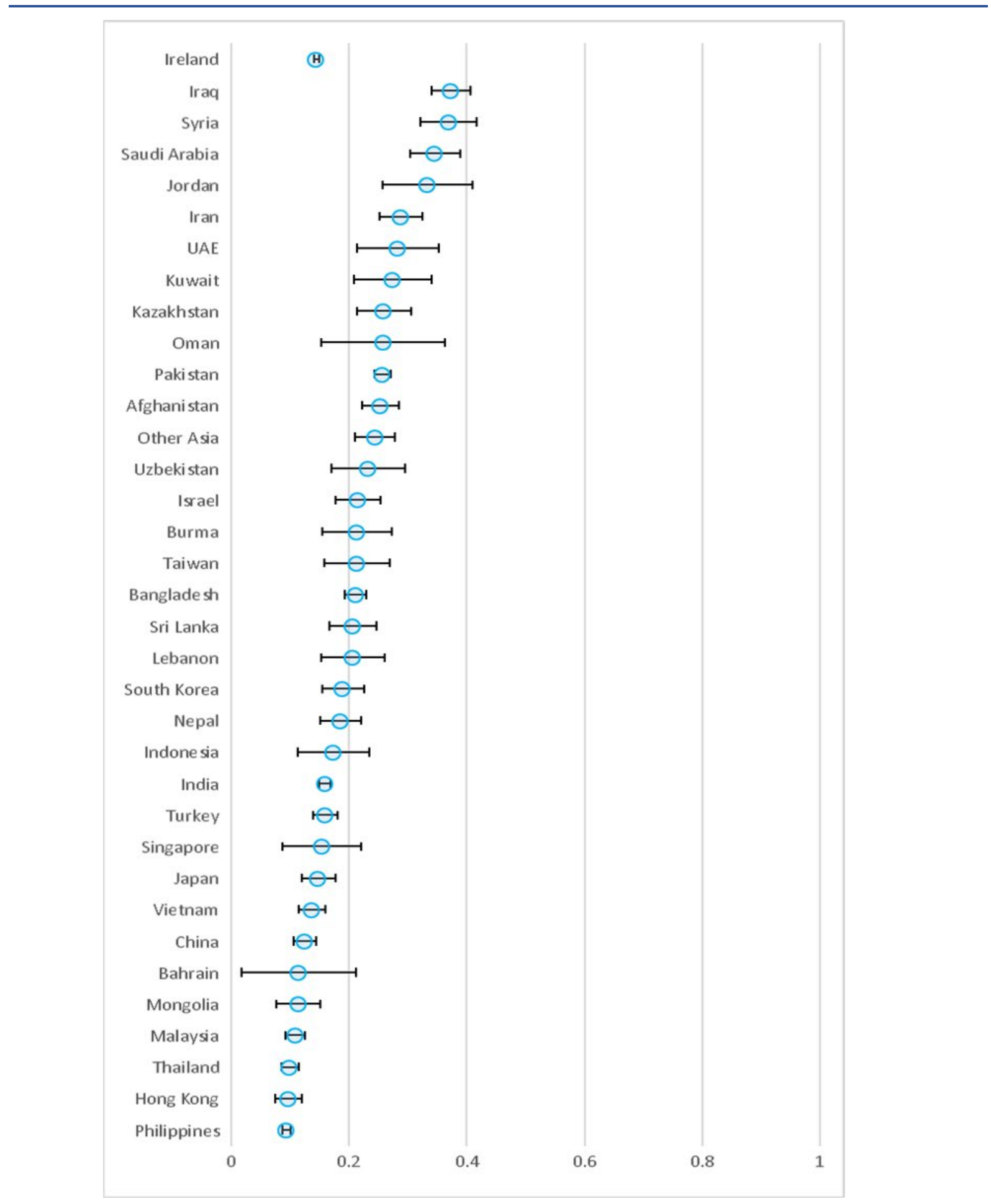

Source: $\quad$ Census 2016, own calculations. 15 to 64-year-old migrants and Irish born (5 per cent sample) whose principal economic status is employed or unemployed $(n=480,225)$.

Note: $\quad$ Modelled results are highlighted with a blue circle, controlling for the gender, age of respondents, their

English language ability, their education and respondent's ethnicity. Black bars represent $95 \%$ confidence interval. Countries are sorted in descending order according to country model estimates. 
FIGURE 4.2 PREDICTED PROBABILITIES OF BEING UNEMPLOYED: AFRICAN MIGRANTS AND IRISH RESPONDENTS

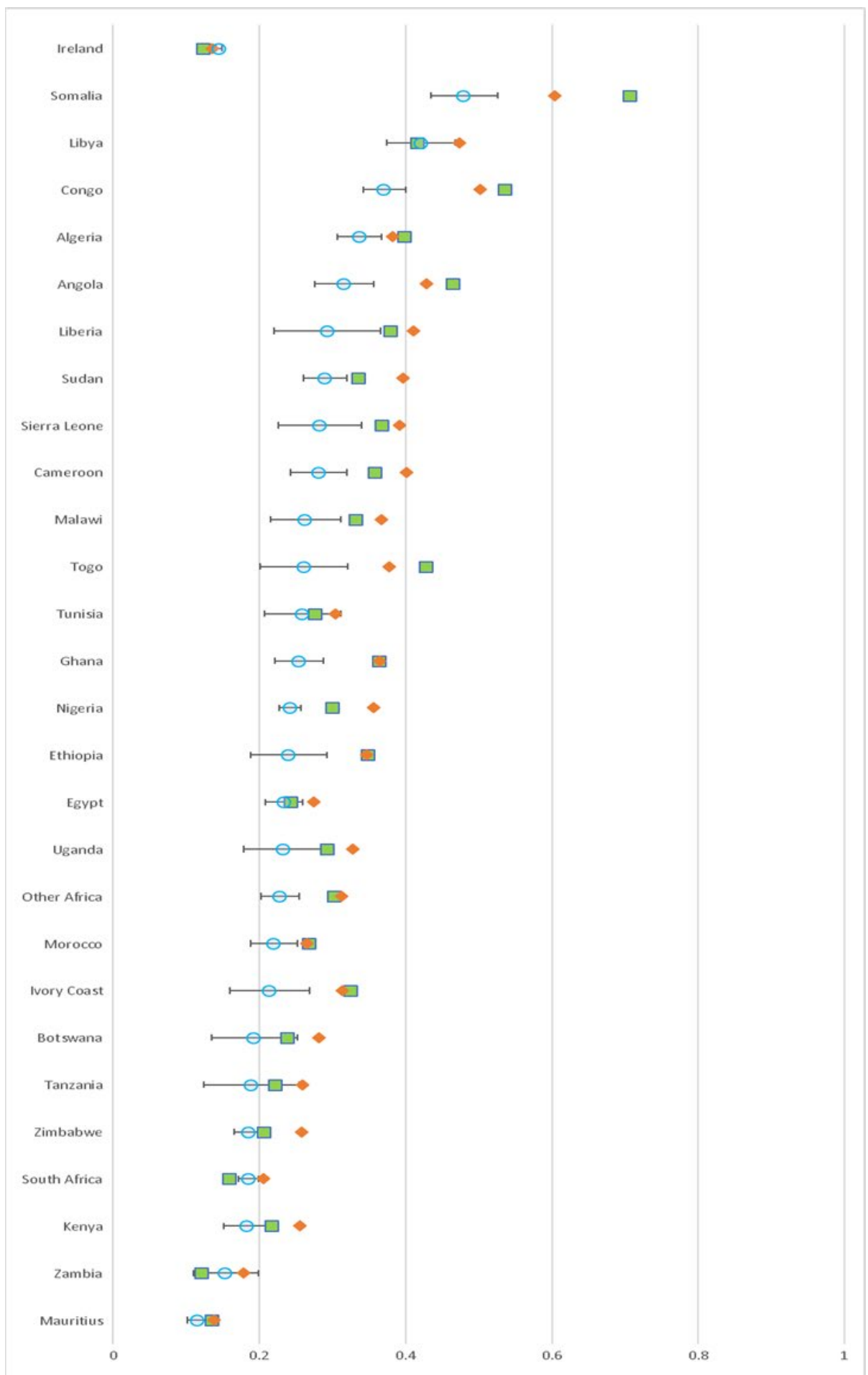

Source: Source: Census 2016, own calculations. 15 to 64-year-old migrants and Irish born (5 per cent sample) whose principal economic status is employed or unemployed $(n=480,225)$.

Note: $\quad$ Raw country-level differences are highlighted with a green square. Modelled results are highlighted with an orange diamond, controlling for the gender, age of respondents, their English language ability and their education. Finally, models controlling for ethnic differences between respondents, in addition to gender, age, English language ability, and education are highlighted with a blue circle. Black bars represent $95 \%$ confidence interval surrounding final model probabilities. Countries are sorted in descending order according to final model country-level estimates.

Figure 4.2 presents the predicted probabilities of three models across African countries: one contains just the country-level differences (marked using a green 
square); one controls for the age, gender, English language ability and educational status of migrants (marked with an orange diamond); and one adds measures of ethnicity to both of these models (marked with a blue circle). African migrants in Ireland have, as a regional grouping, particularly poor labour market outcomes (McGinnity et al., 2018b; DEASP, 2018; O'Connell, 2019). Our analysis suggests that while that may be true for Africans on average, there is considerable variation within the group. The predicted probabilities of unemployment range from 0.15 for Zambians to 0.48 for Somalis, a far bigger difference than that found for any other regional grouping, even the geographically diverse 'rest of the world' grouping. Africans fare badly compared to the Irish-born, with only Zambian migrants having a lower rate of unemployment than people born in Ireland, and only South Africans (0.19) and Mauritians (0.12) being close to the Irish rate. All other countries of birth have much higher predicted probabilities of unemployment than Ireland.

The main trend to emerge is that migrants from Somalia, the Congo and Angola all countries which have recently experienced civil war - have predicted unemployment rates above 45 per cent, while migrants from more stable countries, such as Botswana, Tanzania, Kenya, Zimbabwe, Mauritius, South Africa and Zambia, perform considerably better, with rates under 24 per cent. ${ }^{31}$ This trend is similar to the one seen among the Asian countries, where people from politically unstable countries have much higher unemployment rates, suggesting that the asylum process may be influencing respondent outcomes like unemployment. This is investigated further in Chapter 5.

One potential reason for differences in unemployment between African migrants and respondents born in Ireland is their ethnicity. The blue dots in Figure 4.2 suggest that some of the country-level differences can be explained by the ethnic composition of migrants from these countries, suggesting discrimination may play a part in the Irish labour market, as discussed in Chapter 1 (see also McGinnity et al., 2018a; McGinnity and Gijsberts 2017).

In North African countries (Libya, Algeria, Tunisia, Morocco and Egypt), ethnicity does not play such a significant role. This may be because these countries have fewer ethnically Black migrants when compared to the population of other African countries. The results suggest that Black Africans may be facing the greatest level of ethnic disadvantage in the labour market, even when their language and education are held constant. This finding is in line with findings from McGinnity et al. (2017) and Kingston et al. (2015). With the exception of Somalia and Nigeria, the other control variables make little difference to the probability of African 
migrants being unemployed. Even when we include all our controls, African migrants are worse off than Irish-born people, with only Mauritians having lower rates of unemployment than Irish people in our third model.

FIGURE 4.3 PREDICTED PROBABILITIES OF BEING UNEMPLOYED, EEA MIGRANTS AND IRISH RESPONDENTS

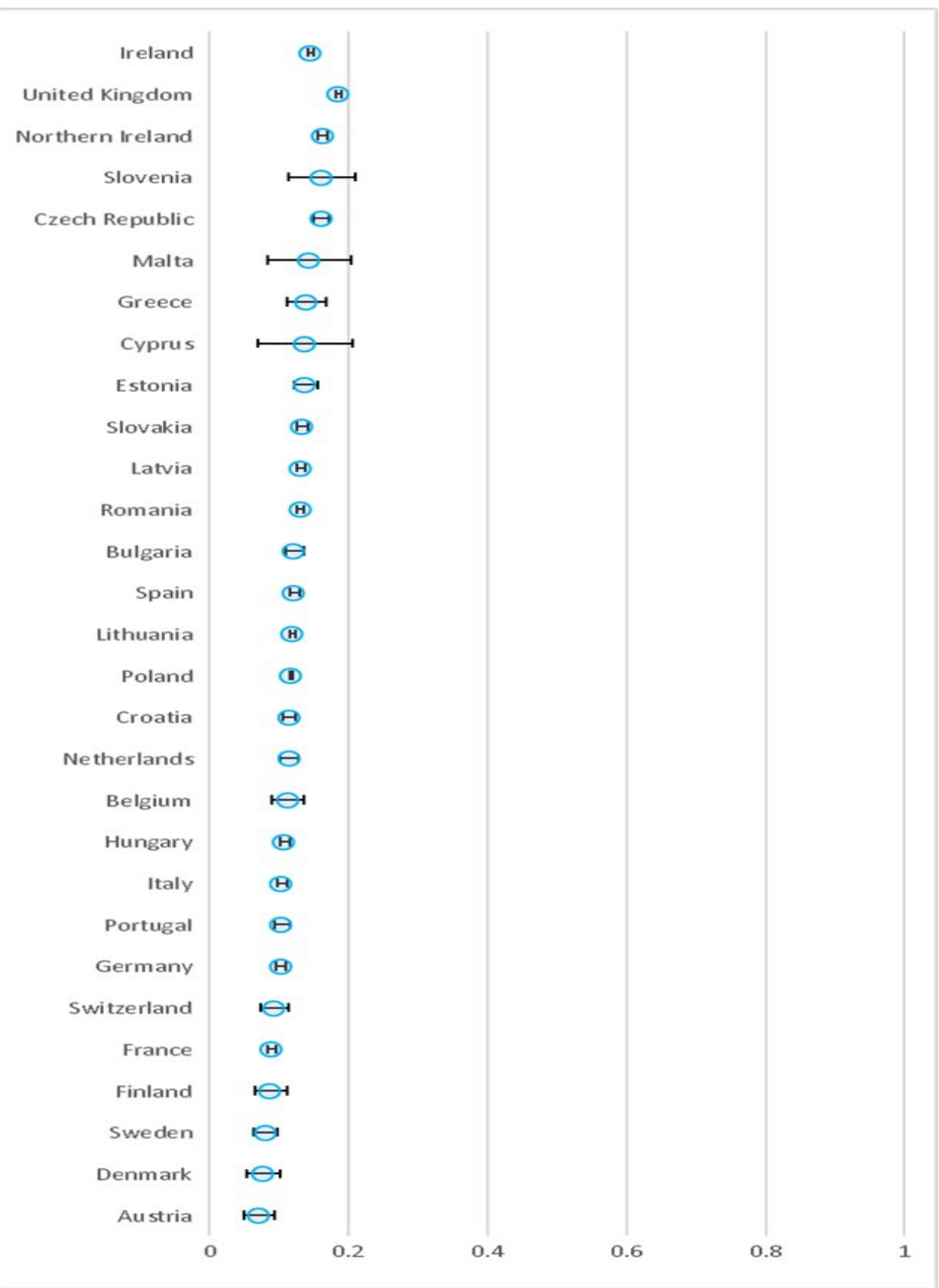

Source: Census 2016, own calculations. 15 to 64-year-old migrants and Irish born (5 per cent sample) whose principal economic status is employed or unemployed $(n=480,225)$.

Note: Modelled results are highlighted with a blue circle, controlling for the gender, age of respondents, their

English language ability, their education and respondent ethnicity. Black bars represent $95 \%$ confidence interval. Countries are sorted in descending order according to country model estimates.

Migrants from countries within the EEA have the smallest spread of unemployment rates and a much lower average unemployment rate than any other country 
grouping (ranging from the United Kingdom (UK) (0.19), to Austria (0.07)). This is in line with the expectations we outlined in Chapter 1, as these migrants have more comprehensive rights to employment and typically do not arrive through the international protection system.

Within Europe, the distribution appears to follow a geographic pattern. The country-of-origin groupings with the highest risk of being unemployed are from the Member States of eastern and southern Europe, such as the Czech Republic, Slovenia, Malta and Greece, whose predicted probabilities of unemployment range from 0.10 for Portugal up to 0.16 for Slovenia. Many of the countries within this cluster, however, have unemployment rates that fall below the 0.145 rate of those born in Ireland. The best performing migrants come from western European countries, with Austrians having the lowest predicted probabilities of unemployment, at 0.07. Exceptions to this trend is the positioning of UK and (presented separately) Northern Ireland migrants, who have the first and second highest unemployment rate, respectively, of all countries of origin considered here. These results show that western Europeans have lower unemployment rates and eastern Europeans have higher rates, a finding that is in line with those of the Monitoring report on integration 2018. 
FIGURE 4.4 PREDICTED PROBABILITIES OF BEING UNEMPLOYED: MIGRANTS IN THE 'REST OF THE WORLD' CATEGORY AND IRISH RESPONDENTS

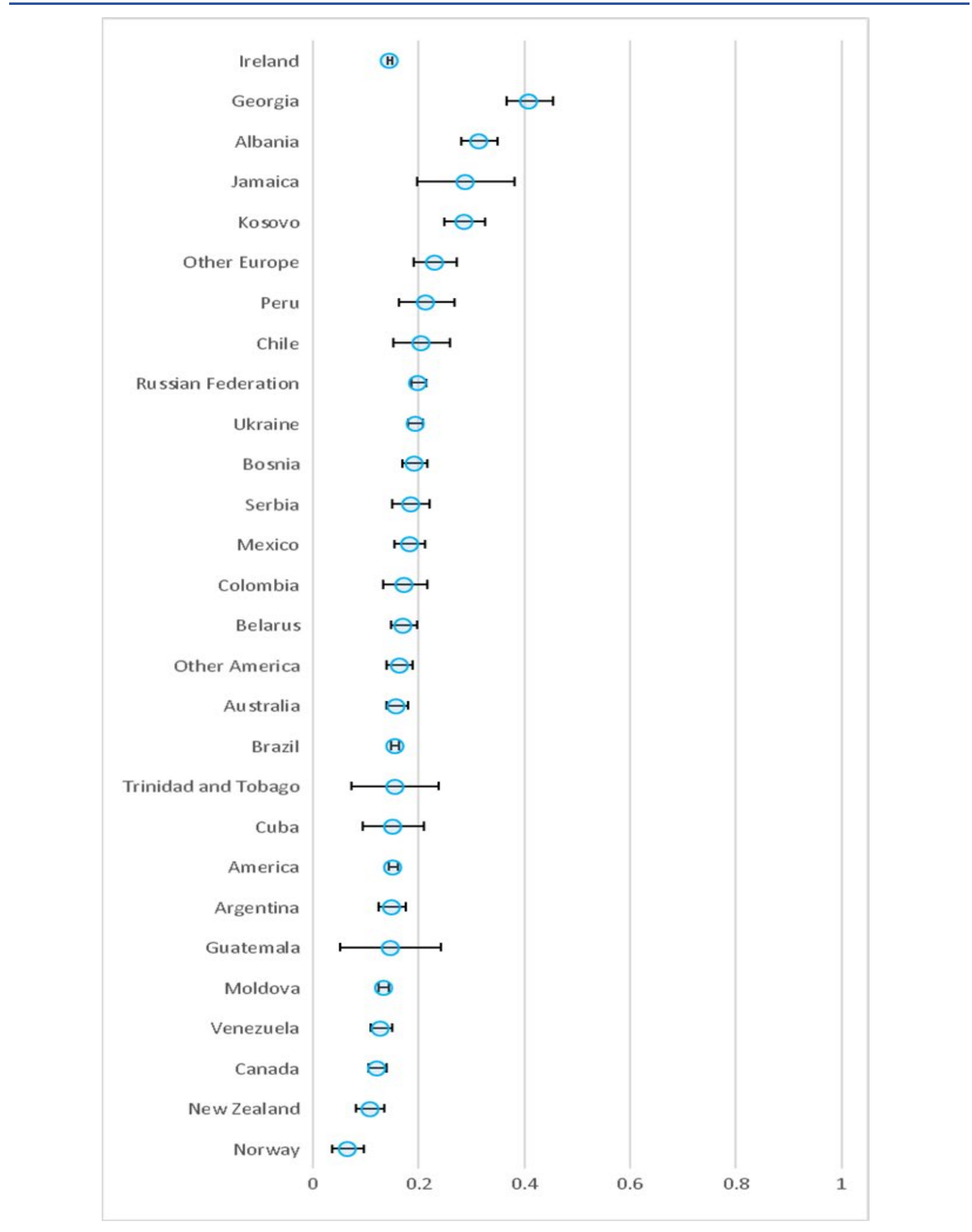

Source: Census 2016, own calculations. 15 to 64-year-old migrants and Irish born (5 per cent sample) whose principal economic status is employed or unemployed $(n=480,225)$.

Note: $\quad$ Modelled results are highlighted with a blue circle, controlling for the gender, age of respondents, their English language ability, their education and respondent ethnicity. Black bars represent $95 \%$ confidence interval. Countries are sorted in descending order according to country model estimates.

Migrants in the 'rest of the world' category follow the trend of African and Asian migrants, in the sense that those from countries with high levels of conflict tend to 
have worse outcomes, such as migrants from Georgia, Albania and Kosovo, with 41 per cent of Georgians in Ireland being unemployed. In contrast, migrants from the most politically stable countries of birth tend to have the lowest unemployment rates, such as those from Canada, New Zealand and Norway, all of whom have lower predicted probabilities of unemployment than people from Ireland. These countries also often tend to be the wealthiest, so potential employers may perceive their educational background to be of a higher quality. Compared to those born in Ireland, most migrants in the 'rest of the world' category fare worse, with only five countries having lower unemployment rates.

Overall, this section highlights the diversity of unemployment outcomes among migrants in Ireland, supporting the finding of Chapter 3 that even within continental groupings there are very diverse outcomes. Further, we find that controlling for the age, gender, language, education and ethnicity of these groups does not eliminate country-level differences, suggesting that country-specific mechanisms are at play. This is highlighted by the fact that there is more diversity between the outcomes in the African grouping than the 'rest of the world' grouping, although we might expect African migrants to be more similar to each other than migrants from places as diverse as Moldova, New Zealand and Jamaica.

We have confirmed our expectation (outlined in Chapter 1) that EEA migrants will on average be more integrated into the Irish labour market than other migrants, as measured by unemployment, although we also found that multiple non-EEA countries fare better in this regard than certain EEA countries. We have also found that people from countries with high levels of civil conflict typically have worse outcomes, which provides support for our expectation that those who came through the protection system would experience worse labour market outcomes, although of course this measure of country of origin is only a proxy. We have also found evidence that Black Africans fare poorly in the labour market, although contrary to our expectations we found little evidence of ethnic disadvantage for other non-White ethnicities, such as Asians. This is in line with findings in McGinnity et al. (2018a) on the disadvantage Black workers face in the labour market compared to White or Asian workers. Lastly, there is some evidence that people from more stable or developed countries, as well as those from Englishspeaking countries, fare well in comparison to other countries, although the evidence for this is more mixed, particularly within the Asian countries.

\subsection{HIGH-SKILLED EMPLOYMENT}

This section examines the predicted probabilities of being in a high-skilled job. Here, we only consider respondents who are employed (due to data limitations we are not able to discern between respondents in regular employment and respondents in self-employment). Our sample is therefore more restricted than 
that used in previous models. We estimate the probabilities of being in a highskilled job from the Census data, controlling for age, gender, English language ability, education and ethnicity. As before, we consider country-level differences by region, comparing these results to those of respondents born in Ireland.

FIGURE 4.5 PREDICTED PROBABILITIES OF BEING IN HIGH-SKILLED EMPLOYMENT: ASIAN MIGRANTS AND IRISH RESPONDENTS

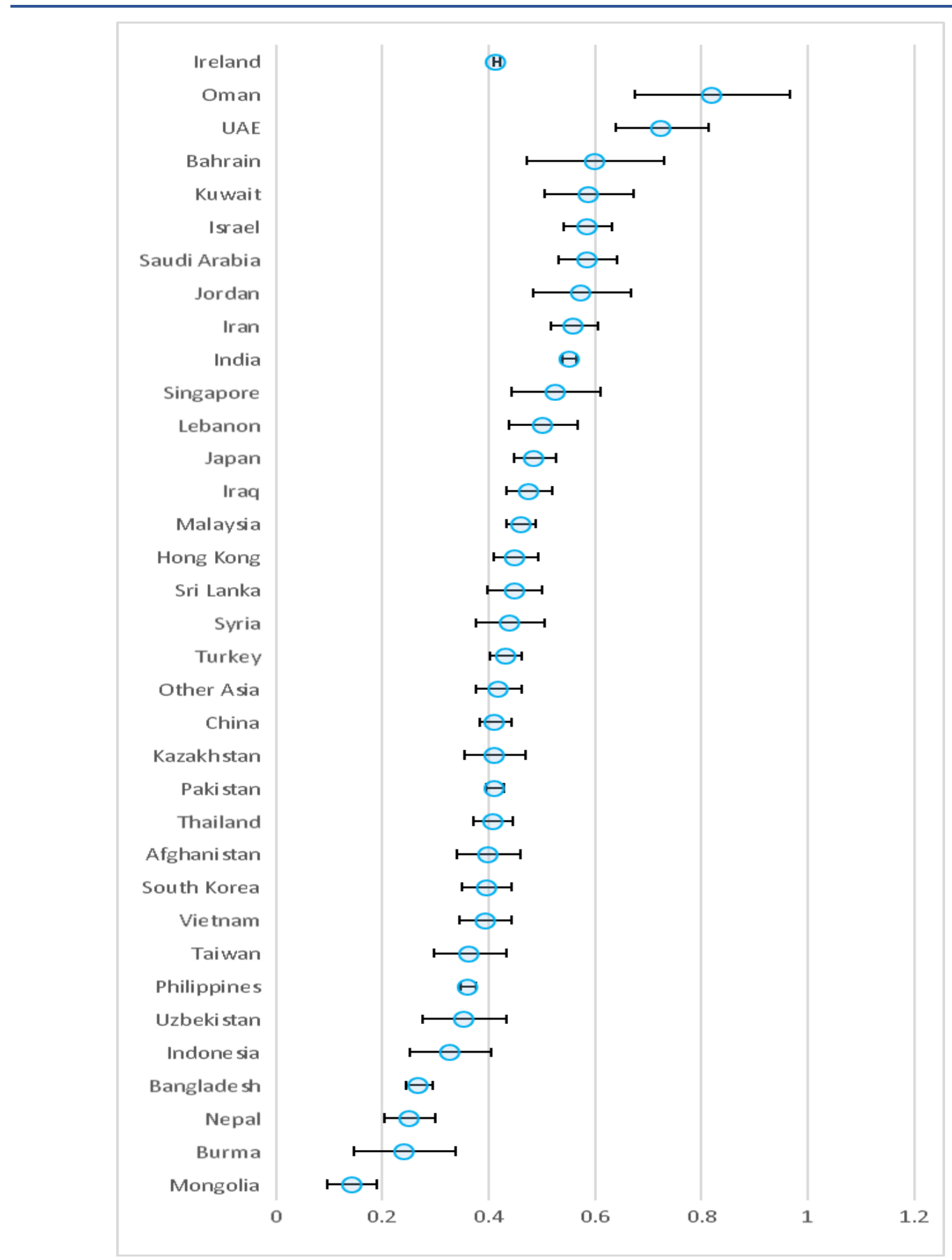

Source: Census 2016, own calculations. 15 to 64-year-old migrants and Irish-born (5 per cent sample) who are in employment $(n=391,947)$.

Note: Modelled results are highlighted with a blue circle, controlling for the gender, age of respondents, their English language ability, their education and respondent ethnicity. Black bars represent $95 \%$ confidence interval. Countries are sorted in descending order according to country model estimates. 
Among Asian migrants, a broad category that contains respondents from both Asia and the Middle East, the main pattern we see is that being from a Middle Eastern country has a positive effect on occupational attainment. Over 60 percent of employed migrants born in Bahrain, Kuwait, Oman and the United Arab Emirates (UAE) work in a high-skilled occupation. Israeli, Jordanian and Saudi migrants score highly on this as well. Indian migrants are also likely to be in a high-skilled job, with a probability of 0.55 . Over 80 per cent of Indian migrants hold a third-level degree, and over 70 per cent speak English very well. When carrying out individual-level (rather than country-level) analysis, the characteristics of Indian migrants can have a big impact, because they are the seventh largest migrant group in Ireland and comprise roughly 22 per cent of all Asian migrants (see Figure 2.2 in Chapter 2). In general, and contrasting with the unemployment outcomes, most migrants from Asian countries of origin fare better than the Irish-born, with only 15 countries out of 35 having high-skilled employment rates below the Irish rate of 42 per cent. 
FIGURE 4.6 PREDICTED PROBABILITIES OF BEING IN HIGH-SKILLED EMPLOYMENT: AFRICAN MIGRANTS AND IRISH RESPONDENTS

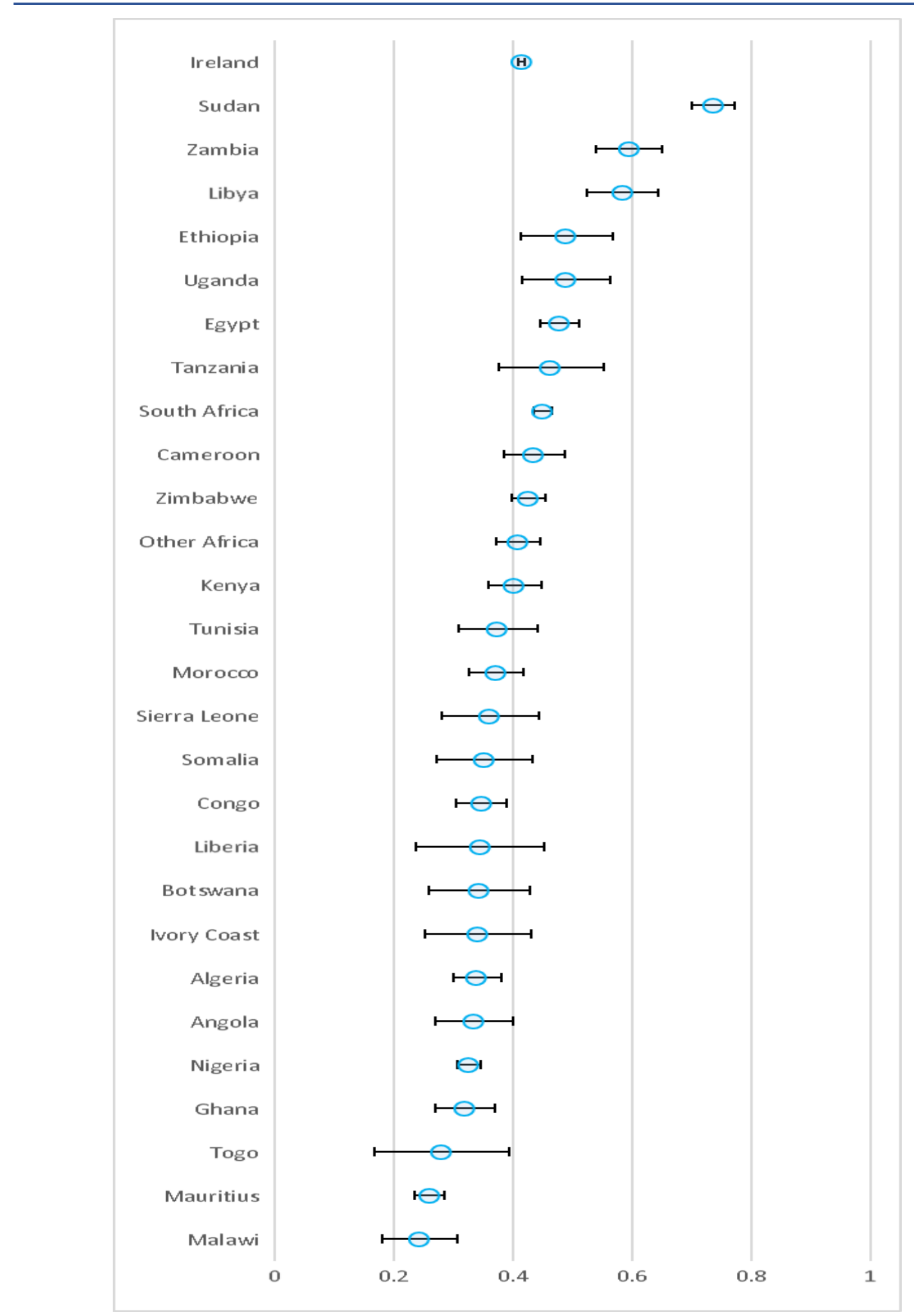

Source: Census 2016, own calculations. 15 to 64-year-old migrants and Irish-born (5 per cent sample) who are in employment $(n=391,947)$.

Note: $\quad$ Modelled results are highlighted with a blue circle, controlling for the gender, age of respondents, their English language ability, their education and respondent ethnicity. Black bars represent $95 \%$ confidence interval. Countries are sorted in descending order according to country model estimates.

Turning to migrants from African countries, countries with higher unemployment (see Section 4.1) also appear to have lower rates of occupational attainment. The 
main exception to this rule is the result for Sudanese migrants. Despite having relatively high unemployment rates, 74 per cent of Sudanese migrants who are in work are in high-skilled jobs compared to the Irish rate of 42 per cent. This is in line with the finding in Chapter 3 regarding Sudanese migrants being among the most educated of African migrants, and closer analysis of the data reveals that over 70 per cent of high-skilled Sudanese workers are healthcare professionals. ${ }^{32}$ Similar to the unemployment outcome, most migrants from African countries of birth are less likely than those born in Ireland to be employed in high-skilled labour. However, the disadvantage is less stark, with nine countries having the same or higher probability than Irish-born people to be in this type of work, compared to only one country having lower unemployment rates than those of the Irish-born population. 
FIGURE 4.7 PREDICTED PROBABILITIES OF BEING IN HIGH-SKILLED EMPLOYMENT: EEA MIGRANTS AND IRISH RESPONDENTS

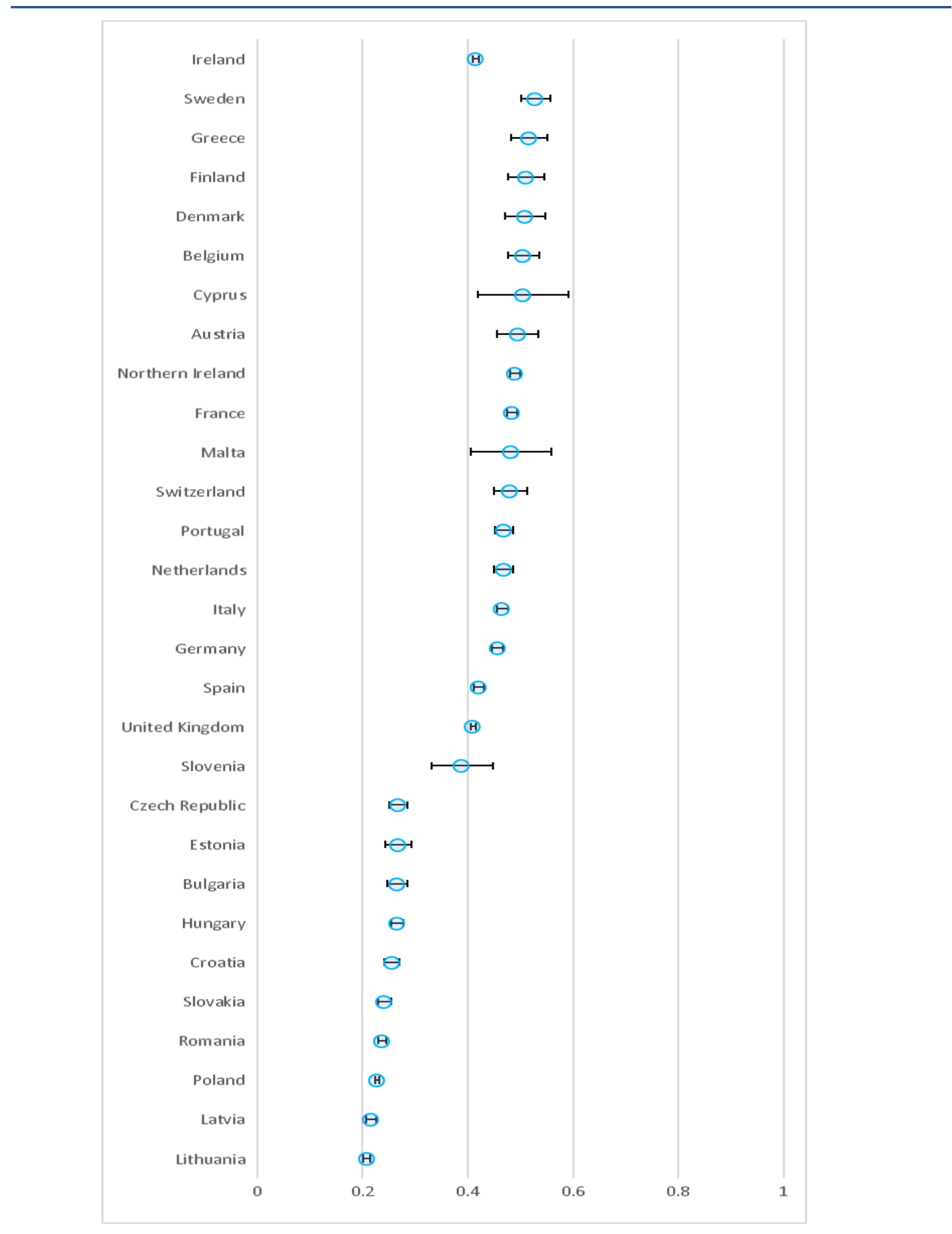

Source: Census 2016, own calculations. 15 to 64-year-old migrants and Irish-born (5 per cent sample) who are in employment $(n=391,947)$.

Note: $\quad$ Modelled results are highlighted with a blue circle, controlling for the gender, age of respondents, their English language ability, their education and respondent ethnicity. Black bars represent $95 \%$ confidence interval. Countries are sorted in descending order according to country model estimates.

One of the strongest patterns to emerge regarding access to high-skilled jobs occurs among the European countries - this is the effect of being born in an eastern 
versus a western European nation. Average high-skilled occupational attainment is less than 40 per cent for each eastern European country of origin. By contrast, highskilled work rates for migrants from west European countries range from 41 percent among UK migrants to 53 per cent among Swedish migrants. Except for the UK, all western European countries have higher probabilities of being in highskilled work than the Irish probability of 0.42 , while eastern European states generally fare worse. This finding is supported by McGinnity et al. (2018a), who find that eastern Europeans are far less likely to be in professional or managerial jobs than western Europeans in Ireland. 
FIGURE 4.8 PREDICTED PROBABILITIES OF BEING IN HIGH-SKILLED EMPLOYMENT: MIGRANTS IN THE 'REST OF THE WORLD' CATEGORY AND IRISH RESPONDENTS

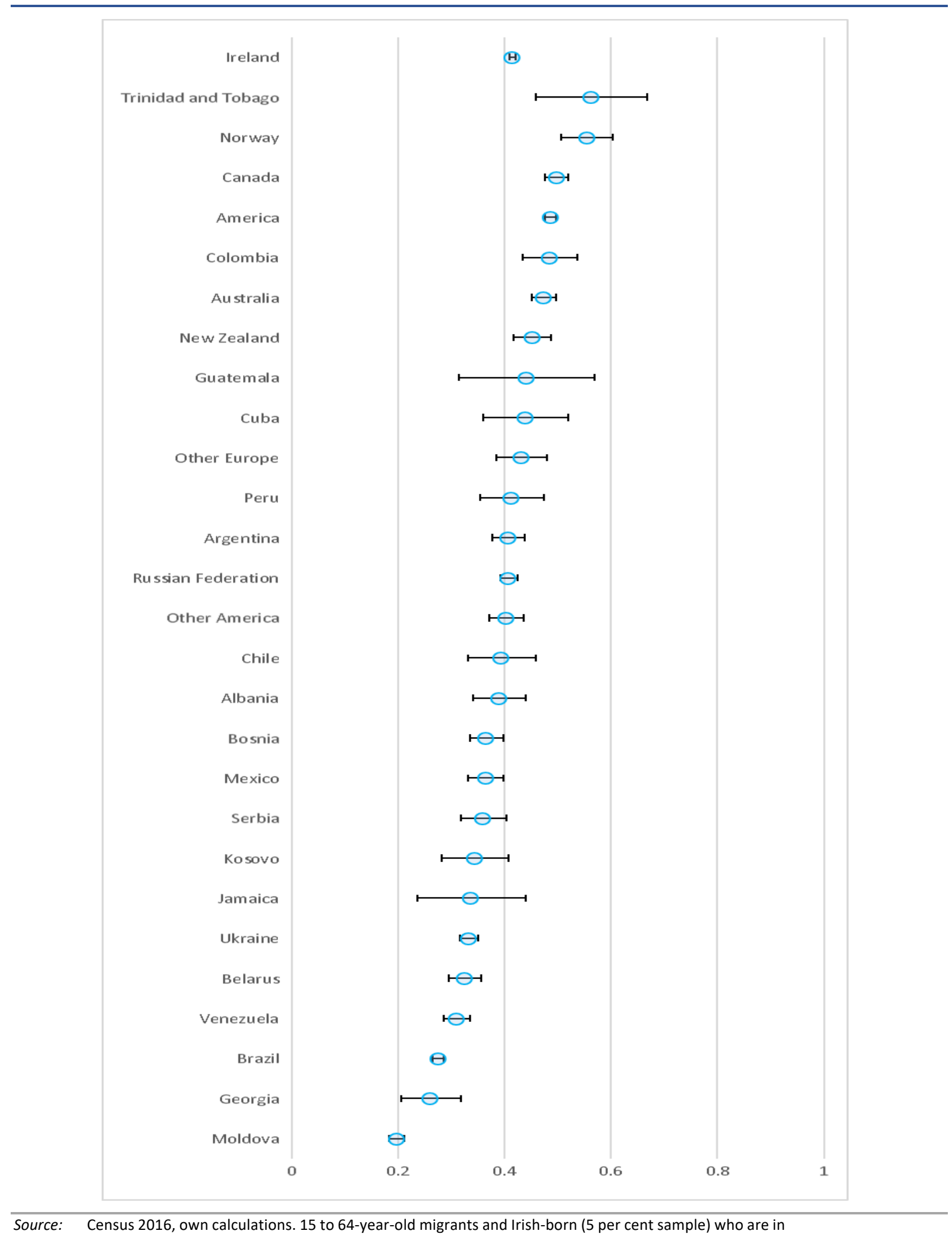
employment $(n=391,947)$.

Note: $\quad$ Modelled results are highlighted with a blue circle, controlling for the gender, age of respondents, their English language ability, their education and respondent ethnicity. Black bars represent $95 \%$ confidence interval. Countries are sorted in descending order according to country model estimates.

Turning to the 'rest of the world' category, we see that migrants from highly developed Anglophone countries such as Canada, the United States (US) and 
Australia perform well on occupational attainment compared to Irish-born respondents, as they did on unemployment levels. This is broadly in line with the expectations set out in Chapter 1 regarding migrants from English-speaking countries having better outcomes. As in the analysis of unemployment rates, we find that migrants from countries which have experienced social or political unrest, such as Georgia, Kosovo and the Ukraine, fare badly in terms of occupational attainment, with Georgians having only a probability of 0.26 of being in high-skilled work. In line with our previous finding that countries of birth from the same region do not tend to converge hugely, we can see that outcomes vary quite substantially among the South American states; for example, the probability of being in a professional managerial occupation is 0.49 for Colombians but only 0.28 for Brazilians.

Overall, like the unemployment rate, the predicted probability of employed migrants working in a high-skilled job differs hugely by country, even within regional groupings. Interestingly, the countries of origin that perform best in terms of occupational attainment are not necessarily the same ones that perform best in terms of unemployment rates. For example, the probability of Sudanese migrants being in a high-skilled job is high (74 per cent) but Sudanese migrants also have above-average unemployment rates ( 29 per cent). This is because we estimate the probability of being in a high-skilled job conditional on being employed. The samples used for the unemployment and high-skilled models are different, as the high-skilled models drop unemployed people, and there are likely to be differences between migrants from the same country who are employed compared to those who are unemployed. Employed migrants are highly selective and are not representative of the overall population. It is therefore important to consider both unemployment and high-skilled employment together when forming a view on how well a migrant group is integrating into the Irish labour market.

As we have seen in Chapter 3, most migrant groups have relatively advantaged educational profiles compared to the Irish-born population. Were it not for this fact, the prevalence of high-skilled jobs among migrants would be a good deal lower. The disadvantage experienced by Black Africans corresponds to our expectations in Chapter 1 , but similar to the unemployment outcomes we find little evidence of disadvantage for other non-White ethnicities.

Regarding our other expectations from Chapter 1, there is some evidence that the pattern in the unemployment rate of countries with high levels of civil conflict performing worse continues in the high-skilled work outcome, with stable countries performing better; however, the relationship seems to be weaker. EEA countries have a slightly smaller range of probabilities than the other continental groupings, but on average Asian and 'rest of the world' countries have higher probabilities of being employed in high-skilled work than EEA countries, including 
Ireland, while African countries have lower average probabilities. The impact of being from an EEA country and of being from a country with a high probability of civil conflict will be explored in more depth in Chapter 5.

\subsection{SUMMARY}

This chapter has reviewed the differences in labour market outcomes for migrants from different countries. Like the previous chapter, it shows that even when controlling for factors that strongly determine employment outcomes, there remain stark differences between countries. It supports the view that while there are some global and regional trends among outcomes of migrants from different countries, there also remain many idiosyncrasies related to specific countries. It also shows that unemployment outcomes and high-skilled work outcomes do not always overlap, and for that reason using multiple measures of labour market integration allows us to gain a better understanding of how migrants from different countries are faring in Ireland.

Several trends became clear throughout the analysis of unemployment. Most migrants have higher predicted probabilities of being unemployed than the Irishborn population. African migrants fare especially poorly on this measure, with only one country having a lower rate of unemployment than the Irish-born. This is partly to do with their ethnicity, which most strongly affects Black Africans compared to any other ethnicity.

Although those born in Ireland fare better than migrants from most countries, we found considerable variation in migrant outcomes depending on the country of birth. People from countries with high levels of civil conflict tend to have higher unemployment rates than people from Ireland, which may be linked to our expectation in Chapter 1 that refugees will be less integrated into labour markets. In contrast, and in line with our expectations that migrants from more economically developed countries will fare better in the labour market, people from politically stable, English-speaking, developed countries in the 'rest of the world' grouping tend to have better outcomes than Irish-born people. In Africa, migrants from more stable countries with higher levels of economic development do not fare as well as those born in Ireland but do comparatively better than other African countries, while in Asia there is no strong relationship between economic development and unemployment. Within the EEA, western and northern European countries of birth have lower predicted probabilities of unemployment, while eastern European countries of birth typically have higher predicted probabilities. This highlights the diversity that can exist within continental groupings of migrants. 
The trends in the high-skilled employment analysis are quite different, in part because the sample of migrants who are employed is quite selective. While people from most countries of birth have higher rates of unemployment than Irish people, with the exception of EEA migrants, outcomes are more positive for the migrants who are employed, with just under half of the countries of origin having higher predicted probabilities of being in high-skilled jobs than that of Irish-born people. Many of those from Asian and 'rest of the world' countries have higher rates of high-skilled work than the Irish-born group, although the majority of those from African countries of birth underperform on this measure compared to those born in Ireland. Within the EEA, there is an even starker split than in the unemployment outcomes, between those born in eastern Europe and the western and northern countries of the region, with those born in the latter countries outperforming eastern European countries in high-skilled job outcomes.

The pattern we discussed in Chapter 1 of migrants from countries of birth with high levels of conflict performing worse than those from stable or more developed countries is also found in the 'rest of the world' countries and, to some extent, in the African countries. As with unemployment, there is evidence that the Black ethnic group has poorer outcomes than the White ethnic group, but we find no evidence of ethnic disadvantage for Asians. However, for those who are employed, the disadvantage for Black Africans regarding the high-skilled job outcome is less than that found for the unemployment outcome. 



\section{CHAPTER 5}

\section{Which migrants fare best in the Irish labour market?}

So far, the analysis has sought to investigate whether migrants from some countries fare better in the labour market than those from other countries. On this point, it has shown substantial country-level differences in both rates of unemployment and occupational attainment. Even controlling for individual-level factors such as age, gender, human capital and ethnicity, unemployment rates range from less than seven per cent among Norwegian-born migrants to 48 per cent among residents born in Somalia. Similarly, modelled high-skilled occupational attainment rates range from 14.5 per cent among Mongolian migrants to 74 per cent among Sudanese migrants.

The current chapter investigates why some migrants are more successful in the labour market than others. To do this, we restrict the dataset to the foreign-born population and estimate a series of logistic regression models with unemployment (conditional on labour market activity) and being in a high-skilled occupation (conditional on being employed) as our outcomes of interest (dependent variables). We use information relating to the migrant's country of origin, as well as individual-level characteristics to investigate these factors.

\subsection{COUNTRY OF ORIGIN}

Broadly speaking, migrants can pursue three legal routes into Ireland - through European Economic Area (EEA) freedom of movement, through the international protection system and through other non-EEA means. We hypothesise that these routes impose selection effects on migrants coming to Ireland in terms of their ability to avoid unemployment and to attain a high-skilled job. That is, the average level of human capital will differ for each of these three types of migrants because each face different restrictions on entry to the country.

\subsubsection{Migrants born in the EEA}

Citizens of EEA countries can freely live and work in Ireland. ${ }^{33}$ The number of migrants falling into this category increased substantially after the 2004 and 2007 eastward expansion of the European Union (EU), and they now make up 70 per cent of the foreign-born population in Ireland. ${ }^{34}$

33 We include people born in Switzerland as EEA-born because they can avail of a similar freedom of movement agreement.

34 CSO Statbank table: 'PEA18 Estimated migration (persons in April) by country, sex, origin or destination and year'. 
While there are no formal restrictions on entry to Ireland for EEA nationals, the very fact that they come from a group of relatively highly developed nations means that (all else being equal) we expect EEA nationals to have higher levels of human capital than non-EEA nationals. For instance, according to the World Bank Human Capital Index, all EEA countries are in the top half of the global distribution of human capital, and all but three countries (Greece, Luxembourg and Slovakia) are in the top quartile. This means that if we assume that migrants are randomly drawn from each country of origin, EEA migrants will likely have higher levels of human capital than non-EEA migrants. However, it is not so straightforward as this; given the fact that non-EEA work permits in Ireland are for high-skilled jobs, non-EEA migrants may be a select group of high-skilled workers, with high levels of human capital, while some EEA migrants may be low-skilled workers, coming to Ireland to seek work.

\subsubsection{International protection}

Non-EEA nationals who come to Ireland seeking international protection are much less likely to be from highly developed countries. The drivers of political migration - political strife and civil conflict - are more likely to affect countries with low levels of economic development (Collier and Hoeffler, 2004). Furthermore, people coming to Ireland through the international protection system may spend some time in the International protection system. Until June 2018, protection applicants were not allowed to work or access vocational training (see Chapter 1), and estimates from 2014, for example, suggest that a significant minority of applicants had spent five years or more in the protection system (McMahon Report, 2015). Since June 2018, asylum applicants who have not received a first-instance decision within nine months may apply for a work permit or access to vocational training. However, this change occurred subsequent to the data used throughout the report, and so does not apply to the analysis presented here. International research suggests that a period of unemployment is associated with poorer labour market outcomes (Gangl, 2006). Previous research in Ireland has suggested that this forced labour market inactivity has created scarring effects, whereby the time in the Direct Provision system creates a gap in a migrant's CV, leading to suboptimal future labour market outcomes (DEASP, 2018; O'Connell, 2019).

\subsubsection{Other non-EEA nationals}

Another key route to Ireland for non-EEA nationals is through the work permit system. These permits require migrants to command a relatively high wage. If the migrant can secure a job in a critical skills area (where the Irish government has determined there to be a skill shortage), they can get a work permit, provided they earn a salary of at least $€ 30,000$ per year (Arnold et al., 2019). If they can command a salary of $€ 60,000$ or more, they can gain a permit without having a critical skill. 
The work permit system therefore means that work permit holders have relatively high levels of human capital, such as educational qualifications and job-specific skills. We would therefore expect this group to perform particularly well in the Irish labour market.

Other categories of non-EEA migrants include students and migrants arriving under family reunification policies. The former are not such an issue for this analysis, which is focused on those who are active in the labour market. The latter category - those arriving under family reunification - are more difficult to account for because they are a diverse group. They include family members of migrants who have come through the international protection system, family members of workpermit holders and people who have married Irish nationals. However, given that people tend to form families within educational groups rather than across them, we can expect the human capital of migrants arriving under family reunification to be correlated to that of their family members who arrived either as work permit holders or protection applicants (Smits, 2003).

To capture these effects, we would like to have a variable in the Census data on the migrant's route into Ireland. Unfortunately, this information is not captured. However, with data on the migrant's exact country of origin, we can tell whether or not they originate from a Member State of the EEA.

Determining the reason for arriving in Ireland among non-EEA nationals (international protection or other) is more complex. We follow the approach used by O'Connell (2019) to estimate the probability that a migrant arrived as a protection applicant (or a family member of an applicant). We take data from the United Nations High Commissioner for Refugees (UNHCR) on the number of applications for asylum made from each country of origin in Ireland between 1999 and 2016 and divide this by the number of people from that country enumerated in the 2016 Census. We call this variable 'asyratio':

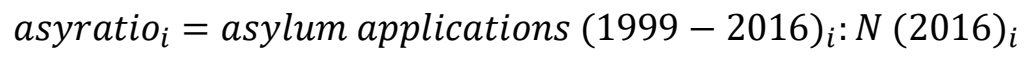

where subscript refers to a country of origin and $\mathrm{N}$ refers to the total number of people enumerated in the Census.

For instance, UNHCR data on Ireland show that, between 1999 and 2016, 1,556 asylum applications were made by people from South Africa. The 2016 Census recorded 7,857 South African born residents in Ireland. This means that people born in South Africa have a score of $0.2(1,556 / 7,857)$ on our measure of likelihood of having come through the asylum system. By contrast, Iranian-born migrants have a much higher score of 0.87 , because UNHCR identifies 949 applications for 
asylum over this period but there are only 1,092 Iranian-born residents enumerated in the Census. This means that there is no variation on asyratio for individuals within countries of origin.

Asyratio is not a measure of the proportion of migrants that are or have been asylum seekers. UNHCR data refer to flows of applications, while the Census data refers to the stock of migrants. It is not clear from the UNHCR data what proportion of applications are successful and what proportion result in deportation. ${ }^{35}$ Migrants who apply for asylum may also be denied asylum but granted permission to remain for other reasons. In this way, focusing on applications, rather than grants, is important, as it captures the general mechanism of migrants from such countries in important ways. ${ }^{36}$ It is also possible that even among those who have gained refugee/subsidiary protection status in Ireland, a significant proportion may have left the country or deceased before the 2016 Census. In fact, many countries of origin register a score greater than one on this measure, indicating that more asylum applications have been made from a given country than there are people from that country living in Ireland. In these cases, it is likely that the vast majority of people from that country came into Ireland through the international protection system.

\subsection{INDIVIDUAL CHARACTERISTICS}

Even if we imagine migrants in Ireland as belonging to the three categories of EEA migrants, asylum seekers and other non-EEA migrants, we would expect there to be considerable variation within these groups in terms of their individual characteristics. For instance, some asylum seekers will be more highly educated than others, and some EEA migrants will have better English language skills than others. We therefore control for a suite of individual-level variables in our models. These controls are: educational attainment; self-reported English language skills; age; sex; and ethnicity. We also add two individual-level variables that were not included in the analysis in Chapter 4 but which we expect to be associated with labour market outcomes: the length of time the respondent has lived in Ireland; and whether or not they report their nationality as Irish. These factors are not included in Chapter 4 because they need to be interpreted with care. The duration in Ireland variable is particularly problematic. It is based on a question in the Census, which asks, 'Have you ever lived outside of the Republic of Ireland for a continuous period of one year or more?' If the respondent indicates that they have, they are asked what their previous country of residence was and what year they measure would be misleading because it would not count people that arrived seeking international protection who were refused but were subsequently granted leave to remain. 
last took up residence in Ireland. A weakness of this measure is that some migrants may have come to Ireland, left for a period of over one year, and subsequently returned. In these cases, we would not be able to pick up the time spent in Ireland during the first period of residence. Another issue with this information is that approximately half of all migrants do not answer it. This might be because they think that it only applies to people who have spent time abroad after initially living in Ireland. To get around this problem, we include 'duration missing' as a category in the regression models which follow. ${ }^{37}$

We include an Irish nationality dummy to explore the effect of naturalisation on labour market integration outcomes. This is also an imperfect measure, because people born abroad to Irish parents may record Irish nationality despite never having gone through the naturalisation process. Notwithstanding that issue, we would expect to see an association between Irish citizenship and positive labour market outcomes, as discussed in Chapter 1. However, finding an association would not be evidence of causality, only a difference between those with and without Irish citizenship in a given outcome. It is possible that people who naturalise have different unobservable characteristics than those who do not. For instance, they may be more motivated to find work, or may have an intention to stay in Ireland for longer than those who do not naturalise. Further, naturalisation may be a sorting mechanism in and of itself - respondents with significant resources are best able to secure naturalisation, and as a result, fare better in the labour market than respondents without such resources. However, recent findings suggest that naturalisation has a positive impact on respondents, even when such selection effects are accounted for (Hoxhaj et al., 2019).

\subsection{MODELS OF UNEMPLOYMENT}

We present the results of the models as odds ratios. In the unemployment model, an odds ratio of less than one means that the variable is associated with a lower likelihood of unemployment than the reference category. For instance, in Table 5.1 we can say that, conditional on other factors, the odds that an EEA national will be unemployed are 78 per cent relative to that of a non-EEA national. ${ }^{38}$ An odds ratio of one means that the variable is not associated with the odds of being unemployed, relative to the reference category, and an odds ratio greater than one means that it is positively associated with unemployment, relative to the reference category.

As mentioned, the model clearly shows that EEA nationals have lower levels of unemployment than non-EEA nationals. This is consistent with our expectations, 
given that EEA nationals come from highly developed countries and are therefore more likely to have high levels of human capital and superior work rights.

Our measure of the likelihood of having come to Ireland through the international protection system reveals a strong positive association with unemployment. Going up by one on this measure, which is approximately equivalent to going from the likelihood experienced by people born in Austria, Switzerland, Finland or Denmark (who all score zero) to the likelihood of people born in Iraq (0.94) or Togo (1.06), increases the odds of being unemployed by 76 per cent.

Turning to individual-level factors, most of the findings are consistent with previous research on labour market integration on Ireland (Barrett and Duffy, 2008; Barrett et al., 2016; O'Connell, 2019). All else equal, we find that the odds of being unemployed are higher for migrants with lower levels of educational attainment, poorer self-reported English language skills and for young people, Black people, and women. There is some evidence that migrants who have been in Ireland for longer have lower odds of unemployment, suggesting that the longer they have lived in Ireland, the better integrated they are into the Irish labour market. 


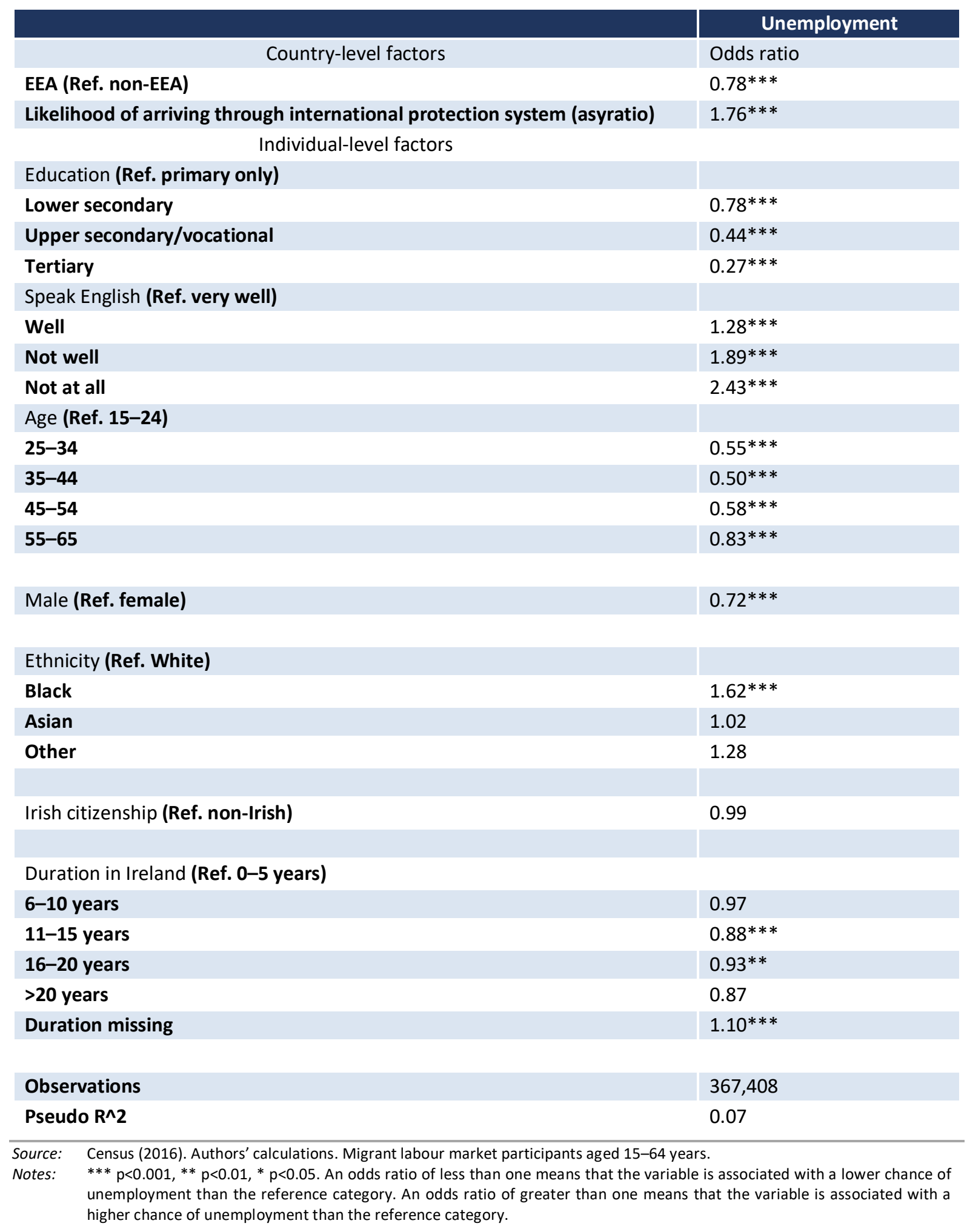


Perhaps surprisingly, we find that having Irish nationality has no impact on the odds of being unemployed for the overall migrant sample. ${ }^{39}$ Given that Irish citizenship may be more salient for those born in non-EEA countries, we estimate the model for respondents born in non-EEA countries only (Table A5.1). Results suggest that non-EEA migrants with Irish citizenship are significantly less likely to be unemployed than non-EEA migrants who are not Irish citizens, as expected. ${ }^{40}$ Additionally, when we estimate the finding for EEA migrants, we find that EEA migrants who are Irish citizens report higher odds of unemployment than EEA migrants who are not Irish citizens (Table A5.1). It could be that EEA migrants who are Irish citizens more closely resemble those born in Ireland in terms of their unemployment. As Figure 4.3 shows, many EEA migrants are less likely to be unemployed than those born in Ireland. As an alternative explanation, it could be that there are two separate pathways to Irish citizenship among EEA and non-EEA migrants. In short, non-EEA migrants may be a (positively) select group who have acquired citizenship through naturalisation. Naturalisation statistics from the past 10 years indicate that a much greater proportion of those born outside the EEA have acquired citizenship than those born within the EEA (McGinnity et al., 2018b). EEA migrants, particularly those from the United Kingdom (UK), may not have naturalised, but may have been born to Irish parents. These potential explanations would require further investigation.

\subsection{MODELS OF HIGH-SKILLED EMPLOYMENT}

Interestingly, although people born in EEA countries have lower conditional odds of being unemployed, they are also less likely to be in a high-skilled job. European migrants are only 74 per cent as likely to be in a high-skilled job as those from outside the EEA. This is consistent with Chapter 4, which revealed low levels of unemployment among people born in EEA countries, but also relatively low levels of occupational attainment from some country-of-origin groups, particularly those from the UK and eastern Europe, who make up the vast majority of EEA migrants. ${ }^{41}$ It is important to note that these models, like those in Chapter 4, consider a subset of the sample, mainly those who are in employment. This is evident in the number of observations in Table $5.1(367,548)$ and Table $5.2(298,164)$. In this way, conclusions about country-level differences in occupational attainment differ from those about country-level differences in unemployment.

The asyratio measure of likelihood of arriving through the protection system has a similarly damaging effect on occupational attainment as it does on unemployment.

Additional checks revealed that this result holds when we do not control for duration. Estimates available on request.

As a robustness check, we weighed the data to ensure that all countries of origin have the same impact on the results (see below). The effect of being an EEA national remains negative and statistically significant for both outcomes. 
A one-unit increase on this measure reduces the odds of being in a high-skilled job by 36 per cent.

\section{TABLE 5.2 MODEL ESTIMATES PREDICTING ODDS OF HIGH-SKILLED OCCUPATION}

\begin{tabular}{|c|c|}
\hline \multirow{2}{*}{ Country-level factors } & High-skilled occupation \\
\hline & Odds ratio \\
\hline EEA (Ref. non-EEA) & $0.74 * * *$ \\
\hline Likelihood of arriving through international protection system & $0.64 * * *$ \\
\hline \multicolumn{2}{|l|}{ Individual-level factors } \\
\hline \multicolumn{2}{|l|}{ Education (Ref. primary only) } \\
\hline Lower secondary & 0.98 \\
\hline Upper secondary/vocational & $1.56 * * *$ \\
\hline Tertiary & $7.67 * * *$ \\
\hline \multicolumn{2}{|l|}{ Speak English (Ref. very well) } \\
\hline Well & $0.35 * * *$ \\
\hline Not well & $0.13 * * *$ \\
\hline Not at all & $0.14 * * *$ \\
\hline \multicolumn{2}{|l|}{ Age (Ref. 15-24) } \\
\hline 25-34 & $1.82 * * *$ \\
\hline $35-44$ & $2.08 * * *$ \\
\hline $45-54$ & $2.17^{* * *}$ \\
\hline $55-65$ & $2.29 * * *$ \\
\hline Male (Ref. female) & $1.18^{* * *}$ \\
\hline \multicolumn{2}{|l|}{ Ethnicity (Ref. White) } \\
\hline Black & $0.82 * * *$ \\
\hline Asian & $1.50 * * *$ \\
\hline Other & $0.93 * * *$ \\
\hline Irish citizenship (Ref. non-Irish) & $1.44^{* * *}$ \\
\hline \multicolumn{2}{|l|}{ Duration in Ireland (Ref. 0-5 years) } \\
\hline $6-10$ years & $0.67 * * *$ \\
\hline $11-15$ years & $0.67 * * *$ \\
\hline $16-20$ years & $0.87 * * *$ \\
\hline$>20$ years & $0.77 * * *$ \\
\hline Duration missing & $0.51 * * *$ \\
\hline Observations & 298,364 \\
\hline Pseudo R^2 & 0.21 \\
\hline Census (2016). Authors' calculations. Sample limited to those in employment agec & ears. \\
\hline $\begin{array}{l}* * * p<0.001, * * p<0.01, * p<0.05 \text {. Sample limited to those in employment aged } 15 \\
\text { is associated with a lower chance of being in a professional/managerial job than th } \\
\text { that the variable is associated with a higher chance of being in a professional/man }\end{array}$ & $\begin{array}{l}\text { An odds ratio of less than one means that the variable } \\
\text { ce category. An odds ratio of greater than one means } \\
\text { b than the reference category. }\end{array}$ \\
\hline
\end{tabular}

On the whole, the individual characteristics have a similar impact on occupational attainment as they do on unemployment. Migrants in high-skilled jobs tend to be 
highly educated, able to speak English very well, aged over 35 years and male. As with unemployment, Black people fare worse than White people in terms of occupational attainment. However, neither group performs as well as migrants with Asian ethnicity. The odds of members of the Asian ethnic group being in a high-skilled job are almost 50 per cent higher than they are for White migrants.

The effect of some individual-level variables can vary, depending on the outcome. While naturalisation has no impact on the odds of being unemployed, it has a positive impact on the odds of being in a high-skilled job, conditional on the respondent being employed. In addition, although people who have recently arrived in Ireland have higher odds of being unemployed, they also have higher odds of being in a high-skilled job.

As an aside, it seems that EEA and Non-EEA respondents are equally affected by naturalisation for this outcome. Where previously naturalisation had opposite effects on respondents, depending on whether they were an EEA or a non-EEA migrant, in this case both groups benefit from the effect somewhat equally. We present additional findings in the appendix (Table A5.2).

\subsection{HOW ROBUST ARE THE FINDINGS?}

We included a series of robustness checks to investigate the findings further. First, because there is substantial variation regarding the size of each country-of-origin group, we were concerned that the results could be driven by migrants from a small number of countries - namely Lithuania, Poland and the UK. To get around this problem, we constructed a weight that effectively equalised the number of people from each country of origin. This meant that migrants from large countryof-origin groups (such as Poland) had a similar effect on the results as migrants from small groups (such as Tanzania). This amendment makes only one significant difference to the results: migrants who report Asian ethnicity are no longer more likely than White migrants to be in high-skilled jobs.

Second, we constructed an alternative measure of likelihood of being an asylum seeker. When constructing asyratio, we make the rather strong assumption that the likelihood of having come through the protection system is the same for all migrants from a given country, regardless of when they came to Ireland. However, the UNHCR data show that for some countries of origin the number of asylum applications varies considerably over time. For instance, annual applications from the Russian Federation numbered in the hundreds in the early 2000s, peaking at 327 in the year 2000, but fell to fewer than 10 from 2013 onwards. To get around this problem, we constructed a measure that accounts for the year the migrant arrived in Ireland. This variable, labelled 'asy_duration_ratio', is constructed as follows: 


$$
\text { asy_duration_ratio }_{i t}=\text { asylum applications }_{i t}: N_{i t}
$$

where the subscript i refers to a given country and the subscript $t$ refers to a given year between 1999 and 2016. This variable has substantially more variation than asyratio, because different migrants from the same country can register different values on it.

The drawback of this approach is that it requires us to drop a substantial portion of the data. This happens for two reasons. One is that the asy_duration_ratio variable is not compatible with cases that are missing on duration. The other is that the UNHCR data only date back to 1999 , so people who record years of arrival before then have to be dropped from the analysis. To avoid collinearity, we also drop the duration variable itself from the model. Using the asy_duration_ratio measure changes the size but not the direction or the level of significance of the effect of the likelihood of having arrived through the protection system on the labour market outcomes. A one-unit increase on this measure is associated with increased odds of being unemployed of six per cent and decreased odds of being in a high-skilled job of nine per cent.

Third, we used yet another measure of likelihood of being an asylum seeker based on information sourced from the World Bank's World Governance Indicators (WGI). This dataset is based on information sourced from surveys of experts, nongovernmental organisations (NGOs), businesspeople and citizens on the overall quality of governance in over 200 countries over the period 1996-2018. In particular, we used the composite indicator for the dimension of 'political stability and absence of violence'. This ranges from approximately -2.5 (most unstable/violent) to +2.5 (most stable/peaceful). For each country of origin, we averaged the score from each year and assigned that value to migrants born in that country. ${ }^{42}$ The logic of this approach is that migrants in Ireland from generally unstable or violent countries are more likely to have come through the international protection system than migrants from more peaceful or stable countries. Using this measure instead of asyratio yields similar results in respect of unemployment. A one-unit increase in this measure, which is the equivalent of going from a country like the Congo $(-1.5)$ to Serbia $(-0.5)$, is associated with a reduction in the odds of being unemployed by approximately 30 per cent. However, using this measure we find that the likelihood of having come through the international protection system has no discernible impact on the odds of having a high-skilled job. 
A weakness of the WGI measure is that it can be heavily influenced by localised or regional conflict or instability within a country. For instance, Spain has a remarkably low value (0.05). This is likely caused by separatist movements in the Basque country and elsewhere, which would have only very small impacts in generating outward flows of asylum seekers. It is for this reason that we chose to use asyratio as the primary measure of the likelihood of having come through the international protection system.

The fourth and final robustness check we carried out involved including the log of the average gross domestic product (GDP) per capita of the migrant's country over the period 2000-2018, measured in current US dollars, in the models. We did this to address potential concerns that the asyratio variable may simply be picking up differences between countries of origin in economic development. This causes the effect of the asyratio variable to weaken in the occupational attainment model. However, it remains negative and statistically significant at the five per cent level.

The log GDP per capita variable itself has a positive effect on unemployment. All else equal, a one-per-cent increase in the migrant's home country's average GDP per capita is associated with a four-per-cent increase in the odds that they will be unemployed. ${ }^{43}$ However, it has a strong, positive effect on occupational attainment. A one-per-cent increase in this measure increases the odds of being in a high-skilled job by six per cent. ${ }^{44}$

\subsection{CONCLUSIONS}

Taking the labour market as an example, this analysis has sought to investigate some of the mechanisms underlying labour market integration in Ireland.

Irish immigration policy favours entry by migrants from relatively economically developed European nations and by high-skilled work permit holders in the 'rest of the world' category. The one exception to this pattern is immigration through the international protection system. The analysis in this chapter has shown that these migrants tend to have higher unemployment rates and less access to high-skilled occupations. Though the finding with respect to occupational attainment is not robust to the use of the WGI measure of likelihood of having come through the protection system (where no significant effect can be discerned), the model findings are consistent in all other specifications.

43 If log GDP per capita is included in the model without asyratio, the effect is negative and statistically significant.

$44 \quad$ We also estimated a random intercept, fixed slope multilevel model for both unemployment and occupational attainment. The intercept varied by country of birth. This design did not alter the effects of the two key measures, EEA status and asyratio. Results are available from the authors on request. Future research could look at random slopes, where countries differ in their impact of EEA status and non-EEA status, or the impact of asyratio. This is beyond the scope of this report. 
This analysis cannot determine whether these poorer labour market outcomes are due to the trauma and disruption experienced prior to and during migration or time spent in the State as an international protection applicant out of the labour market, but it is likely to be a combination of factors. International research has also highlighted the potential detrimental effect of protracted asylum procedures on subsequent employment (Hainmueller et al., 2016).

Controlling for other factors, we also find that people born in EEA countries have lower rates of unemployment than non-EEA migrants. Most EEA migrants are labour migrants and can work in Ireland without restriction. However, they are also less likely to be in high-skilled jobs. This is consistent with the results of Chapter 4, which showed that migrants from the UK and several eastern European countries exhibited these characteristics.

Notwithstanding the strength of these country-level effects, individual characteristics of the migrants also strongly impact on their prospects within the Irish labour market. Migrants with high levels of educational attainment and those who can speak English do better on both outcomes (unemployment and high educational attainment). We also find that male migrants outperform female migrants on both outcomes. In terms of unemployment, the lowest rates are found among those aged 25-44 years, while those aged $\mathbf{3 5}$ years or over do best in terms of occupational attainment.

Members of the Black ethnic group have a much higher rate of unemployment and have much lower odds of being in a high-skilled occupation. This is after accounting for differences in the chances of coming through the international protection system. People who report Asian ethnicity have similar labour market outcomes to White migrants.

There is a monotonic negative relationship between duration in Ireland and the odds of being unemployed. In other words, recent arrivals are much more likely to be unemployed. Perhaps surprisingly, however, conditional on being employed, those who have arrived recently are more likely to be in a high-skilled occupation. However, the difference between recent arrivals and people who have been here for a long time (at least 20 years) is not statistically significant. It appears that the missing values on this variable are not randomly distributed. Having a missing value on duration is very strongly associated with lower odds of being in a high-skilled occupation.

Finally, controlling for other factors, among those born abroad, reporting Irish nationality has no effect on unemployment for the migrant sample overall. However, closer inspection reveals that the effect differs for EEA and non-EEA 
born. Non-EEA migrants with Irish citizenship have lower unemployment rates than non-EEA migrants who are not Irish citizens, but EEA migrants who are Irish citizens have higher unemployment rates. Exploring this question further is beyond the scope of this report but the findings suggest it would be an important topic for future work. For both groups, being an Irish citizen has a strong, positive impact on the likelihood of a respondent being in a high-skilled occupation. 


\section{CHAPTER 6}

\section{Summary and Implications}

\section{$6.1 \quad$ INTRODUCTION}

This report uses Census microdata from 2016 to examine some key integration outcomes for first-generation migrants in Ireland. This use of Census data enabled an investigation of outcomes on a detailed, country-of-birth level; by contrast, much of the quantitative research literature on migrant integration in Ireland up to now has only provided information at a supranational level. The Census data also allowed us to investigate potential explanations for why some migrants fare better than others. This chapter summarises the key findings, before going on to discuss some limitations of the study, future research ideas and implications for integration monitoring in the future.

\subsection{KEY FINDINGS}

This report examines four measures - third-level educational attainment, English language proficiency, unemployment and occupational attainment. Perhaps its strongest finding is that there is significant country-of-birth variation in outcomes within regions, and that in many cases variation within regions is greater than variation between them.

Those from western European countries tend to have higher probabilities of having a third-level education than those from eastern Europe, with the exception of those born in the United Kingdom (UK), including Northern Ireland. ${ }^{45}$ Variation regarding this variable is considerable for those from Asia and Africa: for most country-of-birth groups in Asia, rates of third-level education are much higher than they are for those born in Ireland, but exceptions occur, including those born in Afghanistan, who have very low rates of third-level education. Similarly, those born in most African countries have higher predicted probabilities of third-level education than the Irish-born, with the notable exceptions of migrants born in Somalia and Togo. Similar variation is found for those from the 'rest of the world' category.

An unsurprising but important finding is that those who come from countries where English is widely spoken have much higher chances of reporting their English to be very good. While English language skill and third-level education are both important indicators of human capital and labour market potential in Ireland, we

45 The term 'western European countries' typically refers to the 'old' Member States, prior to enlargement in 2004, excluding the UK and Ireland. 'East European countries' refers to the 'new' Member States that joined the EU in 2004, 2007 and 2013. 
find that in migrants from origin countries who score highly on one of these measures do not necessarily perform well on the other. In addition, several origin countries whose migrants report high levels of English language skills do not have high levels of economic development; conversely in the European Economic Area (EEA) countries tend to have high levels of economic development, but migrants from these countries may not have high levels of English language skills (with the exception of the UK).

This brings us to another important finding: country 'rankings' vary across the outcomes considered - educational attainment, self-rated English language skills, unemployment and working in a high-skilled job. Not only do country-of-birth groups differ in terms of educational attainment and English language skills, we also found that country-of-birth rankings in occupational attainment differ from country-of-birth rankings in unemployment. The majority of foreign-born migrants have higher predicted unemployment probabilities than Irish born, but when only considering those who are employed, migrants from over half the country-of-birth groups have higher chances of being in high-skilled jobs. Migrants from many individual country-of-birth groups from Asia, western Europe and the 'rest of the world' have higher chances of working in a higher skilled job. Migrants from many individual African countries have lower chances of working in a professional/managerial job, but the disadvantage compared to the Irish-born population is not as great as that found for unemployment.

Chapter 5 investigates some of the mechanisms underlying labour market integration for migrants, by adding both country-level and individual-level characteristics in models of unemployment and working in a professional/managerial occupation, for those who are employed. One salient finding is that, consistent with expectations from Chapter 1 and O'Connell (2019), migrants from countries with high rates of applications for international protection relative to their population size have worse labour market outcomes than those with much lower rates of international protection applications. This supports the finding from the analysis of data by individual countries of birth in Chapter 4 .

The models in Chapter 5 control for educational qualifications, language ability, age, gender, ethnicity, nationality and duration in Ireland as other potential explanatory factors regarding labour market outcomes. The effect of rates of applications for international protection is particularly marked for the risk of unemployment, but there is some evidence that it is also associated with lower chances of having a high-skilled job, among those who are employed. There are a number of explanations for this finding, including potential trauma and disruption experienced prior to and during migration, but also perhaps the time spent in the State but out of the labour market as an international protection applicant, particularly if this period was prolonged. 
Chapter 1 suggests that outcomes for EEA nationals would be better, in general, than those for non-EEA nationals, given high levels of economic development in those countries and the superior working rights of EEA nationals. We found that EEA migrants do indeed have lower unemployment rates than non-EEA migrants. However, Chapter 1 also highlights the work permit system, particularly how selective it is, and we find that EEA nationals also have lower occupational attainment than non-EEA migrants, even after controlling for language and duration. This is consistent with McGinnity et al (2018a), who used a different data source, and supports the notion that the selective nature of the employment permit system, which typically awards an employment permit for high-skilled jobs, plays a role in understanding high occupational attainment among working nonEEA migrants.

Ethnicity also plays an important role for migrants in the Irish labour market. Black migrants are 1.6 times as likely to be unemployed as White migrants, even after controlling for factors such as education, nationality, language skills, duration and likelihood of arriving through the protection system. When employed, Black migrants are also less likely (0.8 times as likely) to work in a high-skilled occupation. By contrast, those of Asian ethnicity are no more likely to be unemployed than White migrants and are 1.5 times as likely to work in a high-skilled job. These findings using Census microdata, combined with earlier research in Ireland using evidence on labour market outcomes and self-reported discrimination (McGinnity et al., 2018a), suggest that Black migrants may face discrimination in the Irish labour market on the basis of ethnic origin.

Chapter 5 also found that, in the model that includes all those born abroad, Irish nationality has a strong and statistically significant effect on occupational attainment. It is also associated with lower unemployment rates, but only among non-EEA nationals. Why is this the case? It is because there are very low unemployment rates among eastern European migrants, most of whom are not Irish citizens, and slightly higher unemployment rates among UK-born migrants, who report Irish nationality in large numbers (this merits further analysis). However, even among EEA migrants, being an Irish national appears to confer benefits in terms of occupational attainment. There may be an element of reverse causality here, whereby people in high-skilled jobs become more settled and, for this reason intending to stay in Ireland for a longer period, successfully apply for citizenship. This is discussed in more detail in terms of future research opportunities below.

As expected, migrants with higher educational qualifications and better English language skills are less likely to be unemployed and more likely to be working in a professional or managerial job. Not surprisingly, perhaps, the role of both educational qualifications and English language skills have a greater impact on 
occupational attainment than on having a job at all. The role of educational qualifications in labour market outcomes in Ireland is well established, but the role of English language skills has been less a topic of scrutiny in Ireland, mainly because language skills are not typically measured on surveys. ${ }^{46}$ Of course, the role of English language skills may vary by job. Some jobs are more linguistically demanding than others: language skills may be less relevant for migrants picking mushrooms than those caring for adults or children, for example.

\subsection{LIMITATIONS AND FUTURE RESEARCH IDEAS}

This is the first study to use microdata from the full Census for research on migrant integration, and it illustrates its tremendous potential to contribute to our understanding of integration outcomes (see also Fahey et al., 2019a). It analyses key outcomes - third-level educational attainment, English language proficiency, unemployment and occupational attainment. The labour market and work skills comprise the focus of this report. Inevitably, limitations of space and scope meant that we could not explore all potential research questions using Census microdata.

One clear avenue for future research would be to explore outcomes in the housing and family domains. Relevant topics could include housing tenure (proportion owner-occupied, for example) and how this varies by country of origin, as well as overcrowding as a clearer indicator of disadvantage. Homelessness could also be considered, though here the number of cases might necessitate a form of analysis closer to that used in Chapter 5 , rather than a detailed, country-of-birth approach.

In the domain of family life, study of family composition would be informative; for example, the proportion of lone-parent families by migrant group. It might also be useful to study the number of children per household (UNICEF, 2009). For integration, an important indicator is the proportion of migrants married to or cohabiting with Irish-born residents. This is likely to have an influence on their socio-cultural integration, intentions to stay and English language skills, for example (Rodríguez-García, 2015).

An alternative possible line of enquiry would investigate how country-of-birth outcomes vary by gender (OECD, 2018a). This might be particularly pertinent to labour market outcomes, in terms of the proportion active in the labour market (including employment and unemployment), and how this varies by country of birth for men and women. Factors expected to influence these patterns might include presence and age of children, household composition, as well as educational qualifications, age, duration in Ireland, religion and country of birth. 
There has been increasing interest in the impact of naturalisation on integration outcomes, from both a policy and research perspective (OECD, 2011; Hoxhaj et al., 2019). As noted in McGinnity et al. (2018b), acquisition of Irish citizenship has increased considerably in the past decade. The analysis in Chapter 5 suggests that being an Irish citizen is associated with better outcomes for non-EEA migrants. A more in-depth project could investigate which foreign-born nationals are Irish citizens and whether migrants who are Irish citizens enjoy greater advantages than other migrant groups, for example in terms of education and English language skills. Do these patterns vary by region of origin?

This report only considers first-generation migrants. Children of migrants born in Ireland are included as 'Irish born'. They do not affect the total estimates for those born in Ireland in this report, but their outcomes cannot be analysed separately. In order to analyse the outcomes of second-generation migrants, a survey would need to collect information on parents' country of birth. At present, neither the Census nor any Irish national survey regularly collects this information. ${ }^{47}$ Ireland did not participate in the European Labour Force Survey ad-hoc module in 2014 on the labour market situation of migrants and their immediate descendants, which collected information on parents' country of birth. ${ }^{48}$ Without a measure of parents' country of birth on either the Census or the Central Statistics Office's (CSO) Labour Force Survey (LFS), measuring any outcomes of second-generation immigrants will not be possible in the future.

A clear limitation of this study is that some characteristics that may affect the outcomes of interest are not observed. Factors such as motivation, work experience and the extent and composition of social networks could play a key role in finding a job. Motivation, the composition of social networks and whether the migrants' partner is an English native speaker are all relevant for English language acquisition but are not observed here. Of course, factors like motivation may not differ by country of birth, though others might. In addition, the fact that it is not possible to generate a measure of duration of residence for approximately half of the migrants suggests these questions may not be working as they should in the Census. This is a crucial question for measuring migrant integration and research in the area would be considerably enhanced by having full information on this.

There are also many important outcomes that are not collected by the Census, which gives a partial picture of integration. It contains no indicators of socio-

47 An important exception is the Growing Up in Ireland study, which collects information on parents' country of birth. As this focuses on parents of children of a particular age group, it is not a representative survey of adults, though it can be used to investigate outcomes of the children of immigrants in Ireland (Darmody et al., 2016; Roeder et al., 2017). As this cohort ages, the labour market outcomes of second-generation migrants can be examined. 
cultural integration, such as identity, sense of belonging, intentions to stay or the experience of discrimination. Neither does it collect information on financial resources, so poverty and deprivation cannot be measured. The Survey on Income and Living Conditions (SILC) has robust data on poverty and deprivation, but the sample of migrants is so small that non-EU groups cannot be distinguished (see McGinnity et al., 2018b; Fahey et al., 2019a).

We have also explored the role of Irish citizenship, but it is important to bear in mind that this is not a measure of naturalisation per se. It does not distinguish those born abroad to Irish parents from those who have naturalised, and outcomes may differ for these groups. A Census question on parents' place of birth would help address this issue.

Finally, there is no measure of whether a migrant has come through the protection system, including time spent in the system and whether the migrant is a refugee. The findings about migrants that we estimate are likely to have come through the protection system suggest that it is very important that we accurately capture the outcomes of this group.

\subsection{IMPLICATIONS FOR INTEGRATION RESEARCH}

As illustrated by this report, analysis of Census microdata has much to contribute to monitoring migrant integration outcomes. However, these data are only collected every five years, and only a limited range of outcomes can be considered, as discussed above.

This report has illustrated considerable variation within regions across all of the outcomes. This presents a challenge for of the much quantitative research in this area, which tends to depend on datasets grouping migrants into regions of origin (rather than country). This is often done because small numbers of cases from specific countries can lead to reliability concerns (how representative is that one person of their co-nationals?). However, our findings suggest that the use of regional groupings, such as 'Africa' 'Asia' or, even worse, 'non-EU' or 'non-EEA', leads to important country-specific variation in terms of outcomes being overlooked.

What is the solution? Measuring and reporting on individual country-of-birth outcomes is not feasible given the small number of cases. One solution might be to have 'reasons for migration' recorded more regularly for migrants; for example, on the CSO's quarterly LFS. This could distinguish, for example, between: those who came to Ireland to work (with a job prior to migration); those who came to seek work (without a pre-arranged job); those who came for family reasons; those who came to study; those who sought international protection; and those who 
came for other reasons. We already know the number of residence permissions issued to non-EEA nationals in any given year and can distinguish here by broad purpose (see McGinnity et al., 2018b, Figure 1.5). Nonetheless, having 'reasons for migration' recorded on survey or administrative data could considerably enhance our understanding of outcomes, even without country-of-birth outcomes. This is common practice in surveys with a migration focus (for example the European Labour Force Survey special module). That is not to say that motives are always straightforward: migrants may have mixed motives and these distinctions may not reflect that (Platt, 2019). Motives may also change over time: a student may not have come to Ireland to work but having qualified may have begun working here. Despite this, knowing whether someone has come through the international protection process would be particularly instructive.

A simpler intermediate solution would be to revisit current regional categories in survey data, such as the LFS, to give more meaningful country-level groupings, albeit with a sufficient number of cases.

\subsection{IMPLICATIONS FOR POLICY}

One important finding presented in this report is that those with poor English language skills have a higher risk of unemployment and are less likely to be in professional or managerial jobs. While hardly a surprising finding, it is an important one as English language skills are amenable to policy change. Several actions in the current migrant integration strategy concern the provision of English for speakers of other languages (ESOL) (Department of Justice and Equality, 2017). However, a report published by SOLAS and Educational and Training Boards Ireland (ETBI) as part of efforts to address action 40 in the strategy noted that the provision of ESOL programmes has developed in the absence of a national strategy on ESOL provision (Kett, 2018). Kett (2018) argues that the need for training far exceeds current provision: around 13,000 people participated in ESOL training in 2016, for example, out of just over 61,000 adults who reported that they speak English 'not very well' or 'not at all' in Census 2016. ESOL tuition hours for ETBs who reported providing this were 80 hours per year on average; for many, less intensive provision (two to four hours per week) means progress is slow (Kett, 2018). Arnold et al. (2019) also report a lack of awareness among government departments, service providers and migrants themselves about the relevant services providing English language classes in Ireland. Arnold et al. (2019) focus on the labour market, though of course English language skills are also crucial for social integration.

Recognition of migrants' qualifications is another important part of labour market integration. While many migrants may apply to have their qualifications recognised through the Quality and Qualifications Ireland (QQI) system, Arnold et al. (2019) note that awareness of the service is limited and that soft barriers have been 
reported, including situations whereby employers are not familiar with the university from which a degree was obtained (Gusciute et al., 2016). The QQI system does not give the person in question an equivalent recognition of their qualifications. Canada operates a system that provides an exact equivalent of a person's qualifications, and this may be a more useful approach for those seeking work than translating their qualification to a specific level on the QQI framework. In cases where specific skills and qualifications are not recognised, some migrants may find themselves working in jobs for which they are overqualified, even if they are highly educated. Not only does this result in poorer outcomes for the individual concerned, it also means that at a societal level, potential skills are being underutilised in the Irish labour market.

The finding that those who are likely to have come through the international protection system experience particular difficulties accessing the Irish labour market suggests that these migrants may need additional supports to access the labour market in Ireland (UNHCR, 2013). The European Communities (Reception Conditions) Regulations 2018, which came into effect in June 2018, mean that asylum applicants who have not received a first-instance decision within nine months may apply for permission to access the labour market. ${ }^{49}$ It remains to be seen whether this will make any difference to the labour market outcomes of the cohort of applicants affected by this change. ${ }^{50}$

The Black ethnic group is performing poorly in terms of both unemployment and occupational attainment, even after accounting for country of origin, qualifications and language ability. This, combined with other evidence (for example, McGinnity et al., 2018a), suggests that discrimination may be playing a role for migrants of Black ethnicity in the Irish labour market. This implies upskilling and language courses may not be sufficient in terms of policy effort: government and employerled policies to monitor, prevent and respond to discrimination in seeking employment and in the workplace are also important. Awareness-raising initiatives among employers and the general public also need to be coupled with the provision of information to migrant communities so they know their entitlements under equality law.

49 Access is by way of a labour market access permission issued by the Minister for Justice and Equality. The permission is valid for a period of six months and may be renewable if the applicant has not received a final decision on their protection application. Eligible applicants have access to self-employment as well as all sectors of employment, with the exception of the civil and public service, An Garda Síochána and the Irish Defence Forces. On 30 June 2019, the Department of Justice reported that since 30 June 2018, over 2,700 asylum seekers had been granted a permission to access the labour market access; see http://www.justice.ie/en/JELR/Pages/PR19000179. However, the IHREC report to the UNCERD (IHREC, 2019) highlights some barriers in relation to effective access to employment for asylum seekers. The six-month period for which the permit is granted has been particularly highlighted as a barrier. 


\section{REFERENCES}

Allebeck, P. (1998). 'Methodological problems in register-based studies', Nordic Journal of Psychiatry, Vol. 51(sup39), pp. 49-52.

Arnold, S., C. Ryan and E. Quinn (2018). Ireland's response to recent trends in international protection applicants. Dublin: The Economic and Social Research Institute.

Arnold, S., E. Quinn, S. Groarke, F. McGinnity and C. Durst (2019). Policy and practice targeting the labour market integration of non-EU nationals in Ireland, Dublin: The Economic and Social Research Institute and the European Migration Network.

Arrow, K.J. (1973). 'The theory of discrimination', Discrimination in labor markets, O.A. Ashenfelter and A. Rees (eds.), Princeton, NJ: Princeton University.

Barrett, A., F. McGinnity and E. Quinn (2017). Monitoring report on integration 2016, The Economic and Social Research Institute and Department of Justice and Equality: Dublin.

Barrett, A., A. Bergin, E. Kelly and S. McGuinness (2016). 'Ireland's recession and the immigrant-native earnings gap', Labor migration, EU enlargement, and the Great Recession, Springer, Berlin, Heidelberg, pp. 103-122.

Barrett, A. and D. Duffy (2008). 'Are Ireland's immigrants integrating into its labour market?', International Migration Review, Vol. 42, No. 3, pp. 597-619.

Barrett A. and Y. McCarthy (2007). 'Immigrants in a booming economy: Analysing their earnings and welfare dependence', Labour, Vol. 21, No. 4, pp. 789-808.

Becker, G.S. (1975). Human capital: A theoretical and empirical analysis, with special reference to education, Chicago: University of Chicago Press.

Borjas, G.J. (1999). 'The economic analysis of immigration' in O. Ashenfelter and D. Card (eds.), Handbook of labor economics, Vol. 3, Amsterdam: North-Holland.

Buchmann, C., T.A. DiPrete and A. McDaniel (2008). 'Gender inequalities in education', Annual Review of Sociology, Vol. 34, pp. 319-337.

Central Statistics Office (CSO) (2017a). 'Diversity', Census 2016 thematic reports, Central Statistics Office, available at

https://www.cso.ie/en/media/csoie/releasespublications/documents/population /2017/Chapter_5_Diversity.pdf.

Central Statistics Office (CSO) (2017b). 'CSO Statbank Table E7053: Population usually resident and present in the State 2011 to 2016 by birthplace, nationality and census year', available at

https://www.cso.ie/px/pxeirestat/Statire/SelectVarVal/Define.asp?maintable=E7 053\&PLanguage $=0$.

Central Statistics Office (CSO) (2018) FIGURE 1.1 Population and migration statistics, Cork: CSO, available at

https://www.cso.ie/en/methods/population/populationandmigrationestimates/.

Central Statistics Office (CSO) 'Census 2016 published reports', available at https://www.cso.ie/en/census/census2016reports/. 
Collier, P. and A. Hoeffler (2004). 'Greed and grievance in civil war', Oxford Economic Papers, Vol. 56, No. 4, pp. 563-595.

Darmody, M., F. McGinnity and G. Kingston (2016). 'The experiences of migrant children in Ireland', Cherishing all the children equally?, Williams, J., E. Nixon, E. Smyth and D. Watson (eds.), Dublin: Oaktree Press.

Darmody, M. and E. Smyth (2018). 'Immigrant student achievement and educational policy in Ireland', Immigrant student achievement and education policy, Volante L., D. Klinger, O. Bilgili (eds.), Springer, Cham, pp. 119-135.

Department of Employment Affairs and Social Protection (DEASP) (2018). Department of Employment Affairs and Social Protection analysis under action 42 of the migrant integration strategy: Characteristics and outcomes of jobseekers of African nationality, Dublin: Department of Employment Affairs and Social Protection.

Department of Justice and Equality (2017). The migrant integration strategy - A blueprint for the future, Dublin: Department of Justice and Equality, available at www.justice.ie/en/JELR/Pages/Migrant_Integration_Strategy__A_Blueprint_for_the_Future.

Eichhorst, W., A. Portela de Souza, P. Cahuc, D. Demazière, C. Fagan., N. Araujo Guimarães, N. and H. Rapoport (2018). 'The future of work-good jobs for all', Rethinking society for the 21st century: Report of the International Panel on Social Progress, Vol. 1: Socio-economic transformations, Cambridge University Press, pp. 255-311.

Esser, H. (2004). 'Does the "new" immigration require a "new" theory of intergenerational integration?', International Migration Review, Vol. 38, No. 3, pp.1126-1159.

Edele, A., J. Seuring, C. Kristen and P. Stanat (2015). 'Why bother with testing? The validity of immigrants' self-assessed language proficiency', Social Science Research, Vol. 52, pp. 99-123.

European Union Agency for Fundamental Rights (FRA) (2017). Second European Union minorities and discrimination survey: Main results, Luxembourg: Publications Office of the European Union.

Fahey, É., F. McGinnity and E. Quinn (2019a). Data for integration: Gaps, challenges and opportunities, Dublin: The Economic and Social Research Institute and Department of Justice and Equality.

Fahey, É., H. Russell, F. McGinnity and R. Grotti (2019b). Diverse neighbourhoods: An analysis of the residential distribution of immigrants in Ireland, Dublin: The Economic and Social Research Institute and Department of Justice and Equality.

Favell, A. (2008). 'The new face of East-West migration in Europe', Journal of Ethnic and Migration Studies, Vol. 34, pp. 701-716.

Gangl, M. (2006). 'Scar effects of unemployment: An assessment of institutional complementarities', American Sociological Review, Vol. 71, No. 6, pp. 986-1013.

Groarke, S. and C. Durst. (2019). Attracting and retaining international higher education students: Ireland, Dublin: The Economic and Social Research Institute and the European Migration Network. 
Groarke, S. and P. Brazil (2020). National statuses granted for protection reasons in Ireland, European Migration Network, ESRI Research Series No. 96, Dublin: the Economic and Social Research Institute.

Gusciute, E., S. Arnold and E. Quinn (2016). Integration of beneficiaries of international protection into the labour market: Policies and practices in Ireland, Dublin: The Economic and Social Research Institute and the European Migration Network.

Hainmueller, J., D. Hangartner and D. Lawrence (2016). 'When lives are put on hold: Lengthy asylum processes decrease employment among refugees', Science advances, Vol. 2, No. 8, e1600432.

Heath, A. and S.Y. Cheung (eds.) (2007). 'Unequal chances: Ethnic minorities in western labour markets', Oxford: Oxford University Press.

Hoxhaj, R., M. Vink and T. Prokic-Breuer (2019). Immigrant naturalisation, employment and occupational status in western Europe, Robert Schuman Centre for Advanced Studies Research Paper No. RSCAS, Vol. 16.

INIS (2016). Policy document on non-EEA family reunification, Dublin: Department of Justice and Equality.

IHREC (2019). Ireland and the Convention of the Elimination of Racial Discrimination, Dublin: Irish Human Rights and Equality Commission, available at https://www.ihrec.ie/app/uploads/2019/11/IHREC_CERD_UN_Submission_Oct_1 9.pdf.

Kett, M. (2018). English language provision and language assessment for low-skilled and unemployed migrants: Recommendations for good practice at NFQ levels 1-3 in ETBs, Dublin: ETBI and SOLAS.

King-O'Riain, R.C. (2007). 'Counting on the "Celtic Tiger": Adding ethnic census categories in the Republic of Ireland', Ethnicities, Vol. 7, No. 4, pp. 516-542.

Kingston, G., F. McGinnity and P.J. O'Connell (2015). 'Discrimination in the labour market: Nationality, ethnicity and the recession', Work, Employment and Society, Vol. 29, No. 2, pp. 213-232.

Kristen, C., P. Muehlau and D. Scahacht (2016). 'Language acquisition of recently arrived immigrants in England, Germany, Ireland and the Netherlands', Ethnicities, Vol. 16, No. 2, pp. 180-212.

Leckie, G., R. Pillinger, K. Jones and H. Goldstein. (2012). 'Multilevel modeling of social segregation', Journal of Educational and Behavioral Statistics, Vol. 37, No. 1, pp. 330.

Luthra, R., L. Platt and J. Salamońska (2016). Types of migration: The motivations, composition, and early integration patterns of "new migrants" in Europe, International Migration Review.

Massey, D.S. (1990). 'The social and economic origins of immigration', World population: Approaching the year 2000, S.H. Preston (ed.), Annals of the American Academy of Political and Social Science, Vol. 510, Newbury Park: Sage Periodicals Press, pp. 60-72. 
McGinnity, F., R. Grotti, S. Groarke and S. Coughlan (2018a). Ethnicity and nationality in the Irish labour market, Dublin: The Economic and Social Research Institute and Irish Human Rights and Equality Commission.

McGinnity, F., E. Fahey, E. Quinn, S. Arnold, B. Maître and P. O'Connell (2018b). Monitoring report on integration 2018, Dublin: The Economic and Social Research Institute and Department of Justice and Equality.

McGinnity, F. and M. Gijsberts (2017). 'The experience of discrimination among newly arrived Poles in Ireland and the Netherlands', Ethnic and Racial Studies, Vol. 41, No. 5, pp. 919-937.

McGinnity, F., R. Grotti, O. Kenny and H. Russell (2017). 'Who experiences discrimination in Ireland? Evidence from the QNHS equality modules', Dublin: The Economic and Social Research Institute and the Irish Human Rights and Equality Commission.

McGinnity, F. and P. Lunn (2011). 'Measuring discrimination facing ethnic minority job applicants: An Irish experiment', Work, Employment and Society, Vol. 25, No. 4, pp. 693-708.

McGinnity, F., P.J. O'Connell, E. Quinn and J. Williams (2006). Migrants' experience of racism and discrimination in Ireland, Dublin: The Economic and Social Research Institute.

McMahon Report (2015). Working Group to Report to Government Working Group on the Protection Process on Improvements to the Protection Process, including Direct Provision and Supports to Asylum Seekers - Final Report, Dublin.

O'Connell, P.J. (2019). 'Why are so few Africans at work in Ireland? Immigration policy and labour market disadvantage', Irish Journal of Sociology,

https://doi.org/10.1177/0791603519853767.

OECD (2019). Education at a glance 2019: OECD indicators, OECD Publishing, Paris, https://doi.org/10.1787/f8d7880d-en.

OECD (2018a). Settling In 2018: Indicators of Immigrant Integration, OECD Publishing, Paris/European Union, Brussels.

OECD (2018b). Employment outlook, OECD Publishing, Paris, available at https://www.oecd.org/social/oecd-employment-outlook-19991266.htm.

OECD (2013). 'Discrimination against immigrants - Measurement, incidence and policy instruments', in International Migration Outlook 2013, OECD Publishing, Paris, https://doi.org/10.1787/migr_outlook-2013-7-en.

OECD (2011). Naturalisation: A passport for the better integration of immigrants?, OECD Publishing, doi: 10.1787/9789264099104-en.

ORAC (2015). Monthly statistical report December 2015, Office of the Refugee Applications Commissioner.

Penninx, R. and B. Garcés-Mascareñas (2016). 'The concept of integration as an analytical tool and as a policy concept', Integration processes and policies in Europe: Contexts, levels and actors, B. Garcés-Mascareñas and R. Penninx (eds.), IMISCOE Research Series, pp.11-29. 
Platt, L. (2019). Understanding inequalities: Stratification and difference, Cambridge: Polity Press.

Portes, A., P. Fernández-Kelly and W. Waller (2005). 'Segmented assimilation on the ground: The new second generation in early adulthood', Ethnic and racial studies, Vol. 28, No. 6, pp. 1000-1040.

Portes, A. and R.G. Rumbaut (2001). Legacies: The story of the immigrant second generation, University of California Press.

Portes, A. and M. Zhou (1993). 'The new second generation: Segmented assimilation and its variants', The Annals of the American Academy of Political and Social Science, Vol. 530, No. 1, pp. 74-96.

Riach, P.A. and J. Rich (2002). 'Field experiments of discrimination in the market place', The Economic Journal, Vol. 112, No. 483, pp. F480-F518.

Rodríguez-García, D. (2015). 'Introduction: Intermarriage and integration revisited: International experiences and cross-disciplinary approaches', The Annals of the American Academy of Political and Social Science, Vol. 662 (November issue).

Röder, A., M. Ward and C.A. Frese (2018). 'From labour migrant to stay-at-home mother? Childcare and return to work among migrant mothers from the EU accession countries in Ireland', Work, Employment and Society, Vol. 32, No. 5, pp. 850-867.

Russell, H., F. McGinnity and P.J. O'Connell (2017). 'Gender equality in the Irish labour market 1966-2016: Unfinished business?', The Economic and Social Review, Vol. 48, No. 4 (winter issue), pp. 393-418.

Siebers, H. and J. van Gastel (2015). 'Why migrants earn less: In search of the factors producing the ethno-migrant pay gap in a Dutch public organization', Work, Employment and Society, Vol. 29, No. 3, pp. 371-391.

Smits, J. (2003). 'Social closure among the higher educated: Trends in educational homogamy in 55 countries', Social Science Research, Vol. 32, No. 2, pp. 251-277.

Subramanian, S.V., C. Duncan and K. Jones (2001). 'Multilevel perspectives on modelling Census data', Environment and Planning A, Vol. 33, No. 3, pp. 399-417.

Thomson, E. and H. Eriksson (2013). 'Register-based estimates of parents' coresidence in Sweden, 1969-2007', Demographic Research, Vol. 29, pp. 1153-1186.

United Nations Economic and Social Council (ECOSOC) (2019). Special edition: Progress towards the Sustainable Development Goals. Report of the Secretary General, 2019 session, available at https://undocs.org/E/2019/68.

UNHCR (2013). Refugee integration, capacity and evaluation in Europe: Ireland report, Dublin: UNHCR.

UNHCR (2014). Asylum seekers (monthly data), available at http://popstats.unhcr.org/en/asylum_seekers_monthly.

UNICEF (2009). Children in immigrant families in eight affluent countries: Their family, national and international context, Florence: UNICEF Innocenti Research Centre. 
Voitchovsky, S. (2014). 'Occupational downgrading and wages of new Member States immigrants to Ireland', International Migration Review, Vol. 48, No. 2, pp. 500-537.

Weiss, F., M. Klein and T. Grauenhorst (2014). 'The effects of work experience during higher education on labour market entry: Learning by doing or an entry ticket?', Work, Employment and Society, Vol. 28, No. 5, pp. 788-807.

World Bank (2019). 'World governance indicators', available at https://info.worldbank.org/governance/wgi/\#home.

World Bank (2018). 'GDP per capita (current US \$)', available at https://data.worldbank.org/indicator/ny.gdp.pcap.cd.

Zschirnt, E. and D. Ruedin (2016). 'Ethnic discrimination in hiring decisions: A meta-analysis of correspondence tests 1990-2015', Journal of Ethnic and Migration Studies, Vol. 42, No. 7, pp. 1115-1134. 


\section{APPENDIX}

This appendix contains additional models discussed in Chapter 5.

TABLE A5.1 MODEL ESTIMATES PREDICTING ODDS OF UNEMPLOYMENT, BY EEA AND NON-EEA COUNTRY OF BIRTH

\begin{tabular}{|c|c|c|}
\hline & \multicolumn{2}{|c|}{ Unemployment } \\
\hline & EEA & Non-EEA \\
\hline Asyratio & $1.267 * * *$ & $1.998 * * *$ \\
\hline \multicolumn{3}{|l|}{ Education (Ref. primary only) } \\
\hline Lower secondary & $0.696 * * *$ & $0.882 * * *$ \\
\hline Upper secondary/vocational & $0.385^{* * *}$ & $0.661^{* * *}$ \\
\hline Tertiary & $0.232 * * *$ & $0.429 * * *$ \\
\hline \multicolumn{3}{|l|}{ Speak English (Ref. very well) } \\
\hline Well & $1.149 * * *$ & $1.808 * * *$ \\
\hline Not well & $1.810 * * *$ & $2.560 * * *$ \\
\hline Not at all & $2.425^{* * *}$ & $3.217^{* * *}$ \\
\hline \multicolumn{3}{|l|}{ Age (Ref.15-24) } \\
\hline $25-34$ & $0.536 * * *$ & $0.563 * * *$ \\
\hline 35-44 & $0.526 * * *$ & $0.448 * * *$ \\
\hline 45-54 & $0.635^{* * *}$ & $0.448 * * *$ \\
\hline $55-65$ & $0.897 * * *$ & $0.592 * * *$ \\
\hline \multicolumn{3}{|l|}{ Gender (Ref. female) } \\
\hline Male & $0.730 * * *$ & $0.669 * * *$ \\
\hline \multicolumn{3}{|l|}{ Ethnicity (Ref. White) } \\
\hline Black & $1.759 * * *$ & $1.628 * * *$ \\
\hline Asian & $1.302^{* *}$ & 1.028 \\
\hline Other & $1.402 * * *$ & $1.178 * * *$ \\
\hline \multicolumn{3}{|l|}{ Citizenship (Ref. non-Irish) } \\
\hline Irish citizen & $1.148 * * *$ & $0.798 * * *$ \\
\hline \multicolumn{3}{|c|}{ Duration in Ireland (Ref. 0-5 years) } \\
\hline $6-10$ years & $1.209 * * *$ & $0.752 * * *$ \\
\hline $11-15$ years & $1.159 * * *$ & $0.586 * * *$ \\
\hline $16-20$ years & $1.229 * * *$ & $0.589 * * *$ \\
\hline$>20$ years & 1.000 & $0.612 * * *$ \\
\hline Duration missing & $1.330 * * *$ & $0.838 * * *$ \\
\hline Observations & 247,838 & 106,863 \\
\hline Pseudo $R^{\wedge} \mathbf{2}$ & 0.06 & 0.10 \\
\hline
\end{tabular}

Source: Census (2016). Authors' calculations. Labour market participants aged 15-64 years.

Notes: $\quad{ }^{* * *} p<0.001,{ }^{* *} p<0.01, * p<0.05$. Sample limited to those in the labour market aged $15-64$ years. An odds ratio of less than one means that the variable is associated with a lower chance of unemployment than the reference category. An odds ratio of greater than one means that the variable is associated with a higher chance of unemployment than the reference category. 
TABLE A5.2 MODEL ESTIMATES PREDICTING ODDS OF HIGH-SKILLED OCCUPATION BY EEA AND NON-EEA COUNTRY OF BIRTH

\begin{tabular}{|c|c|c|}
\hline & \multicolumn{2}{|c|}{ High-skilled jobs odds ratio } \\
\hline & EEA & Non-EEA \\
\hline Asyratio & $0.159 * * *$ & $0.890 * * *$ \\
\hline \multicolumn{3}{|l|}{ Education (Ref. primary only) } \\
\hline Lower secondary & 1.012 & 0.905 \\
\hline Upper secondary/vocational & $1.779 * * *$ & $1.254 * * *$ \\
\hline Tertiary & $7.932 * * *$ & $7.359 * * *$ \\
\hline \multicolumn{3}{|l|}{ Speak English (Ref. very well) } \\
\hline Well & $0.344 * * *$ & $0.421 * * *$ \\
\hline Not well & $0.134 * * *$ & $0.256 * * *$ \\
\hline Not at all & $0.150 * * *$ & $0.252 * * *$ \\
\hline \multicolumn{3}{|l|}{ Age (Ref.15-24) } \\
\hline $25-34$ & $1.753^{* * *}$ & $1.949 * * *$ \\
\hline 35-44 & $2.116 * * *$ & $2.018 * * *$ \\
\hline 45-54 & $2.268 * * *$ & $1.953 * * *$ \\
\hline $55-65$ & $2.217^{* * *}$ & $2.340 * * *$ \\
\hline \multicolumn{3}{|l|}{ Gender (Ref. female) } \\
\hline Male & $1.221 * * *$ & $0.974^{*}$ \\
\hline \multicolumn{3}{|l|}{ Ethnicity (Ref. White) } \\
\hline Black & $1.196 * *$ & $0.635 * * *$ \\
\hline Asian & $1.824 * * *$ & $1.468 * * *$ \\
\hline Other & $0.936^{* *}$ & $0.942 * *$ \\
\hline \multicolumn{3}{|l|}{ Citizen (Ref. non-Irish) } \\
\hline Irish citizen & $1.246^{* * *}$ & $1.298 * * *$ \\
\hline \multicolumn{3}{|c|}{ Duration in Ireland (Ref. 0-5 years) } \\
\hline $6-10$ years & $0.615 * * *$ & $0.753^{* * *}$ \\
\hline 11-15 years & $0.613^{* * *}$ & $0.700 * * *$ \\
\hline $16-20$ years & $0.824 * * *$ & $0.819 * * *$ \\
\hline$>20$ years & $0.689 * * *$ & 1.004 \\
\hline Duration missing & $0.489 * * *$ & $0.529 * * *$ \\
\hline Observations & 225,293 & 89,888 \\
\hline Pseudo R^2 & 0.197 & 0.182 \\
\hline
\end{tabular}

Source: Census (2016). Authors' calculations. Sample limited to those in employment aged 15-64 years.

Note: $\quad * * * p<0.001, * * p<0.01, * p<0.05$. Sample limited to those in employment aged $15-64$ years. An odds ratio of less than one means that the variable is associated with a lower chance of being in a professional/managerial job than the reference category. An odds ratio of greater than one means that the variable is associated with a higher chance of being in a professional/managerial job than the reference category. 
Whitaker Square,

Sir John Rogerson's Quay, Dublin 2

Telephone $+\mathbf{3 5 3} 1 \mathbf{8 6 3 2 0 0 0}$

Email admindesri.ie

Web www.esri.ie

Twitter RESRIDublin

ISBN 978-0-7070-0496-9
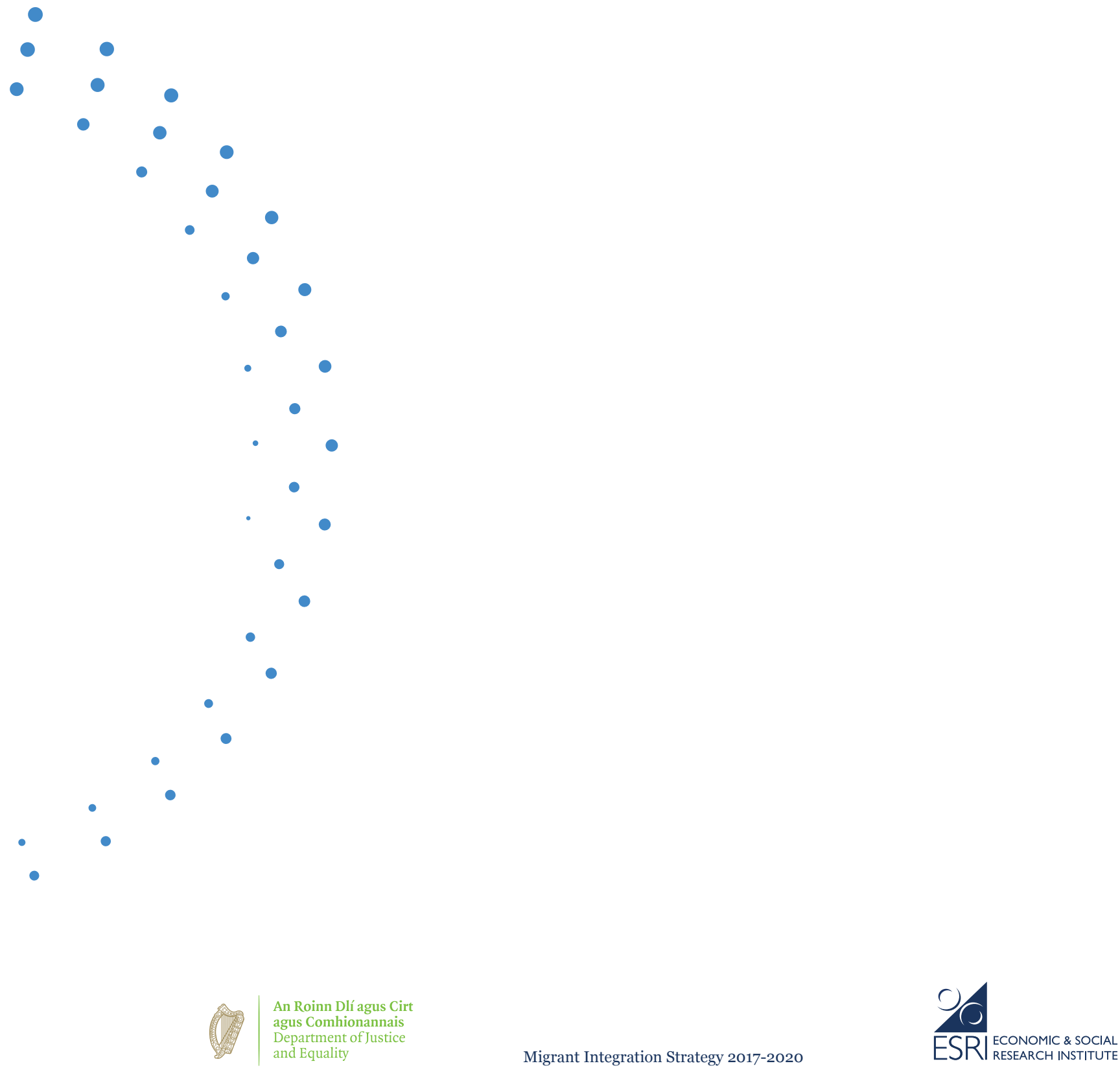